\title{
Targets for body weight management: behavioural and metabolic factors
}

Citation for published version (APA):

Lejeune, M. P. G. M. (2005). Targets for body weight management: behavioural and metabolic factors. [Doctoral Thesis, Maastricht University]. Maastricht University. https://doi.org/10.26481/dis.20050623ml

Document status and date:

Published: 01/01/2005

DOI:

10.26481/dis.20050623ml

Document Version:

Publisher's PDF, also known as Version of record

\section{Please check the document version of this publication:}

- A submitted manuscript is the version of the article upon submission and before peer-review. There can be important differences between the submitted version and the official published version of record.

People interested in the research are advised to contact the author for the final version of the publication, or visit the DOI to the publisher's website.

- The final author version and the galley proof are versions of the publication after peer review.

- The final published version features the final layout of the paper including the volume, issue and page numbers.

Link to publication

\footnotetext{
General rights rights.

- You may freely distribute the URL identifying the publication in the public portal. please follow below link for the End User Agreement:

www.umlib.nl/taverne-license

Take down policy

If you believe that this document breaches copyright please contact us at:

repository@maastrichtuniversity.nl

providing details and we will investigate your claim.
}

Copyright and moral rights for the publications made accessible in the public portal are retained by the authors and/or other copyright owners and it is a condition of accessing publications that users recognise and abide by the legal requirements associated with these

- Users may download and print one copy of any publication from the public portal for the purpose of private study or research.

- You may not further distribute the material or use it for any profit-making activity or commercial gain

If the publication is distributed under the terms of Article $25 \mathrm{fa}$ of the Dutch Copyright Act, indicated by the "Taverne" license above, 
TARGETS FOR BODY WEIGHT MANAGEMENT:

Behavioral and metabolic factors 


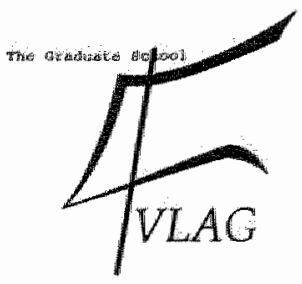

\section{nitrin}

The studies presented in this thesis were performed at the Nutrition and Toxicology Research institute Maastricht (NUTRIM), which participated in the Graduate School VLAG (Food Technology, Agrobiotechnology, Nutrition and Health Sciences) accredited by the Royal Netherlands Academy of Arts and Sciences

The research described in this thesis was supported by grants from Novartis Consumer HealthLtd.

Printing of this thesis was financially supported by the Nederlandse Associatie voor de studie van Obesitas.

Financial support by the Dutch Diabetes Research Foundation and the Netherlands Heart Foundation for the publication of this thesis is gratefully acknowledged.

Cover design: Henk Kreuger, Gouda

Lay-out: Manuela Lejeune

Printed by: Kwak \& van Dalen \& Ronday BV

(C) Manuela Lejeune, Maastricht 2005

ISBN 90-9019504-1 


\section{TARGETS FOR BODY WEIGHT MANAGEMENT:}

\section{Behavioral and metabolic factors}

\section{PROEFSCHRIFT}

ter verkrijging van de graad van doctor aan de Universiteit Maastricht, op gezag van de Rector Magnificus,

Prof. mr. G.P.M.F. Mols

volgens het besluit van het College van Decanen,

in het openbaar te verdedigen

op donderdag 23 juni 2005 om 16:00 uur

door

Manuela Petrus Gerardus Maria Lejeune

geboren te Maastricht op 28 januari 1974 


\title{
Promotor:
}

\author{
Prof. dr. K.R. Westerterp
}

\section{Co-promotor:}

Dr. M.S. Westerterp-Plantenga

Beoordelingscommissie:

Prof. dr. E.C.M. Mariman (voorzitter)

Prof. dr. ir. P.A. van den Brandt

Prof. dr. R-J.M. Brummer

Dr. J.H. Strubbe (Rijksuniversiteit Groningen)

Prof. dr. D. Tomé (Institut National Agronomique Paris-Grignon, France) 


\section{CONTENTS}

$\begin{array}{ll}\text { 1. Introduction } & 7\end{array}$

2. Effects of dietary restraint vs. exercise during weight 23 maintenance in obese men

3. Effect of dietary restraint during and following pegylated 39 recombinant leptin treatment (PEG-OB) of overweight men

4. Reversal of changes in ghrelin and adiponectin during VLCD induced body weight loss with or without human pegylated recombinant leptin treatment

5. Effect of capsaicin on substrate oxidation and weight 69 maintenance after modest body weight loss in human subjects

6. Effects of green tea on weight maintenance after body 89 weight loss

7. Additional protein intake limits weight regain after weight loss in humans

8. 24h satiety, GLP-1, ghrelin, energy- and substrate metabolism during a high-protein diet measured in a respiration chamber

9. General discussion

Summary

Samenvatting

Dankwoord

Publications 



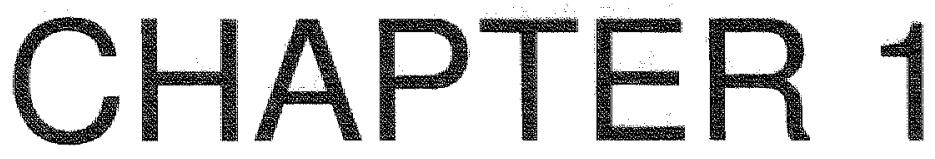

\section{Introduction}




\section{WEIGHT MANAGEMENT AND OBESITY}

A stable body weight can only be achieved if there is a long-term balance between energy intake and energy expenditure. If the equilibrium between energy intake and energy expenditure shifts towards a positive balance, the excess of energy will be stored as adipose tissue. Obesity will develop when this imbalance continues in the long-term. Factors suggested to be related to the development of obesity are increased energy intake and decreased physical activity. Weight loss can thus be achieved by reducing energy intake and/or increasing energy expenditure.

The prevalence of obesity has increased world wide during the past few decades. There is a wide variation in the prevalence of obesity between and within countries. In European countries in the EU region, the prevalence of obesity is approximately the same for men and women. A higher prevalence in women compared to men is seen in central and eastern European countries". The body mass index (BMI) is a common measure to define overweight and obesity. BMI is calculated as body weight divided by height squared $\left(\mathrm{kg} / \mathrm{m}^{2}\right)$. Body fatness plays an important role in overweight and obesity, and is not perfectly represented by the BMI. For instance, women have significantly greater amounts of total body fat compared to men with the same $\mathrm{BMI}^{2}$. The World Health Organization (WHO) has published weight classifications for adults according to body mass index ${ }^{3}$ (table 1 ).

\section{BODY WEIGHT LOSS AND WEIGHT MAINTENANCE}

Weight loss reduces the risk for mortality and morbidity in obese subjects ${ }^{4}$. Risk factors related to obesity, such as lipid abnormalities and hypertension are positively affected by modest weight loss ${ }^{4}$. To improve the metabolic profile, it is not necessary to achieve the ideal body weight. A weight reduction of 5 to $10 \%$ is often sufficient to induce a clinically relevant effect ${ }^{5}$. Modest weight loss is a realistic goal for most subjects ${ }^{4 ; 5}$. Commonly used weight control methods such as diet and exercise as well as pharmacological approaches often are successful in the short-term. However, in the long term an increased risk of body weight regain resulting in weight cycling has been reported ${ }^{6-8}$. Interventions to improve long-term weight maintenance are therefore needed in order to treat obesity effectively. 
Table 1 Adult weight classifications according to BMI by the WHO ${ }^{3}$

\begin{tabular}{lll}
\hline Classification & BMI $\left(\mathbf{k g} / \mathbf{m}^{2}\right)$ & Associated health risks \\
\hline Underweight & $<18.5$ & Low (but risk of other clinical problems increased) \\
Normal range & $18.5-24.9$ & Average \\
Overweight & $\geq 25.0$ & \\
Pre-obese & $25.0-29.9$ & Increased \\
Obese class II & $30.0-34.9$ & Moderately increased \\
Obese class II & $35.0-39.9$ & Severely increased \\
Obese class III & $\geq 40.0$ & Very severely increased \\
\hline
\end{tabular}

Body weight management consists of controlling body weight in the long-term by tuning energy intake to energy requirement, and thereby avoiding accumulation of excess energy as fat. Targets for prevention and treatment of overweight and obesity can be distinguished as behavioral and metabolic factors. The main behavioral targets are eating behavior and physical activity. The main metabolic targets are satiety, energy expenditure, substrate oxidation, body composition, and energy efficiency.

\section{BEHAVIOURAL TARGETS}

Eating behavior is one of the determinants of weight maintenance after a weight reduction program. Eating behavior with respect to dieting can be characterized using questionnaires like the Herman-Polivy restraint eating questionnaire ${ }^{9}$, and the Three Factor Eating Questionnaire (TFEQ) by Stunkard and Messick ${ }^{10}$. The extent to which people display concern with their body weight and show behavior to keep their dietary intake in control can be measured by the Herman Polivy questionnaire ${ }^{11}$. The obese score relatively high on this questionnaire and the scores correlate positively with $\mathrm{BM} \mathrm{I}^{12}$. Pasman et $a l^{6}$ showed that the frequency of dieting, measured with the Herman-Polivy questionnaire, prior to a weight loss program explained 50 percent of the variation in weight regain thereafter. The TFEQ measures three different factors relevant to human eating behavior. The first factor of the TFEQ measures cognitive restrained eating: control of food intake by thought and will power. The second factor represents disinhibition: an incidental inability to resist eating cues, or inhibition of dietary restraint, and emotional eating. The third factor examines the subjective feeling of general hunger. It has been shown that the ability to increase restrained eating behavior during an energy restriction period, possibly together with a decrease in inhibition and general hunger, is related to successful weight maintenance thereafter ${ }^{13-17}$. The difference between both questionnaires is that 
the Herman-Polivy questionnaire characterizes weight concern and the TFEQ diet concern. The scores on both questionnaires are not always correlated.

Because of the presumed role of reduced physical activity in the development of obesity, increase of physical activity as a behavioral treatment of obesity, with or without a diet, often has been subject of research ${ }^{18}$. Adding exercise to a diet program is usually unsuccessful in affecting the amount of weight $\operatorname{lost}^{19 ; 20}$. A meta-analysis of weight loss studies using diet, exercise or diet plus exercise interventions over the past 25 years ${ }^{24}$, showed that the continuation of low intensity exercise training during the weight maintenance phase could not limit body weight regain. This is in accordance with a review on associations between physical activity and weight regain, in which it is concluded that the effects of a prescribed exercise program on weight maintenance are small ${ }^{22}$. Ross et al. ${ }^{23}$ showed that exercise-induced weight loss in obese subjects is possible, but this was under extremely guided and controlled conditions. So, influencing behavioral targets, such as primarily dietary restrained eating behavior and possibly physical activity, in the long-term is of importance for prevention and treatment of obesity.

\section{METABOLIC TARGETS}

\section{Satiety}

To develop strategies to prevent and treat obesity it is necessary to understand the mechanisms of regulation of food intake. Satiety is an important factor in this regulation. Two different phases can be distinguished: satiation and satiety. Satiation is the suppression of hunger and appetite within a meal, while satiety refers to the inhibition of hunger and appetite after food consumption. Thus, meal termination is determined by satiation and the inter-meal interval is affected by satiety. Humans have the ability to rate the strength of their motivation to eat and drink. When used appropriately, these subjective ratings are reproducible, sensitive to exposure of food components, and predictive of food intake $e^{24-26}$. Four satiety mediated processes can be distinguished and are classified in a time-specific order as sensory, cognitive, post-ingestive, and post-absorptive ${ }^{27}$. Factors involved in sensory processes are smell, taste, temperature, and texture of food. Cognitive processes are the beliefs held about the properties of foods. Post-ingestive factors imply gastric distention and emptying, and the release of hormones (e.g. glucagon-like peptide 1, cholecystokinin, ghrelin, leptin) when food is processed. Factors involved in post-absorptive processes include blood glucose concentrations, thermogenic 
effect, and hepatic fatty acid oxidation due to metabolism and absorbed nutrients ${ }^{28}$.

There are many central and peripheral factors contributing to the control of eating. Some of these satiety signals are short-term regulators, while others regulate food intake in the long-term (figure 1). The short-term signals act primarily as determinants of satiety to limit the size of individual meals ${ }^{29}$. The long-term regulators of energy homeostasis are activated in proportion to the amount of energy consumed and the body adipose stores over a prolonged period of time ${ }^{29}$.

Signals from the gastrointestinal tract and the liver are involved in short-term satiety. The presence of nutrients in the stomach and the proximal small intestine activate stretch- and chemoreceptors. These receptors trigger vagal afferent signals to the brain. Nutrients arriving via the portal vein can also trigger vagal afferent signals from the liver. The arcuate nucleus of the hypothalamus includes two opposing neuronal circuits, an appetite-stimulating (orexigenic) and an appetite-inhibiting (anorexigenic) circuit ${ }^{30}$. These circuits are influenced by peripheral hormonal signals that are able to cross the blood-brain barrier, and send signals to the arcuate nucleus but also to other nuclei of the hypothalamus (e.g. paraventricular nucleus), which in turn directly can influence feeding behavior (figure 1). The orexigenic circuit produced the neurotransmitters neuropeptide $Y$ (NPY) and agouti-related peptide (AgRP), which are expressed in the same neurons in the medial arcuate nucleus and stimulate appetite. In the lateral arcuate nucleus the anorexigenic neurotransmitters cocaine- and amphetamine-regulated transcript (CART) and mainly proopiomelanocortin (POMC) are expressed, which produces amelanocyte-stimulating hormone $(\alpha-M S H)^{30}$.

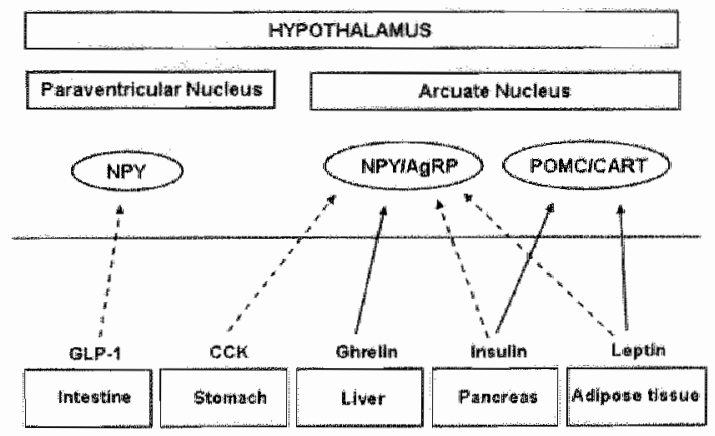

Figure 1 Circulating hormones influencing the regulation of food intake.

Dashed lines indicate inhibitory effects and solid lines indicate stimulatory effects. GLP-1, CCK, and ghrelin represent the short-term satiety signals, whereas insulin and leptin represent the long-term satiety signals. 
One of the peripheral hormonal signals is ghrelin. Ghrelin modulates hypothalamic appetite regulating pathways, primarily the NPY network in the arcuate nucleus ${ }^{30}$. It is synthesized and released primarily by endocrine cells in the stomach, and was originally identified as the endogenous ligand for the pituitary growth hormone secretogogue receptor ${ }^{31}$. Ghrelin has adipogenic and orexigenic properties, and therefore can increase food intake and body weight. Furthermore, it enhances the use of carbohydrates and reduces fat utilization, and increases gastric motility, In humans, ghrelin concentrations are increased during short-term fasting, and decreased after food intake ${ }^{32 ;} 33$.

The presence of nutrients (free fatty acids or amino acids) in the duodenum releases $C C K$, which reaches the liver via the portal vein and the central nervous system via the systemic circulation. It is also released from hypothalamic neurons during feeding ${ }^{34}$. CCK regulates food intake by increasing satiety and decreasing meal size. Since stomach distention seems to be a necessary condition for the effects of CCK, it is suggested that CCK suppresses appetite by delaying stomach emptying ${ }^{35 ; 36}$.

Another short-term peripheral hormonal signal is glucagon-like peptide 1 (GLP1), which is secreted by the endocrine L cells in the ileum in response to the presence of nutrients ${ }^{37}$. Exogenous infusion of GLP-1 reduces appetite in a dose-dependent manner, with the most effective suppression at concentrations slightly above normal physiologic concentrations ${ }^{38 ;}{ }^{39}$. Stimulation of endogenous GLP-1 production by different nutrients shows effects on satiety in normal weight subjects ${ }^{40}$.

The two most important long-term signals regulating food intake and energy homeostasis are insulin and leptin. Insulin, produced by the beta cells of the Islets of Langerhans of the pancreas, decreases food intake by inhibiting the orexigenic and stimulating the anorexigenic neurotransmitters in the hypothalamus ${ }^{411}$. Insulin secretion is stimulated by food ingestion and insulinotropic incretin hormones such as GLP-1. Furthermore, insulin promotes the transport of glucose from the circulation into tissues, decreases the release of glucose by the liver, and stimulates the uptake of glucose and deposition of glycogen by the liver. It also plays a role in lipid utilization and storage. If insulin resistance occurs, a condition that is often seen in obesity, more insulin is secreted to regulate glucose levels. This excess of insulin then causes increased accumulation of fat in adipocytes ${ }^{42}$. Another long-term regulator of food intake is leptin, the product of the ob gene, which is synthesized primarily by adipose tissue ${ }^{43}$. Leptin functions as a peripheral signal in a negative feedback loop to the hypothalamic nuclei involved in the regulation of energy balance. It is thought to regulate the NPY/AgRP and POMC/CART neurons in an opposing manner ${ }^{44 ;}, 45$. Since leptin is secreted from adipocytes in direct proportion to the amount of stored fat, plasma leptin levels are a rather stable 
indicator of body fat ${ }^{42}$. Leptin is thought to reduce food intake and increase energy expenditure, which is supported by the finding that subcuteanous administration of leptin causes additional weight loss during a weight reduction program in obese subjects ${ }^{46}$.

Although the short-term and long-term satiety signals have different functions, it is clear that both systems need to interact to ensure that energy balance is maintained. Dietary treatment of obesity is often unsuccessful in the long-term because of decreased compliance and increased habituation to an energy restricted diet ${ }^{47}$. Therefore, satiety mechanisms may be targets for sustaining or enhancing satiety while energy intake is lowered as a treatment of obesity.

\section{Energy expenditure}

Since a stable body weight in the long-term requires energy balance, an important target in prevention and treatment of obesity is increasing energy expenditure. Daily energy expenditure consists of four components, the sleeping metabolic rate (SMR), the energy cost of arousal, diet-induced thermogenesis (DIT), and the energy cost of physical activity (AEE). The sleeping metabolic rate and the energy cost of arousal are often taken together as the basal metabolic rate (BMR) ${ }^{48}$. To increase total daily energy expenditure it is not necessary to increase all of these components. If one component increases while the others stay stable, this could already have a positive effect on total energy expenditure.

\section{Sleeping metabolic rate and basal metabolic rate}

The energy expenditure of a resting subject in the post-absorptive state in the region of thermoneutrality is defined as basal metabolic rate ${ }^{48}$. Sleeping metabolic rate is very close to basal metabolic rate, the difference being the energy cost of arousal. Basal metabolic rate is dependent on gender, age, height, and body weight. The measurement of basal metabolic rate is often done by indirect calorimetry (the measurement of heat production by measuring oxygen consumption and/or carbohydrate production), but it can also be estimated using predictive equations such as the equation of Harris and Benedict ${ }^{49}$. Basal metabolic rate declines with body weight loss ${ }^{50}$. The decline in basal metabolic rate caused by energy restriction has been shown to be positively correlated with unsuccessful weight maintenance ${ }^{6}$. It has been suggested that subjects with a low basal metabolic rate are more prone to weight gain over time ${ }^{51}$, but this has not been found consistently ${ }^{52 ; 53}$. 


\section{Diet-induced thermogenesis}

Energy expenditure increases after ingestion of food. This increase is called diet-induced thermogenesis (DIT) ${ }^{48}$. It has been suggested that the energy content of food is the main determinant of DIT, followed by the protein fraction of the food54. Studies of macronutrient effects on thermogenesis show a substantial greater increase in energy expenditure after a protein meal compared to a carbohydrate or fat mea ${ }^{55-58}$. Also herbal supplements can increase diet-induced thermogenesis. Yoshioka et al. ${ }^{59 ; 60}$ showed an increase in diet-induced thermogenesis immediately after a meal to which capsaicin, the pungent principle of red pepper, was added. This increase was probably due to $\beta$-adrenergic stimulation. Green tea, rich in catechin polyphenols, especially epigallocatechin gallate, and caffeine, also increases thermogenesis as shown by Dulloo et $a l^{61}$. The impact of a decreased diet-induced thermogenesis on the development of obesity has been shown by Trayhurn et al. ${ }^{62}$, in a study in which obese mice stored nearly three times more body energy than lean mice, despite the same energy intake. Several human experiments reported that diet-induced thermogenesis is reduced in obese subjects ${ }^{63-65}$, but discrepancies persist probably due to methodological variations among the published studies ${ }^{66}$. Dietinduced thermogenesis has also been shown to be negatively correlated to the degree of restraint eating behavior in obese and non-obese subjects ${ }^{67 ; 68}$. Since it is known that protein induces the highest DIT of all macronutrients, Stock ${ }^{69}$ investigated the effects of diets with different protein contents on the cost of weight gain during overfeeding. A survey of several overfeeding studies showed that a low $(<5 \%)$ and a high ( $>15 \%$ ) energy percentage of protein produced the highest energy inefficiency, while a normal (10-15\%) energy percentage induced the highest energy efficiency ${ }^{69}$. So, high energy efficiency (i.e. low dietinduced thermogenesis) seems an unfavorable condition for the prevention and treatment of obesity.

\section{Activity-induced energy expenditure}

The most facultative component of daily energy expenditure is activity-induced energy expenditure. Activity-induced energy expenditure can be estimated by subtracting basal metabolic rate and diet-induced thermogenesis from total energy expenditure. The level of activity is also often expressed as total energy expenditure divided by basal metabolic rate. This quotient is known as the physical activity index (PAI). In daily live PAI varies between 1.2 and 2.2. If PAl, and thus physical activity, is low this is a risk factor for overweight and obesity ${ }^{18}$ 70 


\section{Substrate oxidation}

Weight maintenance requires energy balance, but this also requires a balance between the intake and oxidation of the separate macronutrients ${ }^{71}$.72. Achieving substrate balance is not the same for each macronutrient. The tuning of oxidation to intake is more accurate for carbohydrate than for fat, due to an oxidative hierarchy. The metabolic priority of carbohydrate over fat is appropriate because of the limited glycogen stores in contrast to the triacylgiycerol stores in adipose tissue. Schrauwen et al. ${ }^{73}$ showed that lean subjects adjust fat oxidation to fat intake after an abrupt increase in dietary fat intake within 7 days. However, when glycogen stores are lowered, both lean and obese subjects can rapidlly adjust fat oxidation to a higher fat intake $\mathrm{f}^{74_{i} 75}$.

An indicator for substrate oxidation is the respiratory quotient (RQ), which is defined as the ratio between measured carbon dioxide production and oxygen consumption. The RQ is 0.7 for fat oxidation, 1.0 for carbohydrate oxidation, and between 0.7-1.0 for a mixed diet. A decreased fat oxidation plays a role in the long-term fat balance, and consequently weight management of obesity prone subjects. To increase fat oxidation, the use of herbal supplements has been subject of research. Results of Yoshioka et al ${ }^{60}$ show that capsaicin decreases RQ immediately after a meal to which capsaicin is added, implying a shift in substrate oxidation from carbohydrate to fat oxidation. Another herbal supplement, green tea, promotes fat oxidation more than can be explained by its caffeine content per $\mathrm{se}^{61}$. So, influencing substrate oxidation in favor of fat oxidation is an important metabolic target in obesity treatment.

\section{Body composition}

An important factor in studying overweight and obesity is body composition. The general model for body composition is the two-compartment model, which assumes that the body consists of fat mass and fat free mass. Body composition differs according to gender and age, in that women have a lower fat free mass than men, and older men have a lower fat free mass than young $\operatorname{men}^{76}$.

Body weight loss usually consists for $75 \%$ of fat mass and for $25 \%$ of fat free mass $^{77}$. During weight loss it has been shown that the body composition continuously changes towards a leaner composition ${ }^{78}$. However, the weight regained after weight loss usually has the same composition as the initial weight lost $^{79 ; 80}$. Therefore, changing body composition in a way that fat mass is lost and fat free mass is spared in the long term can be a tool in obesity treatment. 


\section{OUTLINE OF THE THESIS}

The studies described in this thesis investigate targets that may play a role in the prevention and treatment of overweight and obesity. Both behavioral and metabolic targets are focused on. Therefore the effect of dietary restraint with or without exercise on body weight maintenance during a post energy restriction period in overweight men was investigated. The subjects were randomized over a diet and a diet plus exercise group. The study started with an energy restriction period of 10 weeks followed by a weight maintenance period. Before and after the energy restriction period, and after the weight maintenance period body weight and dietary restraint were determined (chapter 2). The balance between behavioral changes and pharmacological treatment was investigated by determining whether pharmacological treatment, i.e. PEG-OB protein treatment, replaces or supports an increase in dietary restraint during treatment (chapter 3). Using the effect of PEG-OB protein treatment for weight loss induction, the effects of weight loss and this treatment on hormone concentrations was assessed further (chapter 4). Focusing on metabolic targets, the role of capsaicin (chapter 5) and green tea (chapter 6) in obesity treatment by improving weight maintenance after weight loss in overweight and moderately obese subjects by increasing energy expenditure and fat oxidation was investigated. Since a stimulating effect of dietary protein has been shown in weight loss studies ${ }^{81-83}$, but until now not during weight maintenance, we investigated whether addition of protein to the diet may limit weight regain after weight loss in moderately overweight subjects (chapter 7). To investigate the effects of high protein consumption on satiety and energy expenditure in more detail these parameters were also determined in a respiration chamber experiment (chapter 8). Finally, the effects of the different targets for weight management studied in the above described experiments are summarized and discussed in a general discussion (chapter 9 ).

\section{REFERENCES}

1. Seidell JC (2002) Prevalence and time trends of obesity in Europe. $J$ Endocrinol Invest 25, 816-822.

2. Gallagher D, Visser M, Sepulveda D, Pierson RN , Harris T, Heymsfield SB (1996) How useful is body mass index for comparison of body fatness across age, sex, and ethnic groups? Am J Epidemiol 143, 228-239.

3. (2000) Obesity: preventing and managing the global epidemic. Report of a WHO consultation. World Health Organ Tech Rep Ser 894, i-xii, 1-253. 
4. Van Gaal LF, Wauters MA, De Leeuw IH (1997) The beneficial effects of modest weight loss on cardiovascular risk factors. Int $J$ Obes Relat Metab Disord 21 Suppl 1, S5-9.

5. Goldstein DJ (1992) Beneficial health effects of modest weight loss. int $J$ Obes Relat Metab Disord 16, 397-415.

6. Pasman WJ, Saris WH, Westerterp-Plantenga MS (1999) Predictors of weight maintenance. Obes Res 7, 43-50.

7. Muls $E$, Kempen $K$, Vansant $G$, Saris $W$ (1995) is weight cycling detrimental to health? A review of the literature in humans. Int $J$ Obes Relat Metab Disord 19 Suppl 3, S46-50.

8. Sjostrom L, Rissanen A, Andersen T, Boldrin M, Golay A, Koppeschaar HP, Krempf M (1998) Randomised placebo-controlled trial of orlistat for weight loss and prevention of weight regain in obese patients. European Multicentre Orlistat Study Group. Lancet 352, 167-172.

9. Herman CP, Polivy J (1980) Restrained eating. In Obesity, pp. 208-224 [AJ] Stunkard, editor]. Philadelphia: W.B. Saunders.

10. Stunkard AJ, Messick S (1985) The three-factor eating questionnaire to measure dietary restraint, disinhibition and hunger. J Psychosom Res 29, 71-83.

11. Heatherton TF, Herman CP, Polivy J, King GA, McGree ST (1988) The (mis)measurement of restraint: an analysis of conceptual and psychometric issues. J Abnorm Psychol 97, 19-28.

12. Westerterp-Plantenga MS, Wouters $L$, ten Hoor F (1991) Restrained eating, obesity, and cumulative food intake curves during four-course meals. Appetite 16, 149-158.

13. Hensrud DD, Weinsier RL, Darnell BE, Hunter GR (1994) A prospective study of weight maintenance in obese subjects reduced to normal body weight without weight-loss training. Am J Clin Nutr 60, 688-694.

14. Fogelholm M, Kukkonen-Harjula $K$, Oja $P$ (1999) Eating control and physical activity as determinants of short-term weight maintenance after a very-low-calorie diet among obese women. Int J Obes Relat Metab Disord 23, 203-210.

15. Clark MM, Marcus BH, Pera V, Niaura RS (1994) Changes in eating inventory scores following obesity treatment. Int $J$ Eat Disord 15, 401-405.

16. Pekkarinen T, Takala I, Mustajoki P (1996) Two year maintenance of weight loss after a VLCD and behavioural therapy for obesity: correlation to the scores of questionnaires measuring eating behaviour. Int $J$ Obes Relat Metab Disord 20, 332-337.

17. Westerterp-Plantenga MS, Kempen KP, Saris WH (1998) Determinants of weight maintenance in women after diet-induced weight reduction. Int $J$ Obes Relat Metab Disord 22, 1-6. 
18. Westerterp KR (1999) Obesity and physical activity. Int J Obes Relat Metab Disord 23 Suppl 1, 59-64.

19. Van Dale D, Saris WH, Schoffelen PF, Ten Hoor F (1987) Does exercise give an additional effect in weight reduction regimens? Int $J$ Obes $11,367-$ 375.

20. van Aggel-Leijssen DP, Saris WH, Hul GB, van Baak MA (2001) Shortterm effects of weight loss with or without low-intensity exercise training on fat metabolism in obese men. Am J Clin Nutr 73, 523-531.

21. Miller WC, Koceja DM, Hamilton EJ (1997) A meta-analysis of the past 25 years of weight loss research using diet, exercise or diet plus exercise intervention. Int $J$ Obes Relat Metab Disord 21, 941-947.

22. Fogelholm $M$, Kukkonen-Harjula $K(2000)$ Does physical activity prevent weight gain - a systematic review. Obesity Reviews 1, 95-111.

23. Ross R, Dagnone D, Jones PJ, Smith H, Paddags A, Hudson R, Janssen I (2000) Reduction in obesity and related comorbid conditions after dietinduced weight loss or exercise-induced weight loss in men. A randomized, controlled trial. Ann Intern Med 133, 92-103.

24. de Graaf $C$ (1993) The validity of appetite ratings. Appetite 21, 156-160.

25. Flint A, Raben A, Blundell JE, Astrup A (2000) Reproducibility, power and validity of visual analogue scales in assessment of appetite sensations in single test meal studies. Int J Obes Relat Metab Disord 24, 38-48.

26. Stubbs RJ, Hughes DA, Johnstone AM, Rowley E, Reid C, Elia M, Stratton $\mathrm{R}$, Delargy $\mathrm{H}$, King $\mathrm{N}$, Blundell JE (2000) The use of visual analogue scales to assess motivation to eat in human subjects: a review of their reliability and validity with an evaluation of new hand-held computerized systems for temporal tracking of appetite ratings. Br J Nutr 84, 405-415.

27. Blundell JE, Hill AJ, Rogers $P J$ (1988) Hunger and the satiety cascade their importance for food acceptance in the late 20th century. In Food acceptability, pp. 233-250 [DMH Thompson, editor]. London: Elsevier.

28. Blundell JE, Lawton CL, Hill AJ (1993) Mechanisms of appetite control and their abnormalities in obese patients. Horm Res 39 Suppl 3, 72-76.

29. Havel PJ (2001) Peripheral signals conveying metabolic information to the brain: short-term and long-term regulation of food intake and energy homeostasis. Exp Biol Med (Maywood) 226, 963-977.

30. Gale SM, Castracane VD, Mantzoros CS (2004) Energy homeostasis, obesity and eating disorders: recent advances in endocrinology. $J$ Nutr 134, 295-298.

31. Kojima M, Hosoda H, Date Y, Nakazato M, Matsuo H, Kangawa K (1999) Ghrelin is a growth-hormone-releasing acylated peptide from stomach. Nature 402, 656-660. 
32. Shilya T, Nakazato M, Mizuta M, Date $Y$, Mondal MS, Tanaka M, Nozoe S, Hosoda $\mathrm{H}$, Kangawa K, Matsukura S (2002) Plasma ghrelin levels in lean and obese humans and the effect of glucose on ghrelin secretion. $J$ Clin Endocrinol Metab 87, 240-244.

33. Cummings DE, Purnell JQ, Frayo RS, Schmidova K, Wisse BE, Weigle DS (2001) A preprandial rise in plasma ghrelin levels suggests a role in meal initiation in humans. Diabetes 50, 1714-1719.

34. Beinfeld MC (1983) Cholecystokinin in the central nervous system: a minireview. Neuropeptides 3, 411-427.

35. Melton PM, Kissileff HR, Pi-Sunyer FX (1992) Cholecystokinin (CCK-8) affects gastric pressure and ratings of hunger and fulliness in women. Am J Physiol 263, R452-456.

36. Kissileff HR, Carretta JC, Geliebter A, Pi-Sunyer FX (2003) Cholecystokinin and stomach distension combine to reduce food intake in humans. Am J Physiol Regul Integr Comp Physiol 285, R992-998.

37. Drucker DJ (1998) Glucagon-like peptides. Diabetes 47, 159-169.

38. Flint A, Raben A, Ersboll AK, Holst JJ, Astrup A (2001) The effect of physiological levels of glucagon-like peptide-1 on appetite, gastric emptying, energy and substrate metabolism in obesity. Int $J$ Obes Relat Metab Disord 25, 781-792.

39. Gutzwiller JP, Goke B, Drewe J, Hildebrand P, Ketterer S, Handschin D, Winterhalder R, Conen D, Beglinger C (1999) Glucagon-like peptide-1: a potent regulator of food intake in humans. Gut 44, 81-86.

40. Adam TCM, Westerterp-Plantenga MS (2005) Nutrient-stimulated GLP-1 release in normal weight men and women. Horm Metab Res In press.

41. Baskin DG, Wilcox BJ, Figlewicz DP, Dorsa DM (1988) Insulin and insulinlike growth factors in the CNS. Trends Neurosci 11, 107-111.

42. Benoit SC, Clegg DJ, Seeley RJ, Woods SC (2004) Insulin and leptin as adiposity signals. Recent Prog Horm Res 59, 267-285.

43. Friedman JM, Halaas $\mathrm{JL}(1998)$ Leptin and the regulation of body weight in mammals. Nature $395,763-770$.

44. Baskin DG, Breininger JF, Schwartz MW (1999) Leptin receptor mRNA identifies a subpopulation of neuropeptide $Y$ neurons activated by fasting in rat hypothalamus. Diabetes 48, 828-833.

45. Cheung CC, Clifton DK, Steiner RA (1997) Proopiomelanocortin neurons are direct targets for leptin in the hypothalamus. Endocrinology 138, 44894492.

46. Hukshorn CJ, Westerterp-Plantenga MS, Saris WH (2003) Pegylated human recombinant leptin (PEG-OB) causes additional weight loss in severely energy-restricted, overweight men. Am J Clin Nutr 77, 771-776. 
47. Doucet $E$, Imbeault $P$, St-Pierre $S$, Almeras $N$, Mauriege $P$, Richard $D$, Tremblay A (2000) Appetite after weight loss by energy restriction and a low-fat diet-exercise follow-up. Int J Obes Relat Metab Disord 24 „906-914.

48. Westerterp KR (1994) Energy expenditure. In Food intake and energy expenditure, pp. 235-257 [MS Westerterp-Plantenga, EW Fredrix, AB Steffens, editors]. Boca Raton: CRC Press.

49. Harris JA, Benedict FG (1919) A biometric study of basal metabolism in man. Washington: Carnegie Institution.

50. Astrup A, Gotzsche PC, van de Werken K, Ranneries C, Toubro S, Raben A, Buemann B (1999) Meta-analysis of resting metabolic rate in formerly obese subjects. Am J Clin Nutr 69, 1117-1122.

51. Ravussin E, Lillioja S, Knowler WC, Christin L, Freymond D, Abbott WG, Boyce V, Howard BV, Bogardus C (1988) Reduced rate of energy expenditure as a risk factor for body-weight gain. $N$ Engl $J$ Med 318, 467472.

52. Seidell JC, Muller DC, Sorkin JD, Andres R (1992) Fasting respiratory exchange ratio and resting metabolic rate as predictors of weight gain: the Baltimore Longitudinal Study on Aging. Int J Obes Relat Metab Disord 16, 667-674.

53. Weinsier RL, Nelson KM, Hensrud DD, Darnell BE, Hunter GR, Schutz Y (1995) Metabolic predictors of obesity. Contribution of resting energy expenditure, thermic effect of food, and fuel utilization to four-year weight gain of post-obese and never-obese women. J Clin Invest 95, 980-985.

54. Westerterp KR (2004) Diet induced thermogenesis. Nutr Metab (Lond) 1, 5.

55. Johnston CS, Day CS, Swan PD (2002) Postprandial thermogenesis is increased $100 \%$ on a high-protein, low-fat diet versus a high-carbohydrate, low-fat diet in healthy, young women. J Am Coll Nutr 21, 55-61.

56. Westerterp-Plantenga MS, Rolland V, Wilson SA, Westerterp KR (1999) Satiety related to $24 \mathrm{~h}$ diet-induced thermogenesis during high protein/carbohydrate vs high fat diets measured in a respiration chamber. Eur J Clin Nutr 53, 495-502.

57. Tappy L (1996) Thermic effect of food and sympathetic nervous system activity in humans. Reprod Nutr Dev 36, 391-397.

58. Karst H, Steiniger J, Noack R, Steglich HD (1984) Diet-induced thermogenesis in man: thermic effects of single proteins, carbohydrates and fats depending on their energy amount. Ann Nutr Metab 28, 245-252.

59. Yoshioka M, Lim K, Kikuzato S, Kiyonaga A, Tanaka H, Shindo M, Suzuki $M$ (1995) Effects of red-pepper diet on the energy metabolism in men. $J$ Nutr Sci Vitaminal (Tokyo) 41, 647-656.

60. Yoshioka M, St-Pierre S, Suzuki M, Tremblay A (1998) Effects of red pepper added to high-fat and high-carbohydrate meals on energy 
metabolism and substrate utilization in Japanese women. $\mathrm{Br} J$ Nutr 80 , 503-510.

61. Dulloo AG, Duret C, Rohrer D, Girardier L, Mensi N, Fathi M, Chantre P, Vandermander $J(1999)$ Efficacy of a green tea extract rich in catechin polyphenols and caffeine in increasing 24-h energy expenditure and fat oxidation in humans. Am J Clin Nutr 70, 1040-1045.

62. Trayhurn P, Jones PM, McGuckin MM, Goodbody AE (1982) Effects of overfeeding on energy balance and brown fat thermogenesis in obese (ob/ob) mice. Nature 295, 323-325.

63. Nelson KM, Weinsier RL, Long CL, Schutz $Y$ (1992) Prediction of resting energy expenditure from fat-free mass and fat mass. Am $J$ Clin Nutr 56, 848-856.

64. Golay A (1993) Blunted glucose-induced thermogenesis: a factor contributing to relapse of obesity. Int $J$ Obes Relat Metab Disord 17 Suppl $1, \mathrm{~S} 23-27$.

65. Segal KR, Dunaif A (1990) Resting metabolic rate and postprandial thermogenesis in polycystic ovarian syndrome. Int J Obes 14, 559-567.

66. Granata GP, Brandon LJ (2002) The thermic effect of food and obesity: discrepant results and methodological variations. Nutr Rev 60, 223-233.

67. Westerterp-Plantenga MS, Wouters L, ten Hoor F (1990) Deceleration in cumulative food intake curves, changes in body temperature and dietinduced thermogenesis. Physiol Behav 48, 831-836.

68. Westerterp-Plantenga MS, Van den Heuvel $E$, Wouters $L$, Ten Hoor $F$ (1992) Diet-induced thermogenesis and cumulative food intake curves as a function of familiarity with food and dietary restraint in humans. Physiol Behav 51, 457-465.

69. Stock MJ (1999) Gluttony and thermogenesis revisited. Int J Obes Relat Metab Disord 23, 1105-1117.

70. Schoeller DA, Shay K, Kushner RF (1997) How much physical activity is needed to minimize weight gain in previously obese women? Am J Clin Nutr 66, 551-556.

71. Flatt JP (1987) Dietary fat, carbohydrate balance, and weight maintenance: effects of exercise. Am J Clin Nutr 45, 296-306.

72. Flatt JP (1993) Dietary fat, carbohydrate balance, and weight maintenance. Ann N Y Acad Sci 683, 122-140.

73. Schrauwen $P$, van Marken Lichtenbelt WD, Saris WH, Westerterp KR (1997) Changes in fat oxidation in response to a high-fat diet. Am J Clin Nutr 66, 276-282.

74. Schrauwen $P$, van Marken Lichtenbelt WD, Saris WH, Westerterp KR (1997) Role of glycogen-lowering exercise in the change of fat oxidation in response to a high-fat diet. Am J Physiol 273, E623-629. 
75. Schrauwen $P$, Lichtenbelt WD, Saris $W H$, Westerterp KR (1998) Fat balance in obese subjects: role of glycogen stores. Am $J$ Physiol 274, E1027-1033.

76. Westerterp-Plantenga MS, Goris AH, Meijer EP, Westerterp KR (2003) Habitual meal frequency in relation to resting and activity-induced energy expenditure in human subjects: the role of fat-free mass. Br J Nutr 90, 643649.

77. Garrow JS, Summerbell CD (1995) Meta-analysis: effect of exercise, with or without dieting, on the body composition of overweight subjects. Eur $J$ Clin Nutr 49, 1-10.

78. Dulloo $A G$, Jacquet $\mathrm{J}$ (1999) The control of partitioning between protein and fat during human starvation: its internal determinants and biological significance. Br J Nutr 82, 339-356.

79. Wadden TA, Foster GD, Stunkard AJ, Conill AM (1996) Effects of weight cycling on the resting energy expenditure and body composition of obese women. Int $J$ Eat Disord 19, 5-12.

80. van der Kooy K, Leenen R, Seidell JC, Deurenberg P, Hautvast JG (1993) Effect of a weight cycle on visceral fat accumulation. Am J Clin Nutr 58, 853-857.

81. Skov AR, Toubro S, Ronn B, Holm L, Astrup A (1999) Randomized trial on protein vs carbohydrate in ad libitum fat reduced diet for the treatment of obesity. Int J Obes Relat Metab Disord 23, 528-536.

82. Dumesnil JG, Turgeon J, Tremblay A, Poirier P, Gilbert M, Gagnon L, StPierre S, Garneau C, Lemieux I, Pascot A, Bergeron J, Despres JP (2001) Effect of a low-glycaemic index--low-fat--high protein diet on the atherogenic metabolic risk profile of abdominally obese men. $\mathrm{Br} J$ Nutr 86 , 557-568.

83. Layman DK, Boileau RA, Erickson DJ, Painter JE, Shiue H, Sather C, Christou DD (2003) A reduced ratio of dietary carbohydrate to protein improves body composition and blood lipid profiles during weight loss in adult women. $J$ Nutr $133,411-417$. 


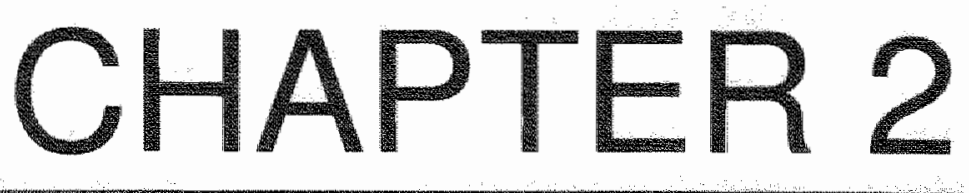

\section{Effects of dietary restraint versus exercise during weight maintenance in obese men}

MPGM Lejeune, DPC van Aggel-Leijssen, MA van Baak, and MS Westerterp-Plantenga

Eur J Clin Nutr. 2003; 57: 1338-1344 


\section{ABSTRACT}

Objective: To investigate the effect of dietary restraint with or without exercise during weight maintenance after energy restriction.

Subjects and methods: Forty obese male subjects (mean BMI $32.3 \mathrm{~kg} / \mathrm{m}^{2}$; mean age 39 y) were recruited and randomly divided in a diet $(D ; n=20)$ and a diet plus exercise $(D E ; n=20)$ group. Both groups participated in an energy restriction program (ER), which was followed by a weight maintenance phase (WM). Subjects in the DE also participated in an exercise program. Body mass (BM) and the scores on the Three Factor Eating Questionnaire (TFEQ) were measured before and after the ER and after WM.

Results: No significant differences between both groups were found. All data taken together showed that, BM loss during ER was explained by initial BM $\left(r^{2}=0.3, p<0.0005\right)$ and inversely by initial cognitive restraint $(F 1) \quad\left(r^{2}=0.4\right.$, $p<0.0005)$ in a stepwise regression. BM regain during WM was explained by BM loss $\left(r^{2}=0.5, p<0.001\right)$ and by increase in $F 1$ during ER $\left(r^{2}=0.6, p<0.001\right)$, while the exercise intervention did not contribute further to the explained variation. Subjects with a relatively high diet-frequency prior to the study had relatively significant higher initial $F 1$ scores $(p<0.05)$. During $E R$, increase in $F 1$ was associated with decrease in general hunger (F3).

Conclusion: Successful BM loss was associated with higher initial BM and lower initial F1. Successful WM was explained by BM loss and increase in F1 during $E R$, irrespective of possible exercise training effects. Successful WM was reduced when $F 1$ scores reach their limit, due to diet-frequency.

Keywords: Three Factor Eating Questionnaire, energy restriction, body weight regain, diet-frequency 


\section{INTRODUCTION}

In many Western European countries and in the USA the prevallence of overweight and obesity has increased over the last decades ${ }^{1 ; 2}$. It has been suggested that since fat and energy intake have decreased, especially in the USA, that a reduced daily physical activity, rather than an increased energy intake, has played an important role in the increase of obesity. This is called the American paradox'. However "measurements of habitual food intake are difficult, especially in obese subjects, because of underreporting energy and fat intake ${ }^{3-5}$ and this may lead to incorrect conclusions ${ }^{5}$. Therefore the American paradox might be less paradoxical than it seems to be.

Although it has been shown that physical activities decrease with increasing body fatness, subjects with a high body fatness do not spend less energy on physical activity, because of the energy costs of bearing their body mass ${ }^{\hat{b}}$. Because of the presumed role of reduced physical activity in the development of obesity, increase of physical activity as a life-style treatment of obesity, with or without a diet, often has been subject of research ${ }^{7}$. Introduced exercise has not always been successful in treating obesity. However, if it is guided and rigorously controlled, exercise-induced weight loss is possible in obese subjects $^{8-10}$.

The other life-style approach, i.e. energy restriction, has been shown to be an effective treatment of obesity on the short term ${ }^{11-13}$. On a group level weight loss can be successful by either energy restriction ${ }^{11-13}$ or exercise ${ }^{8-10}$. Contrarily, on a group level successful long-term weight maintenance, either with energy restriction, prescribed exercise, or diet and exercise hardly has been shown ${ }^{11 ;} i^{13}$. 17. However, on the individual level differences in successful weight maintenance after an energy restriction period have been shown to be related to increases in cognitive restrained eating behaviour during the energy restriction phase ${ }^{15 ; 17 \cdot 20}$. Since this relationship has been reported mostly from observations in females during weight maintenance ${ }^{13 ; 17 ; 20}$, the question remains whether this phenomenon would also appear in men. Moreover, since successful exercise induced weight loss has been shown in men $^{6}$, effects of exercise during weight maintenance is of interest.

In this study we investigated the effect of dietary restraint with or without exercise on body weight maintenance during a post energy restriction period in men. 


\section{SUBJECTS AND METHODS}

\section{Subjects}

Forty obese male subjects (BMI: $29-35 \mathrm{~kg} / \mathrm{m}^{2}$, age: $27-50 \mathrm{y}$ ), recruited by an advertisement in a local newspaper, participated in this study. All subjects were in gooid health as assessed by medical history and physical examination. The subjects did not spend more than two hours a week in sports activities and had no physically demanding jab. Subjects had a stable body weight $(<3 \mathrm{~kg}$ change) over the last three months and did not receive medication known to influence the variables measured. Subjects were matched with respect to age, body mass index (BMI), body fat percentage, weight and maximal oxygen uptake and randomly divided in two groups, the diet (D) or diet + exercise group (DE). The study was approved by the Medical Ethics Committee of the University of Maastricht. A written informed consent was obtained from all participants. Three subjects in the $D$ group did not complete the energy restriction intervention ( 1 due to illness (enteritis) and 2 due to lack of motivation). Two subjects in the D group (due to lack of motivation) and six subjects in the DE group ( 3 due to illness ( 2 knee injuries not related to the training program; 1 nephritis) and 3 due to lack of motivation) did not complete the weight maintenance period. Subject characteristics are shown in Table 1.

\section{Experimental design}

The study lasted for 53 weeks, and consisted of two phases, an energy restriction phase and a weight maintenance phase. All subjects in the D and DE group participated in an energy restriction program for 10 weeks. At the same time the subjects in the DE group also took part in a low intensity exercise training program. During the weight maintenance phase subjects in the $D E$ group continued their low intensity exercise training program. The subjects in the $D$ group were instructed not to change their habitual activity pattern over this period. Body weight, body composition and the scores on the Three Factor Eating Questionnaire ${ }^{21 ; 22}$ were measured before the start of the study (week 0), after the energy restriction phase (week 13), and after the weight maintenance phase (week 53). 


\section{Diet}

All subjects participated in the energy restriction program. The first six weeks subjects received a very low energy diet "Modifast, Novartis Nutrition, Breda, The Netherlands). This diet provided $2.1 \mathrm{MJ} /$ day and was a protein enriched formula diet, containing $50 \mathrm{~g}$ carbohydrates, $52 \mathrm{~g}$ protein, $7 \mathrm{~g}$ fat and a micronutrient content which meets the Dutch recommended daily allowance. From week 7 until week 10, subjects increased their energy intake gradually. They received less formula diet and were instructed to complete this with a free choice of food items. In week 7 and 8 subjects received $1.4 \mathrm{MJ} /$ day of the formula diet and completed this up to about $3.5 \mathrm{MJ} /$ day by a free choice of food items. In week 9 and 10 they received $0.7 \mathrm{MJ} /$ day of the formula diet and they completed this up to about $4.9 \mathrm{MJ} /$ day by other food items. In week 11 and 12 subjects received a dietary instruction to stabilize body weight.

\section{Exercise training}

The subjects in the D group were instructed not to change their habitual activity pattern during the study period. The subjects in the DE group participated, in addition to the energy restriction program, in an exercise training program during the study period. They trained 4 times one hour per week, 3 times at the laboratory under supervision of a professional trainer and once at home. The exercise training program consisted of cycling on an ergometer (Bodyguard Cardiocycle, Sandnes, Norway or Lode, Groningen, The Netherlands), walking and aqua-jogging. All exercises were executed at a low intensity $(40 \%$ $\mathrm{VO}_{2}$ max). The heart rate corresponding with $40 \% \mathrm{VO}_{2} \max$ was determined in an incremental cycle ergometer test. Training intensity was checked by monitoring heart rate during the laboratory training sessions (Polar Electro, $\mathrm{Oy}$, Finland). Every three months a maximal aerobic capacity test was performed and exercise intensity was corrected if necessary. Subjects were instructed to execute low intensity endurance exercise once a week at home. Subjects' attendance at the training sessions was recorded and the trainer inquired regularly for the extra exercise at home.

\section{Measurements}

Anthropometric and body composition measurements

Body weight was measured on a digital balance accurate to $0.1 \mathrm{~kg}$ (Sauter D7470 , Ebingen, Germany). Height was measured to the nearest $0.1 \mathrm{~cm}$ using a 
wall-mounted stadiometer (Seca, model 220, Hamburg, Germany). BMI was calculated from weight and height $\left(\mathrm{kg} / \mathrm{m}^{2}\right)$. Body density was measured by hydrostatic weighing, with a correction for residual lung volume estimated by helium dilution with a spirometer (Volugraph 2000, Mijnhardt, The Netherlands) at the moment of underwater weighing. Body composition was calculated according to the formula of $\operatorname{Sir}^{23}$.

\section{Body weight regain and weight maintenance}

Body weight regain during the weight maintenance period was expressed as the percentage of the weight lost during the energy restriction period:

$\%$ Body weight regain = body weight regain $(\mathrm{kg}) /$ body weight loss $(\mathrm{kg}) * 100 \%$

Weight maintenance was expressed as the inverse percentage body weight regain of the weight lost:

Weight maintenance $=100-\%$ body weight regain

\section{Eating behaviour}

Eating behaviour was characterized using a Dutch translation of the Three Factor Eating Questionnaire (TFEQ) ${ }^{21:} 22$. The TFEQ consists of 49 questions representing three different factors relevant to human eating behaviour. The first factor of the TFEQ (F1) measures cognitive restrained eating: control of food intake by thought and will power. The second factor (F2) represents disinhibition: an incidental inability to resist eating cues, or inhibition of dietary restraint (F1), and emotional eating. The third factor (F3) examines the subjective feeling of general hunger. The factors are randomly divided over the questions. The maximum score for $\mathrm{F} 1, \mathrm{~F} 2$ and $\mathrm{F} 3$ are respectively 21,14 and 14.

Frequency of dieting was assessed separately before the start of the study by the question 'How often are you dieting?". The answer categories were 'never', 'rarely', 'sometimes', 'most of the time' and 'always'.

\section{Statistical analysis}

Data are presented as means \pm standard deviation (SD). A factorial ANOVA was used to determine possible difference between the $D$ and DE group in all measured parameters. Possible differences of the variables over time between the groups were analyzed with a two-factor repeated-measures ANOVA. Post hoc analyses were done with the Scheffe F-test. A factorial ANOVA was done 
to test possible differences in cognitive restraint between subjects with high versus low diet-frequency. The possible relationships between the TFEQ scores, body weight loss, body weight regain, body composition were assessed by simple regression analysis. Stepwise regression analyses were done to analyze the relationships between body weight loss, initial body weight and initial cognitive restraint and between body weight regain, body weight loss; changes in cognitive restraint and attendance at exercise training. A p-value $<0.05$ was regarded as statistically significant. Statistical procedures were performed by using Statview SE+ Graphics (Abacus Concepts, Berkeley, CA, 1988).

\section{RESULTS}

The exercise intervention did not induce a significant difference between the $D$ and DE group in any of the parameters measured, i.e. body weight loss $(p=0.8)$, change in BMI ( $p=0.6)$, percentage body fat $(p=0.9)$, fat mass ( $p=0.9)$, fat free mass $(p=0.4)$, body weight regain $(p=0.3)$ and the factors of the TFEQ ( $F 1$ : $p=0.4 ; F 2 ; p=0.5$ " $F 3: p=0.8$ ).

A more detailed analysis of the exercise induced effects has been published by Van Aggel-Leijssen et al. ${ }^{24 ; 25}$. Body weight for the two groups at the different timepoints is shown in figure 1.

For further analysis the two intervention groups were taken together. Unless otherwise stated all results of the energy restriction period have been analyzed using 37 subjects. The results of the weight maintenance period have been analyzed using 29 subjects, due to the drop out of eight subjects.

Changes in body weight, BMI, body fat percentage, fat mass and fat free mass at the different timepoints are shown in table 1. During the energy restriction phase body weight decreased significantly. The mean body weight loss during the energy restriction phase was $15.0 \mathrm{~kg}$ (SD $5.8 \mathrm{~kg}$, range $6.2-28.3 \mathrm{~kg}$ ). At the end of the weight maintenance phase body weight showed a significant decrease compared to week 0 , but a significant increase compared to week 13 . At week 53 the mean body weight loss was $7.1 \mathrm{~kg}$ (SD $8.3 \mathrm{~kg}$, range $-3.8-31.3$ $\mathrm{kg}$ ) compared to week 0 . During the weight maintenance phase the mean body weight regain was $8.0 \mathrm{~kg}$ (SD $4.5 \mathrm{~kg}$, range $14.2--3.4 \mathrm{~kg}$ ). The BMI, body fat percentage, fat mass and fat free mass also decreased significantly during the energy restriction phase. After the weight maintenance phase BMI, body fat percentage and fat mass showed a significant decrease compared to week 0 , but a significant increase compared to week 13 . At week 53 fat free mass was significantly different from week 13 , but no longer different from week 0 . 
The cognitive restraint scores (F1) increased significantly during the energy restriction phase, while the hunger scores (F3) decreased significantly. The disinhibition scores (F2) showed no changes. The cognitive restraint and hunger scores did not change significantly during the weight maintenance phase, but stayed significantly different compared to week 0 (Table 1).

Body weight loss during the energy restriction period was positively correlated with body weight before the study, thus a higher initial body weight predicts more weight loss (Figure 2a). There was a negative relationship between the body weight loss during the energy restriction period and the cognitive restraint scores ( $F 1$ ) at week 0 , indicating that less weight loss is predicted by higher initial cognitive restraint scores (Figure $2 b$ ).

Stepwise regression analysis with body weight loss as a function of initial body weight and initial cognitive restraint showed that body weight loss was primarily explained by initial body weight $\left(r^{2}=0.3, p<0.0005\right)$ and secondarily by initial cognitive restraint $\left(r^{2}=0.4, p<0.0005\right)$.

Subjects with a higher diet-frequency (i.e. 'most of the time' or 'always') prior to the study showed a significantly higher initial cognitive restraint score than the subjects with a lower diet-frequency (i.e. 'never', "rarely' or 'sometimes') (Factorial Anova, $p<0.05$ ).

Weight regain during the weight maintenance phase was negatively correlated with body weight loss during the energy restriction period, indicating that a higher body weight loss predicts less weight regain (Figure $3 \mathrm{a}$ ). There was also a negative correlation between weight regain and the increase in cognitive restraint during energy restriction, thus less weight regain is predicted by larger early increases in cognitive restraint (Figure 3b).

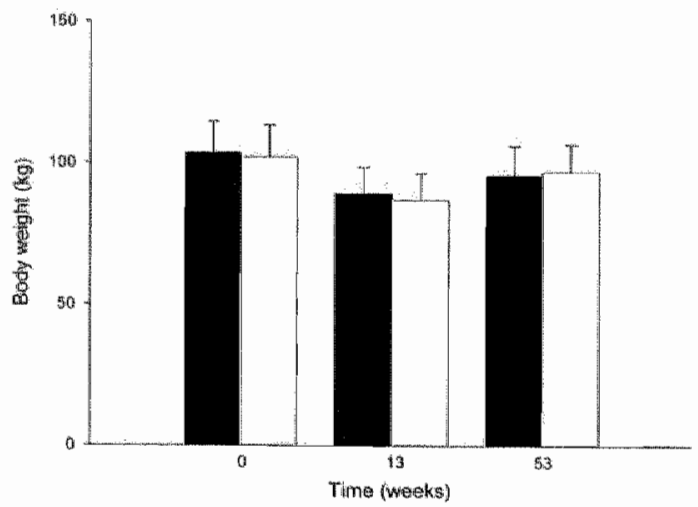

Figure 1 Mean bodly weight before the energy restriction phase (week 0), after the energy restriction phase (week 13) and after the weight maintenance phase (week 53) for the $D$ group (black) (week 0 and 13: $n=17$, week 53: $n=15$ ) and the DE group (white) (week 0 and 13: $n=20$, week $53: n-14)$. SD are shown by vertical bars. 
Table 1 Subject characteristics before the energy restriction phase (week 0), after the energy restriction phase (week 13) and after the weight maintenance phase (week 53)

\begin{tabular}{lccc}
\hline & Week 0 $(\mathrm{n}=37)$ & Week 13 $(\mathrm{n}=37)$ & Week 53 $(\mathrm{n}=29)$ \\
\hline Age (yr) & $39.0 \pm 7.1$ & & \\
Body weight (kg) & $102.7 \pm 11.0$ & $87.7 \pm 9.3^{*}$ & $96.0 \pm 9.9^{* * * *}$ \\
BMI (kg/m2) & $32.3 \pm 2.3$ & $27.7 \pm 2.2^{* *}$ & $29.9 \pm 2.8^{* \text { *** }}$ \\
Bodly fal (\%) & $34.0 \pm 4.5$ & $25.4 \pm 5.5^{*}$ & $28.0 \pm 5.4^{* * * *}$ \\
Fat free mass (FFM) (kg) & $67.7 \pm 8.5$ & $65.3 \pm 7.9^{*}$ & $68.8 \pm 6.4^{* *}$ \\
Fat mass (kg) & $35.0 \pm 6.1$ & $22.4 \pm 5.8^{*}$ & $27.1 \pm 6.7^{* * * *}$ \\
F1 (cognitive restraint) & $5 \pm 3.7$ & $10 \pm 4.1^{*}$ & $7 \pm 4.3^{*}$ \\
F2 (disinhibition) & $5 \pm 2.2$ & $4 \pm 2.4$ & $5 \pm 2.5$ \\
F3 (hunger) & $5 \pm 3.0$ & $3 \pm 2.4^{* * *}$ & $3 \pm 2.9^{* * *}$ \\
\hline
\end{tabular}

Data are presented as means \pm SD. Statistical significance was determined by ANOVA for repeated measures. "Significantly different from week $0 \quad(p<0.0001)$. **Significantly different from week 13 $(p<0.0001)$." ${ }^{* * *}$ Significantly different from week $0(p<0.003)$.

Stepwise regression analysis showed that weight regain was primarily explained by body weight loss $\left(r^{2}=0.5, p<0.001\right)$ and secondarily by early increase in cognitive restraint $\left(r^{2}=0.6, p<0.001\right)$, while attendance at exercise training (total hours) did not add to the explained variation. Moreover, the increase in dietary restraint was not correlated to attendance at exercise training.

(a)

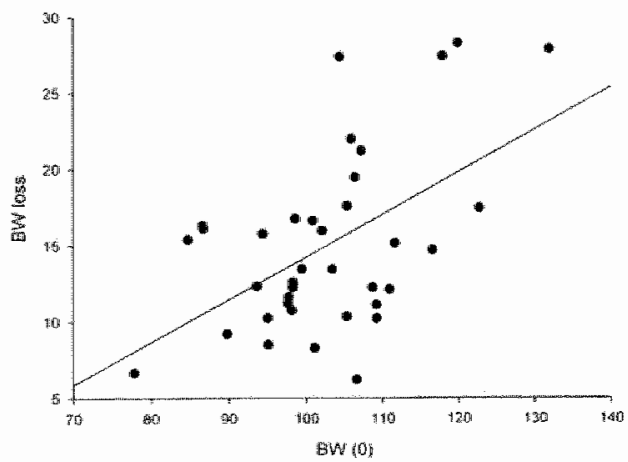

(b)

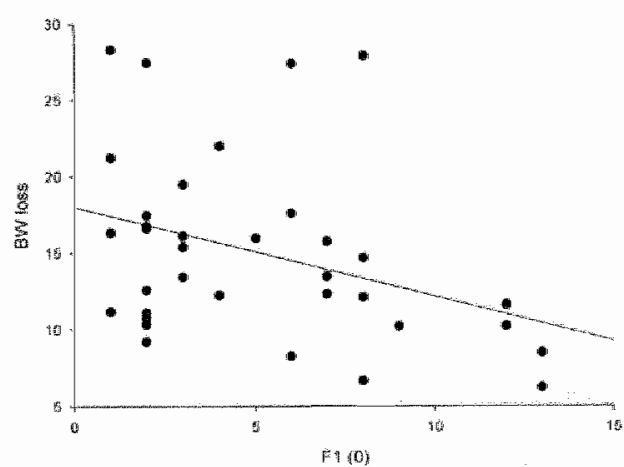

Figure 2 Correlation between body weight loss during the energy restriction period and (a) initial body weight ( $B W$ loss $=0.3 \mathrm{BW}(0)-13.7, r^{2}=0.28, p<0.001$ ); (b) initial cognitive restraint scores (BW loss $\left.=-0.61 \mathrm{~F} 1(0)+18.0, r^{2}=0.13, p<0.05\right)$. 
(a)

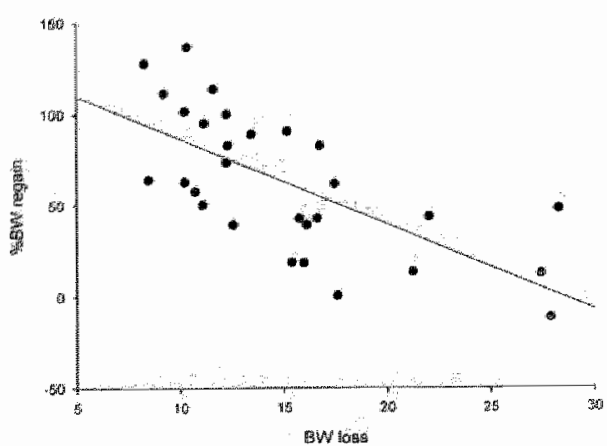

(b)

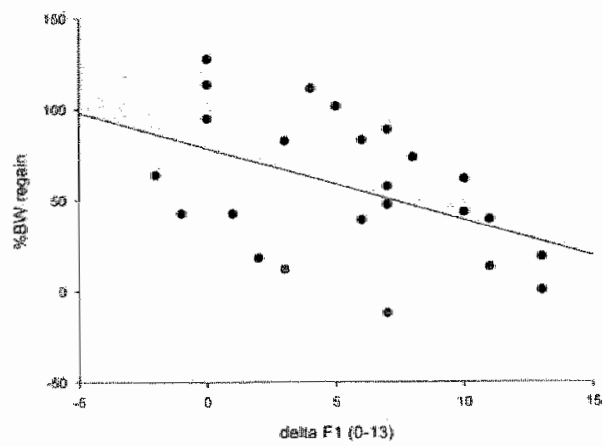

Figure 3 Correlation between percentage body weight regain during the weight maintenance period and (a) body weight loss during the energy restriction period (\%BW regain $=-4.7 \mathrm{BW}$ loss +13.4 , $r^{2}=0.46, p<0.0005$ ); (b) cognitive restraint score during the energy restriction period (\%BW regain = $\left.4.0 \Delta F 1(0-13)+78.6, r^{2}=0.22, p<0.05\right)$.

The increase in cognitive restraint was inversely correlated with initial cognitive restraint scores, indicating that a lower initial cognitive restraint predicts greater increase in cognitive restraint $\left(\Delta \mathrm{F} 1(0-13)=-0.6^{*} \mathrm{~F} 1(0)+7.9, \mathrm{r}^{2}=0.19, p<0.05\right)$. The increase in cognitive restraint was also related to the decrease in general hunger (indicated by $\Delta F 3)\left(\Delta F_{1}(0-13)=-0.5^{\star} \Delta F 3(0-13)+4.2, r^{2}=0.13, p<0.05\right)$. Decreases in general hunger were predicted by higher initial general hunger scores $\left(\Delta F 3(0-13)=-0.8^{*} F 3(0)+2.2, r^{2}=0.54, p<0.0005\right)$.

\section{DISCUSSION}

The results of the present study demonstrate that weight maintenance in obese men after an energy restriction program was predicted by body weight loss and by an increase in cognitive restrained eating behavior during the energy restriction period. This implies that the higher the body weight loss, the less the body weight regain. An explanation for this might be that when body weight loss is only moderate, subjects tend to restore their original body weight as a settling point mechanism ${ }^{26}$. Since the increase in dietary restraint during the energy restriction program was correlated with the decrease in hunger, it appeared that weight maintenance, due to an increase in cognitive restraint, was indirectly supported by a decrease in general hunger. Wadden et al..$^{27}$ also reported a relatively greater appetite reduction due to a very low energy diet, which is in line with the decrease in general hunger during the diet intervention that we report in the present study. Previously, we also showed a relationship between 
increase in cognitive restraint during energy restriction and weight maintenance thereafter in women ${ }^{20}$. However, in that study no additional exercise protocol was provided. Here we created the situation that weight maintenance could be improved by prescribed low intensity exercise training in men. But the group that followed the low intensity exercise training program did not show a better weight maintenance than the non-exercise group.

Because the increase in dietary restraint during weight loss predicts the percentage body weight regain, this implies also a prediction of the rate of body weight regain. This means that the results and conclusions may be the same two years after the intervention although the resulting body weight regain is probably higher then.

The pre-study body weight and cognitive restraint scores predicted the body weight loss during the energy restriction phase. Subjects with lower body weight and who were highly cognitively restrained before the start of the study lost less body weight during the diet intervention compared to lower dietary restrained subjects with higher initial body weight.

Pre-study cognitive restraint was related to the frequency of dieting before the study. Obviously, a history of frequent dieting related to pre-study cognitive restraint limited the successfulness of subsequent dieting. When dieting has been infrequent, there is still room for improvement, indicated by a low cognitive restraint at the start, which still can increase. This is in accordance with the data of a study by Pasman et al..$^{13}$, who reported that subjects with a high frequency of dieting prior to a diet intervention showed higher restrained eating behaviour together with a higher disinhibition, and a less successful weight maintenance. Thus, appears the picture of a possibility for successful dieting when starting with a relatively high $\mathrm{BMI}$ and a low dietary restraint, due to little previous dieting. With repeated dieting success decreases. This has been called the weight cycling effect, which was suggested to be caused by the continuously decreasing basal metabolic rate. This has been shown very clearly by Van Gemert et al. ${ }^{28}$ in morbidly obese subjects during follow-up after vertical banded gastroplasty. The reduction in sleeping metabolic rate due to a lowered body weight was larger than expected based on the reduction in fat free mass. They suggest that the disproportional reduction in sleeping metabolic rate, even 12 months after vertical banded gastroplasty when weight loss was very mild, reflected the persistent susceptibility of the formerly obese subjects to weight regain. In studies in obese, but not morbidly obese, subjects a weight cycling history appeared not to be associated with resting energy expenditure ${ }^{16}$. Here we suggest an additional mechanism for weight cycling, namely a limit in the possibility to increase cognitive restrained eating behaviour. When the cognitive dietary restraint score approaches the limit (a F1 score of 21), the success of subsequent dieting will decrease. Thus, we have confirmed that factor 1 of the 
TFEQ, dietary restraint, in relation to factor 3 (general hunger) can be used as an indicator of increased eating control20. Since reporting of food intake in humans cannot be expected to be completely reliable because of reasons of privacy29 and thus often leads to incorrect conclusions ${ }^{3-5}$, using the TFEQ scores for assessing eating control appears to be sufficiently representative for changing eating behaviour regarding energy intake and food choice. In this study dietary restraint was stimulated by giving dietary instructions during the energy restriction phase. If subjects had adhered to the dietary instructions, they would have experienced an energy intake restriction of on average 12.8 $\mathrm{MJ} /$ day during the first 6 weeks, of $9.9 \mathrm{MJ} /$ day during week 7 and 8 , and of 8.0 $\mathrm{MJ} /$ day during week 9 and 10 . Together they would have reduced $788 \mathrm{MJ}$, which should have resulted in a body weight loss of $24 \mathrm{~kg} 30$. The range of body weight loss, 6.2 to $28.3 \mathrm{~kg}$, thus shows a range in compliance with the diet. This range in body weight loss was correlated to increase in dietary restraint. So, increase in dietary restraint appeared to be a measurement for compliance, as we showed before ${ }^{20}$.

Data of the present study show that addition of a prescribed low intensity exercise training to a diet intervention program has no extra effect on changes in body weight and body composition (see also ${ }^{24 ; 25}$ ). This is in accordance with the results of a meta-analysis of weight loss studies using diet, exercise or diet plus exercise interventions over the past 25 years $^{31}$, showing that the continuation of low intensity exercise training during the weight maintenance phase could not limit body weight regain. In a review on associations between physical activity and weight regain, Fogelholm and Kukkonen-Harjula ${ }^{9}$ conclude that the effects of a prescribed exercise program on weight maintenance are small. An explanation for this maybe that subjects tend to compensate the energy costs of exercise training by reducing their activity outside the training sessions, therefore their physical activity index (PAl) does not change ${ }^{7}$. Moreover, an increase in physical activity is necessary to compensate for the reduction in activity induced energy expenditure due to weight loss. Increased physical activity is facilitated by the lower body mass, but this still does not lead to an increase of PAI. It is likely that with the low intensity exercise training program used in our study a higher PAl was also not achieved. Since the combination of diet and exercise usually shows minor extra effects on weight loss $^{31}$, we might consider comparisons between effects of diet and of exercise separately instead of diet plus exercise effects. For instance Garrow and Summerbell ${ }^{10}$ showed that aerobic exercise without dieting causes a modest weight loss, and Ross et al. ${ }^{8}$ showed exercise-induced weight loss in obese subjects when exercise without dieting was guided and controlled.

In conclusion, successful body weight loss depended on the starting situation, i.e. a higher initial body weight and a lower dietary restraint. Subsequent body 
weight loss and increase in dietary restraint (related to decrease in general hunger) during weight reduction determined weight maintenance thereafter, irrespective of possible exercise training effects. When dietary restraint scores approach their limit, due to diet-frequency, successful weight maintenance is reduced. This also may contribute to body weight cycling.

\section{REFERENCES}

1. Heini AF, Weinsier RL (1997) Divergent trends in obesity and fat intake patterns: the American paradox. Am J Med 102, 259-264.

2. Seidell JC (1998) Dietary fat and obesity: an epidemiologic perspective. Am J Clin Nutr 67, 546S-550S.

3. Goris AH, Westerterp KR (1999) Underreporting of habitual food intake is explained by undereating in highly motivated lean women. J Nutr 129,878 882.

4. Goris AH, Westerterp KR (2000) Improved reporting of habitual food intake after controntation with earlier results on food reporting. Br J Nutr 83, 363369.

5. Goris $A H$, Westerterp-Plantenga MS, Westerterp KR (2000) Undereating and underrecording of habitual food intake in obese men: selective underreporting of fat intake. Am J Clin Nutr 71, 130-134.

6. Schulz LO, Schoeller DA (1994) A compilation of total daily energy expenditures and body weights in healthy adults. Am J Clin Nutr 60, 676681.

7. Westerterp KR (1999) Obesity and physical activity. Int $J$ Obes Relat Metab Disord 23 Suppl 1, 59-64.

8. Ross R, Dagnone D, Jones PJ, Smith H, Paddags A, Hudson R, Janssen I (2000) Reduction in obesity and rellated comorbid conditions after dietinduced weight loss or exercise-induced weight loss in men. A randomized, controlled trial. Ann Intern Med 133, 92-103.

9. Fogelholm M, Kukkonen-Harjula K (2000) Does physical activity prevent weight gain - a systematic review. Obesity Reviews 1, 95-111.

10. Garrow JS, Summerbell CD (1995) Meta-analysis: effect of exercise, with or without dieting, on the body composition of overweight subjects. Eur $J$ Clin Nutr 49, 1-10.

11. van Dale D, Saris WH (1989) Repetitive weight loss and weight regain: effects on weight reduction, resting metabolic rate, and lipolytic activity before and after exercise and/or diet treatment. Am J Clin Nutr 49, 409416. 
12. Kempen KP, Saris WH, Westerterp KR (1995) Energy balance during an 8wk energy-restricted diet with and without exercise in obese women. Am J Clin Nutr 62, 722-729.

13. Pasman WJ, Saris WH, Westerterp-Plantenga MS (1999) Predictors of weight maintenance. Obes Res 7, 43-50.

14. Froidevaux $F$, Schutz $Y$, Christin $L$, Jequier $E$ (1993) Energy expenditure in obese women before and during weight loss, after refeeding, and in the weight-relapse period. Am J Clin Nutr 57, 35-42.

15. Hensrud DD, Weinsier RL, Darnell BE, Hunter GR (1994) A prospective study of weight maintenance in obese subjects reduced to normal body weight without weight-loss training. Am J Clin Nutr 60, 688-694.

16. Muls $E$, Kempen $K$, Vansant $G$, Saris $W$ (1995) is weight cycling detrimental to health? A review of the literature in humans. Int $J$ Obes Relat Metab Disord 19 Suppl 3, S46-50.

17. Fogelholm M, Kukkonen-Harjula $K$, Oja $P$ (1999) Eating control and physical activity as determinants of short-term weight maintenance after a very-low-calorie diet among obese women. Int J Obes Relat Metab Disord 23, 203-210.

18. Clark MM, Marcus BH, Pera V, Niaura RS (1994) Changes in eating inventory scores following obesity treatment. Int J Eat Disord 15, 401-405.

19. Pekkarinen T, Takala I, Mustajoki P (1996) Two year maintenance of weight loss after a VLCD and behavioural therapy for obesity: correlation to the scores of questionnaires measuring eating behaviour. Int $J$ Obes Relat Metab Disord 20, 332-337.

20. Westerterp-Plantenga MS, Kempen KP, Saris WH (1998) Determinants of weight maintenance in women after diet-induced weight reduction. Int $J$ Obes Relat Metab Disord 22, 1-6.

21. Stunkard AJ, Messick $S$ (1985) The three-factor eating questionnaire to measure dietary restraint, disinhibition and hunger. J Psychosom Res 29, 71-83.

22. Westerterp-Plantenga MS, Rolland V, Wilson SA, Westerterp KR (1999) Satiety related to $24 \mathrm{~h}$ diet-induced thermogenesis during high protein/carbohydrate vs high fat diets measured in a respiration chamber. Eur J Clin Nutr 53, 495-502.

23. Siri WE (1956) The gross composition of the body. Adv Biol Med Phys 4, 239-280.

24. van Aggel-Leijssen DP, Saris WH, Hul GB, van Baak MA (2001) Shortterm effects of weight loss with or without low-intensity exercise training on fat metabolism in obese men. Am J Clin Nutr 73, 523-531. 
25. Van Aggel-Leijssen DP, Saris WH, Hul GB, Van Baak MA (2002) Longterm effects of low-intensity exercise training on fat metabolism in weightreduced obese men. Metabolism 51, 1003-1010.

26. Keesey RE, Hirvonen MD (1997) Body weight set-points: determination and adjustment. J Nutr 127, 1875S-1883S.

27. Wadden TA, Stunkard AJ, Day SC, Gould RA, Rubin CJ (1987) Less food, less hunger: reports of appetite and symptoms in a controlled study of a protein-sparing modified fast. Int $J$ Obes 11, 239-249.

28. van Gemert WG, Westerterp KR, van Acker BA, Wagenmakers AJ, Halliday D, Greve JM, Soeters PB (2000) Energy "substrate and protein metabolism in morbid obesity before, during and after massive weight loss. Int J Obes Relat Metab Disord 24, 711-718.

29. Blundell JE (2000) What foods do people habitually eat? A dilemma for nutrition, an enigma for psychology. Am J Clin Nutr 71, 3-5.

30. Westerterp KR, Donkers JH, Fredrix EW, Boekhoudt $P$ (1995) Energy intake, physical activity and body weight: a simulation model. $\mathrm{Br} J \mathrm{Nutr} 73$, 337-347.

31. Miller WC, Koceja DM, Hamilton EJ (1997) A meta-analysis of the past 25 years of weight loss research using diet, exercise or diet plus exercise intervention. Int J Obes Relat Metab Disord 21, 941-947. 


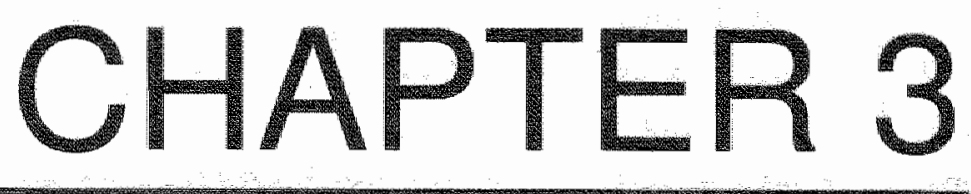

\section{Effect of dietary restraint during and following pegylated recombinant leptin (PEG-OB) treatment of overweight men}

MPGM Lejeune, CJ Hukshorn, WHM Saris, MS Westerterp-Plantenga Int J Obes Relat Metab Disord. 2003; 27: 1494-1499 


\section{ABSTRACT}

Objective: To examine the effect of dietary restraint during and following pegylated recombinant leptin (PEG-OB protein) treatment in overweight men.

Design: A randomized double blind placebo controlled trial in 24 overweight men (BMl: $28.8 \pm 0.3 \mathrm{~kg} / \mathrm{m}^{2}$; age: $34.8 \pm 0.9 \mathrm{yrs}$ ). PEG-OB protein ( $80 \mathrm{mg}$ ) or placebo was administered subcutaneously weekly for 6 weeks, combined with a 2.1 MJ/d energy restriction program. Dietary restraint was determined by the Three Factor Eating Questionnaire before and after treatment, and after 8 weeks follow-up.

Results: During treatment dietary restraint increased and general hunger, resting energy expenditure and respiratory quotient decreased similarly in the PEG-OB and the placebo group. With PEG-OB treatment additional weight loss $(p<0.03)$ was observed. During 8 weeks follow-up, body weight increase was larger in the PEG-OB group compared to placebo $(p<0.05)$, and body weight regain was faster. Body weight regain was inversely correlated with the increase in cognitive dietary restraint during treatment (PEG-OB group: $r^{2}=0.49$; $p<0.02$; placebo group: $r^{2}=0.60 ; p=0.01$ ).

Conclusion: Although treatment with PEG-OB protein led to a greater body weight loss relative to placebo, weight maintenance thereafter was mainly supported by dietary restraint, which was more effective in the placebo treated group, resulting in a slower regain of body weight.

Keywords: Three Factor Eating Questionnaire, PEG-OB protein, dietary restraint, leptin, obesity, weight loss 


\section{INTRODUCTION}

In many Western European countries and in the USA the prevalence of overweight and obesity has increased over the last decades'. Obesity is associated with a relatively high rate of morbidity and early mortality if it remains untreated $^{2-5}$. Commonly used weight control methods such as diet and exercise ${ }^{6}$ as well as pharmacological approaches ${ }^{7}$ often are successful on the short-term, but on the long term an increased risk of body weight regain resulting in weight cycling has been reported $d^{6 ; 8 ; 9}$. Thus, other treatments that may be effective on the long term are necessary.

In this respect the identification of leptin (or OB-protein, a circulating protein hormone) following the positional cloning of the ob gene ${ }^{10}$ as a possible energy balance regulator is of interest. Expression of the ob gene is present in e.g. adipose tissue and the placenta ${ }^{11}$. Leptin concentration in the serum changes in response to factors known to affect body weight ${ }^{11 ; 12}$. It has been demonstrated that blood levels of leptin correlated with percentages of body fat, and were elevated in obese individuals ${ }^{13}$. In spite of elevated concentrations of leptin, which should reduce food intake and body fat, obese subjects appear to be insensitive or resistant to leptin, and continue to maintain increased body fatness. With weight reduction obese subjects were reported to lower leptin concentrations, which increased again with weight regain ${ }^{14}$.

In previous trials, significant dose-related reductions in body fat and body weight were observed following daily subcutaneous treatment with from 0.01 to $0.30 \mathrm{mg} / \mathrm{kg}$ recombinant human met-leptin for 24 weeks in obese subjects ${ }^{15}$. The treatment of a young obese girl with daily met-leptin caused a reduction in appetite, food seeking behaviour, food intake and body weight ${ }^{16}$. In a previous study with administration of $20 \mathrm{mg} / \mathrm{wk}$ pegylated recombinant human leptin we found that appetite in the post-absorptive state was reduced, but no difference in body mass loss or body composition compared to placebo treatment was demonstrated ${ }^{17}$. In that study hunger (factor 3, Three Factor Eating Questionnaire (TFEQ); Stunkard and Messick ${ }^{18}$ ) was reduced in the PEG-OB group and cognitive restraint (factor 1, TFEQ) was increased in the placebo group, during treatment.

In addition to physiological parameters, psychological parameters that play a role in the treatment of obesity have to be taken into account. Changes in attitude towards eating measured with the TFEQ following a weight reduction program have been observed in that these support weight maintenance ${ }^{19-22}$. The TFEQ measures three factors relevant to human attitude towards eating; cognitive restraint, disinhibition, and hunger. It is often seen that the cognitive restraint score increases during an energy restriction program, while the 
disinhibition and hunger scores decrease ${ }^{19-22}$. The success of weight maintenance after a weight reduction program has been shown to be a function of increase in cognitive restraint during weight reduction ${ }^{20: 23}$. The relationship between dietary restraint and endogenous leptin levels has been studied in overweight women, but no significant correlation was found ${ }^{24: 25}$. To our knowledge this relationship has not yet been investigated in overweight men. The question remains whether pharmacological treatment, i.e. PEG-OB protein treatment replaces or supports an increase of dietary restraint during treatment. Moreover, the effect of PEG-OB protein treatment on subsequent weight maintenance remains to be described. The aim of this study was to assess the role of dietary restraint during treatment with PEG-OB protein, and during the first period of weight maintenance thereafter.

\section{SUBJECTS AND METHODS}

\section{Subjects}

Twenty-four healthy overweight male volunteers (BMI: $25-32 \mathrm{~kg} / \mathrm{m}^{2}$, age: $18-40$ $y)$, were recruited by an advertisement in a local newspaper. Subjects who were willing to participate in the study were screened medically. A written informed consent was obtained from all participants. Screening included a detailed medical history, a physical examination, biochemical tests of renal, hepatic, metabolic and hematological function, 12-lead resting electrocardiogram and vital signs. Subjects were non-smokers, had a stable body weight $(<3 \mathrm{~kg}$ change) over the last three months and did not receive prescription medication. Excluded from the study were subjects with a history of atopy or hypersensitivity to pegylated proteins. The study was approved by the Medical Ethics Committee of the University of Maastricht.

\section{Study design}

This single center trial had a prospective, randomized, double blind, and placebo controlled group design. After screening 24 subjects were enrolled. The study was divided into three phases: a) baseline characterization; b) PEG-OB or placebo treatment and a very low energy diet (VLED) for 6 weeks; c) follow-up for 8 weeks. Subjects were matched in a pairwise fashion with respect to age, BMI, fasting serum leptin and insulin concentration. Subsequently, the subjects of the matched pair were randomly assigned either to the treatment or placebo group. 
Phase a: baseline characterization

In the two weeks before the start of the diet and treatment period, baseline measurements were performed. These measurements consisted of body weight, body composition, serum levels of leptin, resting energy expenditure (REE), respiratory quotient (RQ) and attitude towards eating characterized using a Dutch translation of the Three Factor Eating Questionnaire ${ }^{18_{i}} 26$. All subjects were asked to maintain their body weight during the baseline period and their normal physical activity level throughout the study period.

Phase b: 6 weeks treatment

At the start of the treatment period (day 1) all subjects were prescribed a VLED for 6 weeks to induce a state of semistarvation. At the same time treatment consisting of injections of either $80 \mathrm{mg} \mathrm{PEG-OB} \mathrm{(} 8 \mathrm{ml}, 10 \mathrm{mg} \cdot \mathrm{ml}-1)$ (provided by Hoffmann-La Roche Inc, Nutley, New Jersey) or matching placebo $(8 \mathrm{ml})$ was given subcutaneously in the para-umbilical region, once a week, during the VLED period. At the end of the 6-week treatment period measurements of body weight, body composition, REE, RQ and attitude towards eating were performed again.

Phase c: 8 weeks follow-up

After week 6 the VLED and PEG-OB or placebo injections were stopped. Four and eight weeks later body weight and attitude towards eating measurements were repeated.

\begin{tabular}{|c|c|c|c|c|}
\hline 2 weeks & 6 weeks & & 8 weeks & \\
\hline $\begin{array}{l}\text { Phase a } \\
\text { Baseline }\end{array}$ & $\begin{array}{c}\text { Phase } b \\
\text { VLED + iniections }\end{array}$ & & $\begin{array}{l}\text { Phase c } \\
\text { Follow-up }\end{array}$ & \\
\hline EQ & & $\begin{array}{l}\text { TFEQ } \\
\text { BW } \\
\text { BC } \\
\text { REE/RQ }\end{array}$ & $\begin{array}{l}\text { TFEQ } \\
\text { BW }\end{array}$ & $\begin{array}{l}\text { TFEQ } \\
B W\end{array}$ \\
\hline
\end{tabular}

TFEQ: Three Factor Eating Questionnaire

BW: Body weight

BC: Body composition

LEP: Serum leptin concentration

REE/RQ: Resting energy expenditure and $\mathrm{RQ}$ 
Safety was monitored throughout the study by documentation of adverse events, recording of vital signs, regularly urine analysis and routine measurements of serum chemistry and blood cell counts. Standard clinical chemistry and blood cell counts were conducted at the certified central laboratory of the University Hospital Maastricht, the Netherlands.

\section{PEG-OB protein}

Polyethylene glycols (PEG), expressed and purified from Escherichia coll, are amphophilic polymers of ethylene glycol with varying average molecular weights that can be activated and covalently attached to proteins. Modification of proteins with PEG has resulted in increased serum half-life and reduced immunogenicity to a number of proteins ${ }^{27 ;} 28$. The average molecular weight of branched PEG utilized is 42.000 daltons in a $1: 1$ ratio ${ }^{29: 30}$. To name the administered substance in its original way, and to discriminate between the administered substance and endogenous leptin, we use 'PEG-OB protein' for the human recombinant pegylated administered and 'leptin' for the endogenous substance.

\section{Diet}

All subjects participated in the energy restriction program. The first six weeks subjects received a very low energy diet (Modifast, Novartis Nutrition, Breda, The Netherlands). This diet provided $2.1 \mathrm{MJ} /$ day ( 3 servings/day) and was a protein enriched formula diet, containing $50 \mathrm{~g}$ carbohydrates, $52 \mathrm{~g}$ protein, $7 \mathrm{~g}$ fat and a micronutrient content which meets the Dutch recommended daily allowance. From week 7 until week 10, subjects increased their energy intake gradually. They received less formula diet and were instructed to complete this with a free choice of food items. In week 7 and 8 subjects still received 1.4 $\mathrm{MJ} /$ day ( 2 servings/day) of the formula diet. In week 9 and 10 they received 0.7 MJ/day (1 serving/day).

\section{Measurements}

Body mass and body composition

Body weight was measured on a calibrated digital scale (Sauter D-7470, Ebingen, Germany) accurate to $0.1 \mathrm{~kg}$ and height was measured to the nearest $0.01 \mathrm{~m}$ using a wall mounted stadiometer (Seca, model 220, Hamburg, Germany). BMI was calculated from weight and height $\left(\mathrm{kg} / \mathrm{m}^{2}\right)$. Body composition was determined after an overnight fast by using the combination of 
hydrodensitometry and deuterium dilution according to the Maastricht protocol ${ }^{3 \mathrm{y}}$. Body composition was calculated according to the equations of Siri ${ }^{32}$.

Serum leptin levels

Fasting bloodsamples for the measurement of serum concentrations of leptin were collected. Serum leptin concentrations were measured according to the method described previously ${ }^{33}$.

\section{Attitude towards eating}

Attitude towards eating was characterized using a Dutch translation of the Three Factor Eating Questionnaire (TFEQ) ${ }^{18 ; 28}$. The first factor of the TFEQ (F1) measures cognitive restrained eating: control of food intake by thought and will power. The second factor (F2) represents disinhibition: an incidental inability to resist eating cues, or inhibition of dietary restraint (F1), and emotional eating. The third factor (F3) examines the subjective feeling of general hunger.

Resting Energy expenditure and substrate oxidation

Resting energy expenditure and substrate oxidation were measured with the use of a ventilated hood after the subjects fasted overnight. After the subjects had been supine for $15 \mathrm{~min}$, their oxygen consumption and carbon dioxide production were measured for $45 \mathrm{~min}$ by means of a computerized open-circuit ventilated hood system, similar to the analysis system described by Schoffelen et $a l^{34}$. REE and RQ were calculated according to the formulas of Weir ${ }^{35}$.

\section{Statistical analysis}

Data are presented as means \pm standard error of the mean (s.e.m.). A factorial ANOVA was used to determine possible difference between the PEG-OB and placebo group in all measured parameters. Possible differences of the variables over time between the groups were analysed with a two-factor repeatedmeasures ANOVA. Post hoc analyses were done with the Scheffe F-test. The possible relationships between the TFEQ scores, body weight loss and body weight regain were assessed by regression analysis. A p-value $<0.05$ was regarded as statistically significant. Statistical procedures were performed by using Statview SE+ Graphics (Abacus Concepts, Berkeley, CA, 1988).

\section{RESULTS}

The baseline characteristics of the subjects randomized to each treatment group were similar. Two subjects of the placebo group dropped out voluntarily 
after 1 week, because they were not able to maintain the very low energy diet. Since this study was a part of a greater study "part of the results have been published elsewhere 36 .

Body weight, BMI, percentage body fat, fat free mass and fat mass decreased significantly in both groups (table 1). At the end of the treatment period mean weight loss was $14.6 \pm 0.8 \mathrm{~kg}$ in the PEG-OB group compared to $11.8 \pm 0.9 \mathrm{~kg}$ in the placebo group $(p=0.027)$. BMI decreased more in the PEG-OB group compared to the placebo group $(p=0.049)$. No significant differences between the two groups were found for the decrease in percentage body fat, fat free mass and fat mass (table 1). The REE and RQ significantly decreased in both groups after 6 weeks treatment (table 1). None of the changes in REE and RQ were significantly different between both groups.

The cognitive restraint score (factor 1, TFEQ) increased significantly in both groups during the treatment period. The disinhibition score (factor 2, TFEQ) decreased significantly in the PEG-OB group, but did not reach significance in the placebo group. However, the decrease in disinhibition score during the treatment period in the placebo group was positively correlated with the body weight loss during treatment $\left(r^{2}=0.43, p=0.04\right)$. The hunger score (factor 3 , TFEQ) decreased in both groups. In the PEG-OB group the decrease in hunger score during the 6 weeks treatment was positively related to body weight loss during treatment $\left(r^{2}=0.56, p<0.01\right)$. No significant differences in changes in TFEQ scores were found between the two groups (table 1). With respect to the serum leptin levels (table 1), no differences were found between the two groups $(p=0.54)$ and no relationship was found between dietary restraint scores at the start of the treatment and serum leptin levels $(p=0.91)$.

Table 1 Subject characteristics of the placebo and PEG-OB group before and after 6 weeks of injections and VLED

\begin{tabular}{|c|c|c|c|c|c|c|c|}
\hline & \multicolumn{2}{|c|}{ Placebo $(0=10)$} & \multirow[b]{2}{*}{$\begin{array}{l}\mathrm{p}^{\mathrm{a}} \text { for } \\
\operatorname{lime}\end{array}$} & \multicolumn{2}{|c|}{$\mathrm{PEQ}-\mathrm{OB}(\mathrm{n}=12)$} & \multirow[b]{2}{*}{$\begin{array}{l}P^{\text {an }} \text { for } \\
\text { time }\end{array}$} & \multirow[b]{2}{*}{$\begin{array}{l}P^{b} \text { for GxiT } \\
\text { interaction }\end{array}$} \\
\hline & Before & After & & Betore & Alter & & \\
\hline $\begin{array}{l}\text { Ag@ (y) } \\
\text { Serumleptin (ng/ml) }\end{array}$ & $\begin{array}{l}36 \pm 0.9 \\
7.6 \pm 1.2\end{array}$ & & & $\begin{aligned} 35 & \pm 1.2 \\
7.11 & \pm 0.7\end{aligned}$ & & & \\
\hline Woight (kg) & $96.6 \pm 3.7$ & $84.8 \pm 4.0$ & 0.0001 & $97.9 \pm 1.9$ & $83.3 \pm 1.6$ & 0.0001 & 0.027 \\
\hline BMI $(\mathrm{kg} / \mathrm{m} 2)$ & $29.0 \pm 0.6$ & $25.4 \pm 0.7$ & 0.0001 & $29.1 \pm 0.4$ & $24.8 \pm 0.4$ & 0.0001 & 0.049 \\
\hline Pody fat (\%) & $30.1 \pm 1.2$ & $23.2 \pm 1.2$ & 0.0001 & $28.8 \pm 1.6$ & $20.5 \pm 2.1$ & 0.0001 & NS \\
\hline fat lroe inass $(\mathrm{kg})$ & $67.3 \pm 2.3$ & $64.9 \pm 2.7$ & 0.002 & $69.3 \pm 1.4$ & $65.6 \pm 1.3$ & 0.0007 & $\mathrm{NS}$ \\
\hline Fat mass $(\mathrm{kg})$ & $29.3 \pm 1.9$ & $19.9 \pm 1.7$ & 0.0001 & $28.3 \pm 20$ & $97.2 \pm 2.0$ & 0.0001 & NS \\
\hline Factor il & $5 \pm 1.0$ & $12 \pm 1.2$ & 0.0004 & $5 \pm 1.2$ & $12 \# 1.2$ & 0.0001 & NS \\
\hline Factor? & $5 \pm 0.4$ & $4 \pm 0.9$ & NS & $5 \pm 0.7$ & $4 \pm 0 . \pi$ & 0.006 & NS \\
\hline Factor 3 & $6 \pm 1.2$ & $3 \pm 1.1$ & 0.02 & $6 \pm 0.9$ & $3 \pm 1.1$ & 0.004 & NS \\
\hline REE $(M \mathrm{M} / \mathrm{d})$ & $8.62 \pm 0.25$ & $7.27 \pm 0.30$ & 0.001 & $8.71 \pm 0.19$ & $7.67 \pm 0.25$ & 0.001 & NS \\
\hline $1 \mathrm{RQ}$ & $0.81 \pm 0.01$ & $0.77 \pm 0.01$ & 0.05 & $0.82 \pm 0.0$ & $0.77 \pm 0.01$ & 0,05 & NS \\
\hline
\end{tabular}

Data are presented as mean \pm s.e.m. Factor 1: cognitive restraint; Factor 2: disinhibition; Factor 3 : hunger. No significant differences were present before the 6-week treatment period.

ANOVA repeated measures.

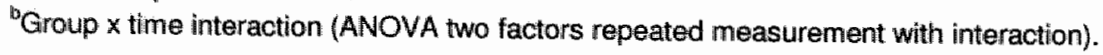


The PEG-OB group showed significant increases in body weight and BMI after 4 and after 8 weeks follow-up, and also from 4 to 8 weeks follow-up (table 2). In the placebo group a significant increase in body weight and BMI was found only after 8 weeks follow-up (table 2). Body weight increase went slower in the placebo than in the PEG-OB group, as is shown by the rates of body weight regain being expressed as \%regain $=0.47 \times$ follow-up days $-1.52\left(r^{2}=0.95\right.$, $p=0.005$ ) in the $P E G-O B$ group and as $\%$ regain $=0.28 \times$ follow-up days -0.003 $\left(r^{2}=0.98, p=0.002\right)$ in the placebo group (figure 1).

Body weight regain during follow-up was, in the placebo group, inversely correlated with the change in cognitive restraint during follow-up $\left(r^{2}=0.60\right.$, $p=0.01)$. The decrease in hunger score during follow-up in the placebo group correlated inversely with body weight regain during follow-up $\left(r^{2}=0.47, p=0.04\right)$. After 8 weeks follow-up body weight regain in the PEG-OB group was inversely correlated with the increase in cognitive restraint during the treatment period $\left(r^{2}=0.49, p<0.02\right)$. Body weight regain during follow-up was not related to initial body weight or body weight loss during the VLED (PEG-OB group: $p=0.40$; placebo group: $p=0.74$ ).

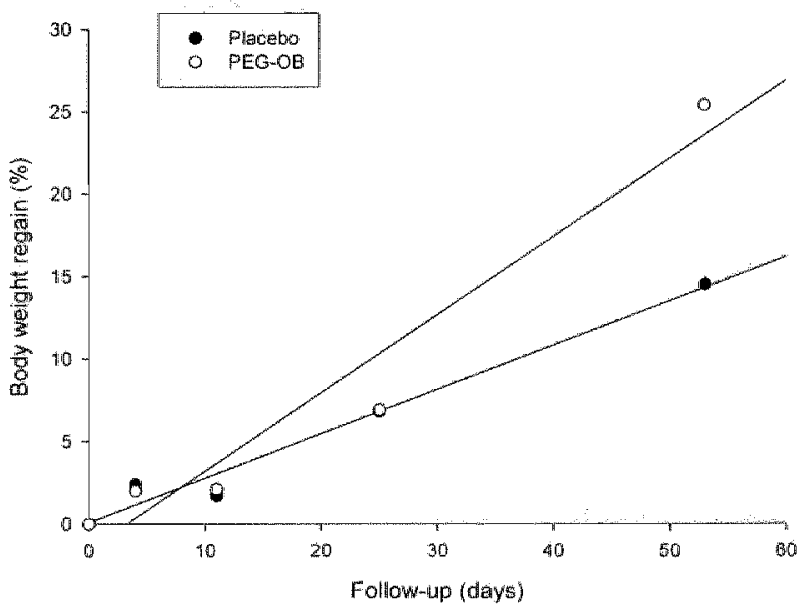

Figure 1 Body weight regain over time for the placebo $(n=10)$ and the PEG-OB $(n=12)$ group. 
Table 2 Subjects characteristics of the placebo and PEQ-OB group after treatment and after 4 and 8 weeks follow-up

\begin{tabular}{|c|c|c|c|c|c|c|c|}
\hline & \multicolumn{3}{|c|}{ Placebo $(n=10)$} & \multicolumn{3}{|c|}{ PEG-OB $(n=12)$} & \multirow[b]{2}{*}{$\begin{array}{l}\mathrm{P}^{\text {t }} \text { for } \mathrm{GXT} \\
\text { interaction }\end{array}$} \\
\hline & $\begin{array}{c}\text { After } \\
\text { Mreatment }\end{array}$ & $\begin{array}{l}\text { 4. weeks } \\
\text { follow-up }\end{array}$ & $\begin{array}{l}8 \text { weeks } \\
\text { followi-up }\end{array}$ & $\begin{array}{c}\text { After } \\
\text { reatment }\end{array}$ & $\begin{array}{l}4 \text { weeks } \\
\text { tollow-up }\end{array}$ & $\begin{array}{l}8 \text { weeks } \\
\text { follow-up }\end{array}$ & \\
\hline Weight (kg) & $84.6 \pm 40$ & $85.8 \pm 3.7$ & $86.6 \pm 3.8^{\circ}$ & $83.3 \pm 1.6$ & $242+1.6$ & $869 \pm 1.7^{4}$ & 0.03 \\
\hline BNI (kg/nis) & $25.4 \pm 0.7$ & $25.8 \pm 0.6$ & $26.0 \pm 0$. & $24.8 \pm 0.4$ & $25+1 \pm 0.4$ & $25.9 \pm 0.5^{4}$ & 0,03 \\
\hline Reman $(\%)$ & & $6.8 \pm 4.3$ & $14.5 \pm 4.0$ & & $6.9 \pm 22$ & $251.4 \pm 5.5 \%$ & NS \\
\hline Factor & $12 \pm 1.2$ & $13 \pm 1.5$ & $1 * \pm 1.8$ & $12 \pm 1.2$ & $12 \pm 0.9$ & $12 \pm 1.0$ & NS: \\
\hline Fation 2 & $4 \pm 0.9$ & $4 \pm 0.5$ & $3 \pm 0.6$ & $4 \pm 0.7$ & $4 \pm 0.8$ & $4 \pm 0.7$ & NS \\
\hline Factor 3 & $3 \pm 1.1$ & $1 \pm 0.5$ & $2 \pm 0.4$ & $3 \pm 1,1$ & $2 \pm 1.0$ & $2 \pm 0.9$ & NS \\
\hline
\end{tabular}

Data are presented as mean \pm s.e.m. For differences compared to after treatment (ANOVA repeated measures): " $p<0,01$. For differences compared to 4 weeks follow-up (ANOVA repeated measures): \#p<0.005. Regain: percentage body weight regain; Factor 1: cognitive restraint; Factor 2. disirihibition; Factor 3: hunger.

Group $x$ time interaction (ANOWA two factors repeated measurement with interaction)for 4 versus 8 weeks follow-up. No group $x$ time interaction was found between after treatment versus 4 and 8 weeks follow-up.

\section{DISCUSSION}

The present study demonstrates that weight loss in both groups (PEG-OB protein treated and placebo) was mainly supported by an increase in dietary restraint and a reduction in general hunger. However, additional weight loss in the PEG-OB group was due to the treatment of weekly subcutaneous injection of $80 \mathrm{mg}$ PEG-OB protein ${ }^{30}$. Thus, results with respect to weight loss from comparable animal model studies ${ }^{37 ;}{ }^{38}$ and initial intervention studies in humans $15 ; 16$ were reproduced in this study ${ }^{36}$.

The additional weight loss in the PEG-OB group during treatment was probably not a metabolic effect, because the reduction in resting metabolic rate was similar for both groups. This is in line with results we reported previously, where metabolic effects were measured by means of a respiration chamber and also no differences between groups were found ${ }^{17}$. Therefore the additional weight loss can only be explained by a stronger reduction in food intake in the PEG-OB group compared to the placebo group. During the 6 weeks treatment, the subjects in both groups were in a negative energy balance and appeared to be in compliance to the energy deficit creating dietary instructions. Compliance to the dietary instructions independent of treatment was indicated by the increases in dietary restraint scores during the energy restriction program. The relationship between the decrease in general hunger scores and body weight loss during treatment in the PEG-OB group under negative energy balance conditions is in line with the reduced food intake in rats after PEG-OB protein treatment ${ }^{37 ; 38}$, and with the observations on reduction of appetite as reported by Farooqi ${ }^{16}$. 
With respect to serum leptin levels, in this study with overweight men no relationship was found between dietary restraint and endogenous leptin levels. This is in line with results found in overweight women ${ }^{24 ;}$. The rate of body weight regain (expressed as percentage of the weight loss) after 8 weeks follow-up was larger in the PEG-OB than in the placebo group. Since there was no relationship between body weight regain and weight loss, this was not due to the larger body weight loss. An explanation could be that the placebo group experienced a greater support from changes in dietary restraint and in general hunger for weight maintenance than the PEG-OB group did. After 4 weeks follow-up no significant differences in the percentage body weight regain between both groups were seen yet, which can be explained by the long-lasting effect of the PEG-OB injections.

\section{Conclusion}

Although treatment with PEG-OB protein led to a greater body weight loss relative to placebo, weight maintenance was not supported by this treatment. Contrarily, dietary restraint was more effective in the first period of weight maintenance in the placebo treated group, resulting in a slower regain of body weight. It might be that pharmacological (PEG-OB protein) treatment limits the change in lifestyle necessary for weight maintenance after weight loss. For weight maintenance after PEG-OB treatment, this treatment might have to be continued, perhaps with a lower dosage.

\section{REFERENCES}

1. Seidell JC (1998) Dietary fat and obesity: an epidemiologic perspective. Am J Clin Nutr 67, 546S-550S.

2. Obesity NloHCDPotHio (1985) Health implications of obesity. Ann Intern Med 103, 1024-1029.

3. Lew EA (1985) Mortality and weight: insured lives and the American Cancer Society studies. Ann Intern Med 103, 1024-1029.

4. Hubert HB, Feinleib M, McNamara PM, Castelli WP (1983) Obesity as an independent risk factor for cardiovascular disease: a 26-year follow-up of participants in the Framingham Heart Study. Circulation 67, 968-977.

5. Donahue RP, Abbott RD, Bloom E, Reed DM, Yano K (1987) Central obesity and coronary heart disease in men. Lancet 1, 821-824.

6. Pasman WJ, Rossner $S$, Westerterp-Plantenga MS, Saris WHM (1999) Body weight changes after treatment of obesity or pregnancy. In 
Regulation of food intake [MS Westerterp-Plantenga, AB Steffens, A Tremblay, editors]. Milan: EDRA.

7. Hanotin C, Thomas F, Jones SP, Leutenegger E, Drouin P (1998) A comparison of sibutramine and dexfenfluramine in the treatment of obesity. Obes Res 6, 285-291.

8. Muls $E$, Kempen $K$, Vansant $G$, Saris $W$ (1995) Is weight cycling detrimental to health? A review of the literature in humans. Int $J$ Obes Relat Metab Disord 19 Suppl 3, S46-50.

9. Sjostrom L, Rissanen A, Andersen T, Boldrin M, Golay A, Koppeschaar HP, Krempf M (1998) Randomised placebo-controlled trial of orlistat for weight loss and prevention of weight regain in obese patients. European Multicentre Orlistat Study Group. Lancet 352, 167-172.

10. Zhang $Y$, Proenca R, Maffei M, Barone M, Leopold L, Friedman JM (1994) Positional cloning of the mouse obese gene and its human homologue. Nature 372, 425-432.

11. Campfield LA, Smith FJ, Burn P (1996) The OB protein (leptin) pathway--a link between adipose tissue mass and central neural networks. Horm Metab Res 28, 619-632.

12. Campfield LA, Smith FJ, Burn P (1997) OB protein: a hormonal controller of central neural network mediating behavioral, metabolic and neuro endocrine responses. Endocrinology and Metabolism 4, 81-102.

13. Considine RV, Sinha MK, Heiman ML, Kriauciunas A, Stephens TW, Nyce MR, Ohannesian JP, Marco CC, McKee LJ, Bauer TL, et al. (1996) Serum immunoreactive-leptin concentrations in normal-weight and obese humans. N Engl J Med 334, 292-295.

14. Pasman WJ, Westerterp-Plantenga MS, Saris WH (1998) The effect of exercise training on leptin levels in obese males. Am J Physiol 274, E280286.

15. Heymsfield SB, Greenberg AS, Fujioka K, Dixon RM, Kushner $R$, Hunt $T$, Lubina JA, Patane J, Self B, Hunt P, McCamish M (1999) Recombinant leptin for weight loss in obese and lean adults: a randomized, controlled, dose-escalation trial. Jama 282, 1568-1575.

16. Farooqi IIS, Jebb $S A$, Langmack $G$, Lawrence $E$, Cheetham $\mathrm{CH}_{\text {, Prentice }}$ AM, Hughes IA, McCamish MA, O'Rahilly S (1999) Effects of recombinant leptin therapy in a child with congenital leptin deficiency. $N$ Engl $J$ Med 341 , 879-884.

17. Westerterp-Plantenga MS, Saris WH, Hukshorn CJ, Campfield LA (2001) Effects of weekly administration of pegylated recombinant human $O B$ protein on appetite profile and energy metabolism in obese men. Am J Clin Nutr 74, 426-434, 
18. Stunkard AJ, Messick S (1985) The three-factor eating questionnaire to measure dietary restraint, disinhibition and hunger. J Psychosom Res 29, 71-83.

19. Pasman WJ, Saris WH, Westerterp-Plantenga MS (1999) Predictors of weight maintenance. Obes Res 7, 43-50.

20. Westerterp-Plantenga MS, Kempen KP, Saris WH (1998) Determinants of weight maintenance in women after diet-induced weight reduction. Int $J$ Obes Relat Metab Disord 22, 1-6.

21. Pekkarinen $T$, Takala I, Mustajoki $P$ (1996) Two year maintenance of weight loss after a VLCD and behavioural therapy for obesity: correlation to the scores of questionnaires measuring eating behaviour. Int $J$ Obes Relat Metab Disord 20, 332-337.

22. Clark MM, Marcus BH, Pera V, Niaura RS (1994) Changes in eating inventory scores following obesity treatment. Int J Eat Disord 15, 401-405.

23. Lejeune MPGM, Hukshorn CJ, Saris WH, Westerterp-Plantenga MS (2003) Effect of dietary restraint during and following pegylated recombinant leptin (PEG-OB) treatment of overweight men. Int J Obes Relat Metab Disord 27, 1494-1499.

24. d'Amore A, Massignan C, Montera P, Moles A, De Lorenzo A, Scucchi S (2001) Relationship between dietary restraint, binge eating, and leptin in obese women. Int J Obes Relat Metab Disord 25, 373-377.

25. Von Prittwitz S, Blum WF, Ziegler A, Scharmann S, Remschmidt $H_{\text {, }}$ Hebebrand $J$ (1997) Restrained eating, measured with the TFEQ is associated with low leptin levels in underweight females. Mol Psychiatry 2, 420-422.

26. Westerterp-Plantenga MS, Rolland V, Wilson SA, Westerterp KR (1999) Satiety related to $24 \mathrm{~h}$ diet-induced thermogenesis during high protein/carbohydrate vs high fat diets measured in a respiration chamber. Eur J Clin Nutr 53, 495-502.

27. Nucci ML, Shorr R, Abuchowski A (1991) The therapeutic value of poly (ethylene glycol)-modified proteins. Advanced Drug Delivery Reviews 6, 133-151.

28. Fuertges F, Abuchowski A (1990) The clinical efficacy of poly(ethylene glycol)-modified proteins. J Controlled Rel 11, 139-148.

29. Campfield LA, Devos R, Guisez $Y(2-15-2000)$ Pegylated obese (OB) protein compositions. US Patent Number 6,025,324.

30. Bailon $P$, Campfield LA, Devos $\mathbb{R}$ (2-15-2000) Pegylated obese (OB) protein compositions. US Patent Number 6,025,324.

31. Westerterp KR, Wouters L, van Marken Lichtenbelt WD (1995) The Maastricht protocol for the measurement of body composition and energy expenditure with labeled water. Obes Res 3 Suppl 1, 49-57. 
32. Siri WE (1956) The gross composition of the body. Adv Biol Med Phys 4, 239-280.

33. Hukshorn CJ, Saris WH, Westerterp-Plantenga MS, Farid AR, Smith FJ, Campfield LA (2000) Weekly subcutaneous pegylated recombinant native human leptin (PEG-OB) administration in obese men. J Clin Endocrinol Metab 85, 4003-4009.

34. Schoffelen PF, Westerterp KR, Saris WH, Ten Hoor F (1997) A dualrespiration chamber system with automated calibration. J Appl Physiol 83, 2064-2072.

35. Weir JB (1949) New Methods for calculating metabolic rate with special reference to protein metabolism. Journal of Physiology 109, 1-9.

36. Hukshorn CJ, Westerterp-Plantenga MS, Saris WH (2003) Pegylated human recombinant leptin (PEG-OB) causes additional weight loss in severely energy-restricted, overweight men. Am J Clin Nutr 77, 771-776.

37. Kahler A, Geary N, Eckel LA, Campfield LA, Smith FJ, Langhans W (1998) Chronic administration of $\mathrm{OB}$ protein decreases food intake by selectively reducing meal size in male rats. Am J Physiol 275, R180-185.

38. Eckel LA, Langhans W, Kahler A, Campfield LA, Smith FJ, Geary N (1998) Chronic administration of $\mathrm{OB}$ protein decreases food intake by selectively reducing meal size in female rats. Am J Physiol 275, R186-193. 


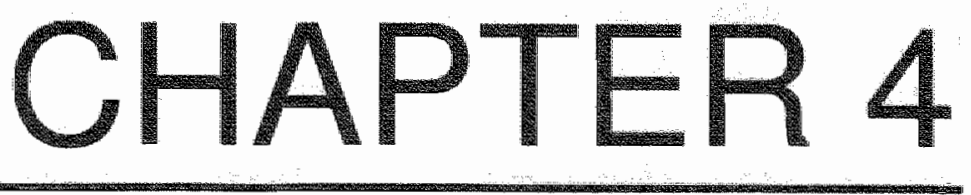

\section{Reversal of changes in ghrelin and adiponectin during human pegylated recombinant leptin induced body weight loss}

MPGM Lejeune, CJ Hukshorn, WHM Saris, MS Westerterp-Plantenga Submitted for publication 


\section{ABSTRACT}

Objective: To investigate the effects of pegylated recombinant leptin (PEGleptin) induced weight loss on ghrelin, adiponectin, insulin and glucose concentrations.

Research methods and procedures: We performed a randomized doubleblind placebo-controlled trial in 24 moderately overweight/obese men. PEGleptin or placebo was administered weekly for 6 weeks, combined with a restricted energy intake of $2.1 \mathrm{MJ} / \mathrm{d}$. At day 1,25 , and 46 a blood sample was taken, and body-weight (BW) and satiety were measured. Day 1-25 was named phase 1, and day 25-46 phase 2 .

Results: During phase 1 the rate of BW loss was significantly higher in the PEG-leptin compared to the placebo group $(0.38 \pm 0.07$ vs $0.32 \pm 0.06 \mathrm{~kg} / \mathrm{d}$, $p<0.05$ ). The rate of BW loss during phase 2 was $0.24 \pm 0.08$ and $0.18 \pm 0.09$ $\mathrm{kg} / \mathrm{d}$, respectively $(\mathrm{p}=0.07)$. In both groups the rate of $B W$ loss during phase 1 was significantly higher than during phase $2(p<0.001)$. Energy balance (EB) was significantly more negative during phase 1 than during phase 2 in both groups ( $p<0.0005$ ). During phase 1 insulin, glucose and adiponectin decreased significantly in both groups, ghrelin decreased significantly in the PEG-leptin group. During phase 2 adiponectin and ghrelin concentrations reversed $(p<0.05)$.

Conclusion: Initial BW loss due to a considerable negative EB induced decreased ghrelin, adiponectin, insulin and glucose levels. However, when EB became less negative and the rate of $\mathrm{BW}$ loss decreased these changes were reversed for adiponectin and ghrelin. PEG-leptin had no additional effect on the blood-parameters.

Key words: ghrelin, adiponectin, leptin, body weight loss, energy balance 


\section{INTRODUCTION}

Obesity is strongly associated with a number of diseases, including hypertension, diabetes, and coronary heart disease ${ }^{1-3}$. Obesity is the consequence of a chronic imbalance between energy intake and energy expenditure. The regulation of energy balance is mediated by a network of signals from several endocrine tissues, including the stomach and adipose tissue. Adipose tissue, in addition to its role as an energy reservoir, modulates energy metabolism via secretion of circulating adipokines. One of these adipokines is leptin. Leptin functions as a peripheral signal in a negative feedback loop to hypothalamic nuclei involved in the regulation of energy balance. The orexigenic neuropeptide $Y$ (NPY) and agouti-related peptide (AgRP) are expressed in the same neurons in the medial arcuate nucleus, whereas the anorexigenic proopiomelanocortin (POMC) and cocaine- and amphetamine-regulated transcript (CART) are coexpressed in the lateral arcuate nucleus. Leptin is thought to regulate the NPY/AgRP and POMC/CART neurons in an opposing manner ${ }^{4 ; 5}$. We have previously shown that pegylated recombinant leptin (PEG-leptin) causes additional weight loss in severely energy-restricted, overweight men $^{6}$. In the present study PEG-leptin was used to induce a substantial body weight loss.

Another adipokine is adiponectin, a protein exclusively secreted by mature adipocytes ${ }^{7}$. Adiponectin has been related to insulin sensitivity and has been shown to have anti-atherogenic and anti-inflammatory effects in humans ${ }^{8-11}$. Recently $\mathrm{Qi}$ et al. $^{12}$ showed that adiponectin is also involved in energy homeostasis by acting on the brain. Intracerebroventricular injection with adiponectin decreased body weight by increasing energy expenditure, but did not inhibit feeding in normal and Lep ${ }^{\text {obtob }}$ mice. It has been shown that obese subjects and patients with type II diabetes have decreased adiponectin levels ${ }^{13-}$ ${ }^{15}$. In several studies, large reductions in body weight resulted in increased plasma adiponectin concentrations ${ }^{16-18}$. Ryan et al..$^{19}$ reported no effect of moderate weight loss on adiponectin levels. It is suggested that in obesity adiponectin is under feedback inhibition and that large amounts of weight loss increase adiponectin, which is a favorable condition taking the risk factors accompanying low adiponectin levels into account ${ }^{8-11}$. So far the weight loss effect mediated by leptin is unknown.

Ghrelin is a peptide hormone that is predominantly secreted by the stomach. It was initially found to stimulate the release of growth hormone from the pituitary through binding to specific hypothalamic and pituitary receptors ${ }^{20}$, but it has recently also been shown to play a role in weight regulation. Ghrelin has adipogenic and orexigenic properties, and therefore can increase food intake and body weight. Furthermore, it enhances the use of carbohydrates and 
reduces falt utilization, and increases gastric motility. Ghrelin also modulates hypothalamic appetite regulating pathways, primarily the NPY network in the arcuate nucleus ${ }^{21}$. In humans, ghrelin concentrations are increased during short-term fasting, and decreased after food intake ${ }^{22 ;} 23$. This suggests a possible role for ghrelin in long-term energy balance. Plasma ghrelin concentrations have been reported to be reduced in obese subjects ${ }^{22 ;}{ }^{24}$. However, after weight loss circulating levels of ghrelin are increased, indicating a down regulation of ghrelin as a result of energy excess in obesity ${ }^{18 ; 25-27}$. Wortley et al. ${ }^{28}$ recently proposed that endogenous ghrelin is not an essential regulator of food intake, but plays an important role in fuel selection especially under conditions of high fat intake.

So, the hormones leptin, adiponectin, and ghrelin are central and peripheral factors involved in energy homeostasis. However, the interplay between these hormones needs to be further elucidated. In brief, ghrelin has metabolic effects opposite to those of leptin. Adiponectin and leptin have the same production site and share common mediators in the central nervous system, thereby both having the ability to decrease body weight.

To date, all studies investigating the effects of weight loss on ghrelin and adiponectin concentrations measured after a weight loss period of 6 months or more. Considering the differences in short-term and long-term effects of ghrelin $^{18 ; 22 ; 24-27}$ and adiponectin ${ }^{16-19}$, it is of interest to assess the changes in these concentrations in different phases of body weight loss. In none of the studies the weight loss effect was mediated by leptin injections. Usually the first phase of weight loss is caused by a considerable negative energy balance, whereas the subsequent phase is characterized by a less negative energy balance and slowing down the rate of body weight loss.

The aim of the present study was to assess the effects of PEG-leptin induced weight loss on the changes in ghrelin and adiponectin concentrations, and to investigate if these changes are related to different phases of weight loss. Furthermore, to investigate the relationships between leptin, ghrelin, and adiponectin during a negative energy balance.

\section{SUBJECTS AND METHODS}

\section{Subjects}

Twenty-four healthy overweight/obese male volunteers (BMI: $25-32 \mathrm{~kg} / \mathrm{m}^{2}$, age: $18-40$ y) were recruited by an advertisement in a local newspaper. Subjects who were willing to participate in the study were subsequently screened. A written informed consent was obtained from all participants. Screening included 
a detailed medical history, a physical examination, biochemical tests of renal, hepatic, metabolic and hematological function, 12-lead resting electrocardiogram and vital signs. Subjects were non-smokers, had a stable body weight $(<3 \mathrm{~kg}$ change) over the last three months and did not receive prescription medication. Excluded from the study were subjects with a history of atopy or hypersensitivity to pegylated proteins. The study was approved by the Medical Ethics Committee of the University of Maastricht.

\section{Study design}

This single center trial had a prospective, randomized, double-blind, and placebo-controlled group design. After screening 24 subjects were enrolled. Subjects were matched in a pairwise fashion with respect to age, BMI, fasting serum leptin and insulin concentration. Next, the subjects of the matched pair were randomly assigned either to the treatment or placebo group.

At the start of the treatment period (day 1) all subjects were prescribed a very low energy diet (VLED) for $\mathbf{4 6}$ days to induce a state of semistarvation. The VLED (Modifast, Novartis Nutrition, Breda, The Netherlands) provided 2.1 $\mathrm{MJ} /$ day ( 3 servings/day) and was a protein enriched formula diet, containing 50 $\mathrm{g}$ carbohydrates, $52 \mathrm{~g}$ protein, $7 \mathrm{~g}$ fat and a micronutrient content which meets the Dutch recommended daily allowance. At the same time treatment consisting of weekly injections of either $80 \mathrm{mg}$ PEG-OB ( $8 \mathrm{ml}, 10 \mathrm{mg} \cdot \mathrm{ml}-1)$ (provided by Hoffmann-La Roche Inc, Nutley, New Jersey) or matching placebo $(8 \mathrm{ml})$ was given subcutaneously in the para-umbilical region, during the VLED period. In order to follow the changes in body mass and related parameters, body mass was measured at day 1 , day 25 , and day 46 . At the same time satiety was rated and blood samples were taken for measurements of fasting plasma glucose, ghrelin and adiponectin concentrations and fasting serum insulin and leptin concentrations. The period between day 1 and 25 was named phase 1 , and between day 25 and 46 phase 2 .

Safety was monitored throughout the study by documentation of adverse events, recording of vital signs, regularly urine analysis and routine measurements of serum chemistry and blood cell counts. Standard clinical chemistry and blood cell counts were conducted at the certified central laboratory of the University Hospital Maastricht, the Netherlands.

\section{PEG-leptin}

Polyethylene glycols (PEG), expressed and purified from Escherichia coli, are amphophilic polymers of ethylene glycol with varying average molecular weights 
that can be activated and covalently attached to proteins. Modification of proteins with PEG has resulted in increased serum half-life and reduced immunogenicity to a number of proteins ${ }^{29}$. The average molecular weight of branched $P E G$ utilized is $42 \mathrm{kDa}$ in a $1: 1$ ratio.

\section{Measurements}

\section{Body mass}

After an overnight fast body weight was measured with subjects in underwear on a calibrated digital scale (Sauter D-7470, Ebingen, Germany) accurate to 0.1 $\mathrm{kg}$ and height was measured to the nearest $0.01 \mathrm{~m}$ using a wall mounted stadiometer (Seca, model 220, Hamburg, Germany). BMI was calculated from weight and height $\left(\mathrm{kg} / \mathrm{m}^{2}\right)$.

\section{Hormone measurements}

Venous blood was sampled on day 1 , day 25 and 46 after an overnight fast. The blood for the serum measurements was allowed to clot for $20 \mathrm{~min}$ at room temperature. Immediately after clotting the samples were put on ice and serum was extracted by centrifugation. The blood for plasma measurements was centrifuged immediately. All obtained samples were frozen in liquid nitrogen and stored at $-80^{\circ} \mathrm{C}$ for later measurements. Total serum leptin concentrations (endogenous leptin plus PEG-leptin) were measured according to the method described previously ${ }^{30}$. The intra- and interassay variations were $9 \%$ and $12 \%$, respectively. Serum insulin was measured by an immunofluorimetric sandwich assay ((IFMA), Autodelfia, Perkin Elmer, Turku, Finland). Plasma concentrations of total ghrelin were measured by RIA (Linco Research, Missouri, USA). The intra- and interassay variations were between $3.3 \%-10 \%$ and $14.7 \%-17.8 \%$, respectively. Plasma adiponectin concentrations were measured by ELISA (Linco Research, Missouri, USA). The intra- and interassay variations were between $1.0 \%-7.4 \%$ and $2.4 \%-8.4 \%$, respectively. Plasma glucose concentrations were determined using the hexokinase method (Glucose HK 125 kit, ABX diagnostics, Montpellier, France). To avoid interassay variability, all specimens for a given substance were run in a single assay.

\section{Satiety}

To determine the post-absorptive appetite profile, satiety was rated on anchored $100 \mathrm{~mm}$ Visual Analogue Scales (mmVAS) in the morning before breakfast after an overnight fast. 


\section{Energy balance}

The negative energy balance during the two subsequent phases was calculated using the following equations, in which the $30 \mathrm{MJ} / \mathrm{kg}$ is based upon $2 / 3$ fat mass loss and $1 / 3$ fat free mass loss per $1 \mathrm{~kg}$ body weight loss which is usually seen during weight loss $(2 / 3 \times 37 \mathrm{MJ} / \mathrm{kg}+1 / 3 \times 17 \mathrm{MJ} / \mathrm{kg}=30 \mathrm{MJ} / \mathrm{kg})$.

Phase 1: Energy balance $(\mathrm{MJ} / \mathrm{d})=$ rate of body weight loss phase $1(\mathrm{~kg} / \mathrm{d}) \times 30$ (MJ/kg)

Phase 2: Energy balance $(\mathrm{MJ} / \mathrm{d})=$ rate of body weight loss phase $2(\mathrm{~kg} / \mathrm{d}) \times 30$ $(\mathrm{MJ} / \mathrm{kg})$

\section{Statistical analysis}

Data are presented as mean \pm standard deviation, unless otherwise indicated. Changes in anthropometric measurements and hormone concentrations were analyzed using ANOVA repeated measures. Post-hoc, Bonferonni adjustments were used if needed. A two-factor repeated measures ANOVA was used to compare differences in parameters across the group over time. Significance was defined as $p<0.05$. All statistical tests were performed using SPSS for Windows, version 11.5 (SPSS, Chicago, USA).

\section{RESULTS}

The baseline characteristics of the subjects assigned to each treatment group were similar (table 1). Two subjects of the placebo group dropped out voluntarily after 1 week, because they were not able to maintain the very low energy diet. Since this specific study was a part of a greater study, the general results have been published elsewhere ${ }^{6}$.

Body weight and BMI decreased significantly in both groups (table 1). At the end of the treatment period mean weight loss was $14.6 \pm 0.8 \mathrm{~kg}$ in the PEGleptin group being significantly higher than the $11.8 \pm 0.9 \mathrm{~kg}$ in the placebo group ( $p=0.03$ ). BMI decreased more in the PEG-leptin group compared to the placebo group $(4.3 \pm 0.7$ versus $3.6 \pm 1.0 ; p=0.049$ ).

The rate of body weight loss in the PEG-leptin group was $0.38 \pm 0.07 \mathrm{~kg} / \mathrm{d}$ during phase 1 (day $1-25$ ) compared to $0.24 \pm 0.08 \mathrm{~kg} / \mathrm{d}$ during phase 2 (day $25-46)(p<0.0001)$. In the placebo group the rate of body weight loss was $0.32 \pm$ $0.06 \mathrm{~kg} / \mathrm{d}$ and $0.18 \pm 0.09 \mathrm{~kg} / \mathrm{d}$, during phase 1 and 2 respectively $(p<0.0005)$. 
During phase 1 the rate of body weight loss was significantly higher in the PEGleptin than in the placebo group $(p<0.05)$. This significant difference between both groups disappeared during the second phase $(p=0.07)$.

During phase 1 the negative energy balance was $11.5 \pm 2.0 \mathrm{MJ} / \mathrm{d}$ in the PEGleptin group, which is significantly higher than the $9.7 \pm 1.9 \mathrm{MJ} / \mathrm{d}$ in the placebo group. The negative energy balance was significantly smaller during phase 2 compared to phase 1 in the PEG-leptin as well as in the placebo group, $7.3 \pm$ $2.3 \mathrm{MJ} / \mathrm{d}$ and $5.3 \pm 2.6 \mathrm{MJ} / \mathrm{d}$, respectively.

The effects of energy restriction and treatment on adiponectin, total ghrelin, insulin and glucose concentrations are shown in table 2. Except for total leptin (table 1), no group $x$ time interaction was found in any of the blood parameters, indicating that the PEG-leptin treatment had not affected the changes in these blood parameters differently from placebo treatment.

During the subsequent phases of body weight loss, ghrelin and adiponectin showed a reversal effect, while insulin and glucose showed a marked effect during phase 1 and a minor effect during phase 2 (table 2). With respect to total ghrelin, the concentration was significantly reduced during phase 1 in the PEGleptin group, yet increased significantly during phase 2 (figure 1A). In the placebo group only the increase in phase 2 reached statistical significance. The reversal in ghrelin concentrations was shown in that the total ghrelin levels changed in the opposite direction between phase 1 and 2 (figure 1A). In the placebo group adiponectin was significantly reduced during phase 1 , and reversed during phase 2 (figure 1B). In both groups concentrations of insulin and glucose were significantly reduced during phase 1 , and remained to be reduced during phase 2, although the glucose concentration in the PEG-leptin group started to increase during phase 2 (figure 2). The change was significantly different between phases 1 and 2 .

With respect to the appetite profile, satiety showed a significant increase from $30 \pm 11$ to $43 \pm 13$ mmVAS in the PEG-leptin during phase 1 , but showed no significant change during phase 2 . The satiety in the placebo group did not change significantly in neither of the two phases.

No correlations were found between changes in body weight and changes in any of the blood parameters. Furthermore, the ghrelin, adiponectin, insulin, glucose and leptin concentrations or changes in concentrations were not related. The appetite profile was not related to the blood parameters. 


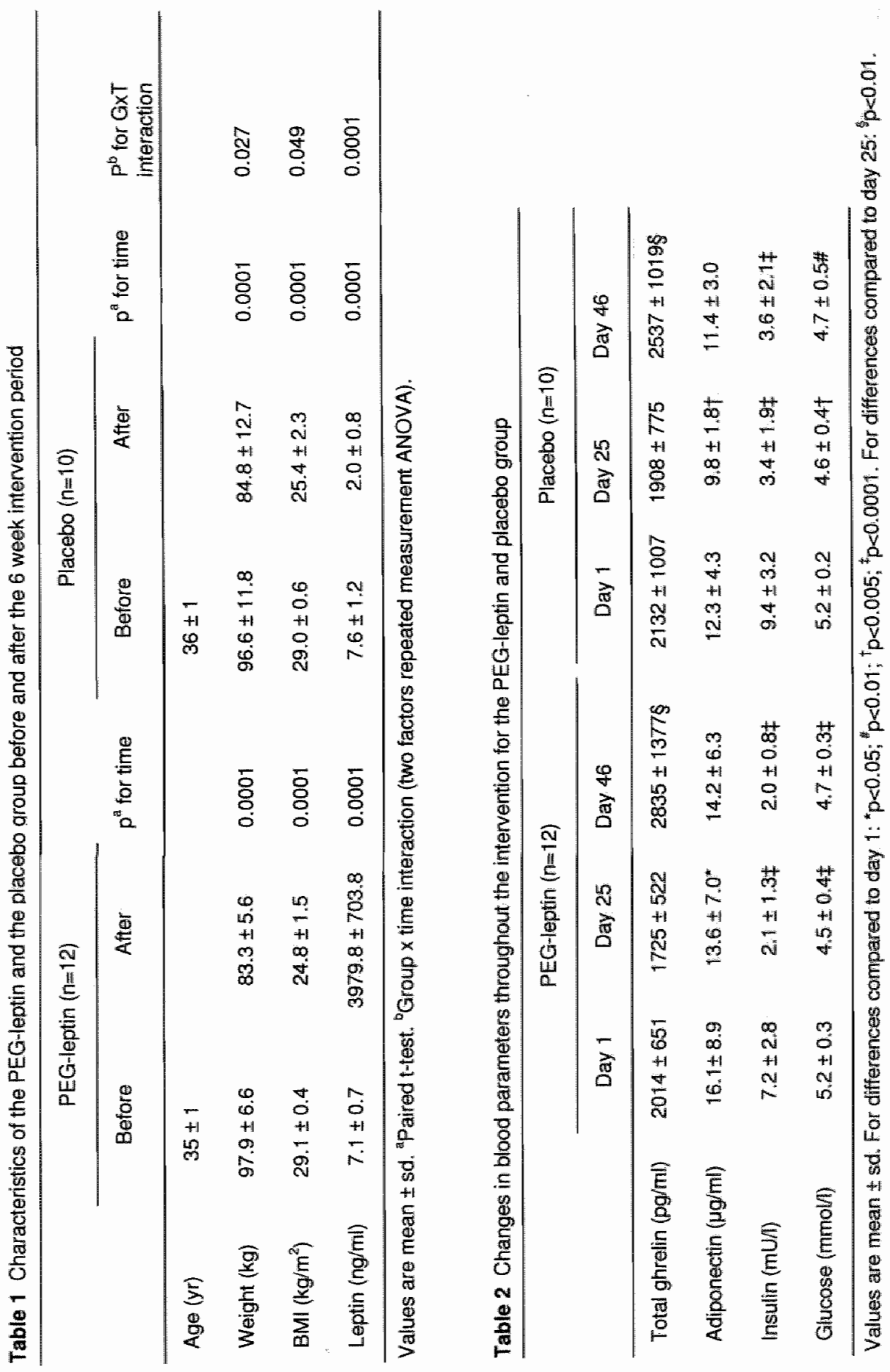


(a)

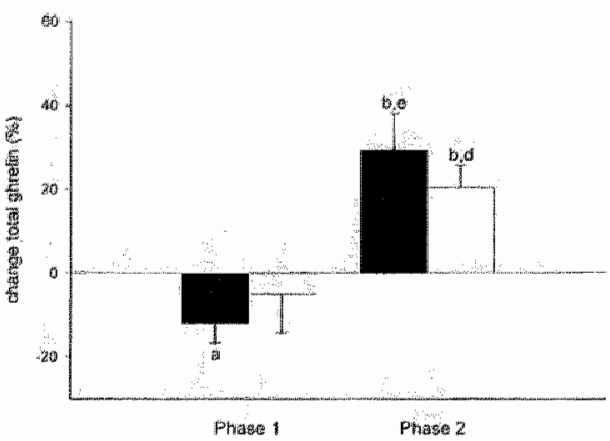

(b)

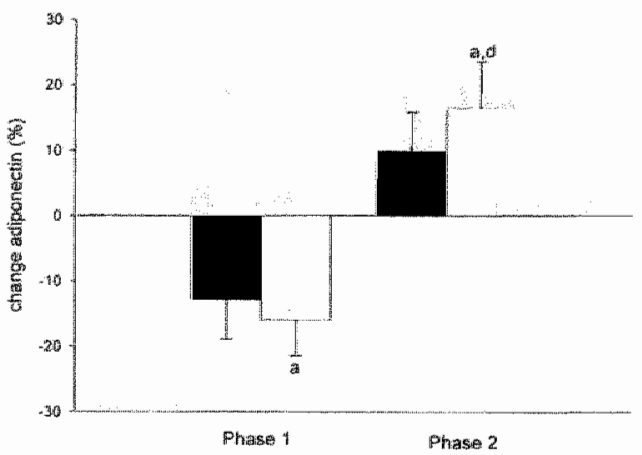

Figure 1 The percentage change in total ghrelin (a) and adiponectin (b) concentrations for the PEG-leptin (black bars) and placebo (white bars) group during phase 1 and phase 2. Values are means with standard errors of the mean shown by vertical bars. For changes during a phase: ${ }^{a} \mathrm{p}<0.05 ;{ }^{b} \mathrm{p}<0.01 ;{ }^{c} \mathrm{p}<0.0001$. For differences compared to phase $1:{ }^{a} p<0.05 ;{ }^{\circ} p<0.001$.

(a)

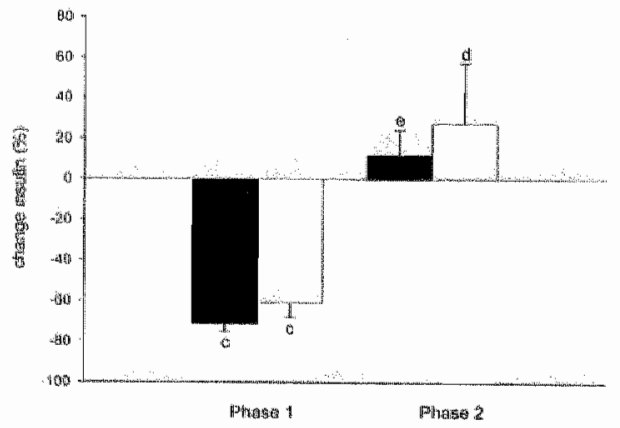

(b)

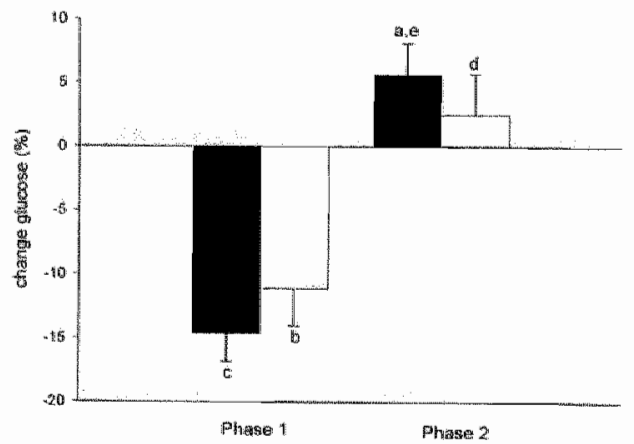

Figure 2 The percentage change in insulin (a) and glucose (b) concentrations for the PEG-leptin (black bars) and placebo (white bars) group during phase 1, phase 2 and during the total intervention period. Values are means with standard errors of the mean shown by vertical bars. For changes during a phase: $p<0.05 ; " \mathrm{p}<0.01 ;{ }^{\circ} p<0.0001$. For differences compared to phase 1 : "p<0.05; $p<0.001$. 


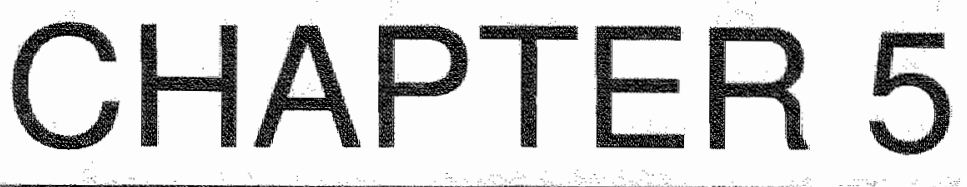

\section{Effect of capsaicin on substrate oxidation and weight maintenance after modest body weight loss in humans}

MPGM Lejeune, EMR Kovacs, MS Westerterp-Plantenga

Br J Nutr 2003; 90: 651-659 


\section{ABSTRACT}

The aim of this study was to investigate whether capsaicin may improve weight maintenance by limiting weight regain after weight loss of 5 to $10 \%$. In this randomized double blind placebo controlled study 91 moderately overweight subjects were randomly assigned to an intensive group that underwent all the measurements, and an extensive group that underwent the same measurements except the metabolism measurements. After a 4-wk very low energy diet (VLED) intervention, a 3 months weight maintenance period followed. During weight maintenance subjects were divided in a capsaicin (135 mg capsaicin/day) and a placebo group. Body mass was measured before and after VLED and after 1,2 and 3 months weight maintenance. The mean ( $\pm \mathrm{sd}$ ) body mass loss during the VLED was $6.6( \pm 2.0) \mathrm{kg}(=7.8( \pm 1.8) \%$ of initial body mass), and was not different between the subsequent treatment and placebo group. During weight maintenance mean \%regain in the treatment was not significantly different compared to placebo ( $33.3 \pm 35.7 \%$ vs $19.2 \pm 41.8 \%$; $P=0.09$ ). Respiratory quotient $(R Q)$ was significantly less increased during weight maintenance in the treatment group compared to placebo $(0.04 \pm 0.06$ vs $0.07 \pm 0.05 ; P<0.05$ ), indicating a relatively more sustained fat oxidation. Fat oxidation $(\mathrm{g} / \mathrm{h})$ after weight maintenance was higher in the capsaicin group compared to placebo $(4.2 \pm 1.1$ vs $3.5 \pm 0.9 ; P<0.05)$. These results indicate that capsaicin treatment showed a sustained fat oxidation during weight maintenance compared to placebo. However, capsaicin treatment has no limiting effect on 3 months weight regain after modest weight loss.

Key words: appetite, energy expenditure, fat oxidation 


\section{INTRODUCTION}

The increasing incidence of obesity is a recognized medical problem in developed countries ${ }^{1}$. Obesity is a major factor for a number of diseases, including coronary heart diseases, hypertension, non-insulin dependent diabetes mellitus, pulmonary dysfunction, osteoarthritis and certain types of cancer ${ }^{2-4}$. Factors suggested to be related to the development of obesity are decreased physical activity and increased energy intake, especially fat intake. Weight loss and loss of body fat can thus be achieved by reducing energy intake and/or increasing energy expenditure. Treatment of obesity is beneficial. Weight loss reduces the risk for mortality and morbidity in obese subjects ${ }^{5}$. Even modest weight loss, 5 to $10 \%$ of the initial body weight, already leads to beneficial health effects ${ }^{5-7}$. Risk factors related to obesity, such as lipid abnormalities and hypertension are positively affected by modest weight loss ${ }^{5}$. Modest weight loss is a realistic goal for most subjects ${ }^{5 ;}{ }^{6}$. However long-term maintenance of the body weight lost can be described as unsuccessful.

Most studies on weight maintenance show that weight regain is usually the case $^{8 \cdot 12}$, indicating that subjects are not able to change their eating and activity behavior adequately ${ }^{\ddagger 3}$. Interventions to improve long-term weight maintenance are therefore needed in order to treat obesity effectively. The limited long-term effectiveness of conventional weight management (dietary intervention, physical activity, and behavioral therapy) requires alternative weight reduction strategies. A rapidly growing therapeutic area, largely embraced by the general public, is the use of natural herbal supplements. A wide selection of herbal products is currently being marketed as weight loss agents. One of these agents is capsaicin, the pungent principle of hot red pepper. Capsaicin has been reported to reduce adiposity in rats which can be partly explained by the enhancing effects on energy and lipid metabolism via catecholamine secretion from the adrenal medulla through sympathetic activation of the central nervous system ${ }^{14:}$ ${ }^{15}$. In a series of human studies Yoshioka et al..$^{16-19}$ showed an increase in dietinduced thermogenesis and a decrease in respiratory quotient (RQ) immediately after a meal to which capsaicin was added, implying a shift in substrate oxidation from carbohydrate to fat oxidation. This increase in the facultative phase of diet-induced thermogenesis was probably due to $\beta$ adrenergic stimulation ${ }^{16}$. They also showed a decreased appetite, decreased cumulative food intake ${ }^{18}$ and increased energy expenditure ${ }^{17_{i}}$ i9 after consumption of capsaicin. Therefore, it is of interest to examine the observations in these short-term experiments on the long-term. We hypothesize that capsaicin consumption on the long-term may have a limiting effect on body weight regain after weight loss, through reduced appetite and food intake and through a thermogenic effect. 
The aim of the present study was to investigate whether capsaicin may improve weight maintenance by preventing or limiting weight regain after weight loss of 5 to $10 \%$ in moderately overweight subjects.

\section{SUBJECTS AND METHODS}

\section{Subjects}

140 male and female subjects, aged between 18 and 60 years, were recruited for this study. They underwent a medical screening. Selection resulted in 120 eligible subjects who were in good health, non-smokers, not using medication and at most moderate alcohol users. These were moderately overweight subjects, with a body mass index (BMI) between 25 and $35 \mathrm{~kg} / \mathrm{m}^{2}$. They all gave their written informed consent. The Medical Ethics Committee of the Academic Hospital in Maastricht approved of the study. Subjects were randomized to an extensive group $(n=40)$ that underwent the same protocol as the intensive group $(n=80)$, but not the metabolism measurements. During the first four weeks, 23 subjects dropped out, due to various reasons: moving house, changing jobs, or not being able to cope with the first diet, or not being able to fulfill the schedule with visits to the University. Finally 97 subjects completed the study, i.e. 68 in the intensive group and 29 in the extensive group. Six outliers were removed from the analyses. These were subjects who continued losing weight during weight maintenance or regained more than $100 \%$ weight during weight maintenance. So, analyses were based upon 91 subjects, i.e. 64 in the intensive group and 27 in the extensive group.

\section{Body welght and body mass index}

Body weight was measured on a digital balance (Seca, model 707, Hamburg Germany; weighing accuracy of $0.1 \mathrm{~kg}$ ) with subjects in underwear, in a fasted state and after voiding their bladder. Height was measured using a wallmounted stadiometer (Seca, model 220, Hamburg, Germany).

Body mass index was calculated as body weight.height ${ }^{-2}\left(\mathrm{~kg} \cdot \mathrm{m}^{-2}\right)$.

\section{Waist/hip-ratio}

The distribution of fat was investigated by measuring the waist and hip circumferences and calculation of the waist-hip ratio (WHR). The waist circumference was measured at the site of the smallest circumference between the rib cage and the ileac crest, with the subjects in standing position. The hip 
circumference was measured at the site of the largest circumference between the waist and the thighs. The WHR was calculated by dividing the waist circumference by the hip circumference.

\section{Body composition}

Total body water (TBW) was measured using the deuterium $\left({ }^{2} \mathrm{H}_{2} \mathrm{O}\right)$ dilution technique ${ }^{20 ; 2 t}$. In the evening, the subjects ingested a dose of deuterium enriched water $\left({ }^{2} \mathrm{H}_{2} \mathrm{O}\right)$ after collecting a background urine sample. After consumption of the ${ }^{2} \mathrm{H}_{2} \mathrm{O}$ no more fluid and food was consumed. The following morning a urine sample from the second voiding was collected between 8:00 $\mathrm{h}$ and 10:00 h. Deuterium concentration in the urine samples was measured using an isotope ratio mass spectrometer (Micromass Optima, Manchester, UK). TBW was obtained by dividing the measured deuterium dilution space by 1.0420 . Fat free mass (FFM) was calculated by dividing the TBW by the hydration factor 0.73 . By subtracting FFM from body weight, fat mass (FM) was obtained. FM expressed as a percentage of body weight is body fat percentage.

\section{Attitude towards eating}

To determine whether attitude towards food intake changed during the experiment, a Dutch translation of the Three Factor Eating Questionnaire (TFEQ) was used ${ }^{22 ;}$ 23. The first factor of the TFEQ (F1) measures cognitive restrained eating: control of food intake by thought and will power. The second factor (F2) represents disinhibition: an incidental inability to resist eating cues, or inhibition of dietary restraint, and emotional eating. The third factor (F3) examines the subjective feeling of general hunger.

In addition the Herman Polivy questionnaire $(\mathrm{HP})^{24}$ was used to determine the frequency of dieting.

\section{Post-absorptive appetite profile}

To determine the post-absorptive appetite profile, hunger and satiety were rated on anchored $100 \mathrm{~mm}$ Visual Analogue Scales (mmVAS) in the morning before breakfast after an overnight fast.

\section{Blood parameters}

In the morning before breakfast after an overnight fast a blood sample of $10 \mathrm{ml}$ was taken and mixed with EDTA to prevent clotting. Plasma was obtained by centrifugation, frozen in liquid nitrogen and stored at $-80^{\circ} \mathrm{C}$ until further analysis. 
Plasma glucose concentrations were determined using the hexokinase method (Glucose HK 125 kit, ABX diagnostics, Montpellier, France). The Wako NEFA C-kit (Wako chemicals, Neuss, Germany) was used to determine free fatty acid concentrations. Insulin concentrations were measured using the RIA-kit (Insulin RIA-100, Kabi-Pharmacia). The glycerolkinase method was used to determine glycerol concentrations (Boehringer Mannheim GmbH, Mannheim, Germany). Triglycerides were measured using the GPO-trinder kit (Sigma Diagnostics Inc., St. Louis, USA). The $\beta$-hydroxybutyrate dehydrogenase method (Sigma Diagnostics Inc.; St. Louis, USA) was used to determine $\beta$-hydroxybutyrate concentrations. Leptin concentrations were measured using the human leptin RIA-kit (Linco Research Inc., St. Charles, USA).

\section{Adverse events}

Adverse events during treatment were recorded and the severity and outcome specified.

\section{Resting energy expenditure and substrate oxidation}

Resting energy expenditure (REE) and substrate oxidation were measured by means of an open circuit ventilated hood system. Subjects came to the laboratory in the morning by car or by bus to minimize the amount of physical activity before the test. REE was measured with subjects in a fasted state while lying supine for $30 \mathrm{~min}$. Gas analyses was performed by a paramagnetic oxygen analyzer (Servomex type 500A, Crowborough Sussex, UK) and an infrared carbon dioxide analyzer (Servomex type 500A), similar to the analysis system described by Schoffelen et al. ${ }^{25}$. Calculation of REE was based upon the Weir's formulas ${ }^{26}$. $\mathrm{RQ}$ was calculated as $\mathrm{CO}_{2}$ produced/ $/ \mathrm{O}_{2}$ consumed. Fat oxidation was calculated using the following equation ${ }^{27}$ :

Fat oxidation $(\mathrm{g} / \mathrm{h})=\left(1.695 \times \mathrm{VO}_{2}(\mathrm{l} / \mathrm{min})-1.701 \times \mathrm{VCO}_{2}(1 / \mathrm{min})\right) \times 60$

\section{Physical activity}

Physical activity level (PAL) was determined using an uni-axial accelerometer $(\mathrm{CSA})^{28}$, or a tri-axial accelerometer for movement registration (Tracmor) ${ }^{29}$ during one week. Subjects were wearing the CSA or Tracmor during waking hours in a belt at the back of the waist. 
PAL was calculated using the following equations:
$\operatorname{CSA}^{28}$ :
PAL $=(0.000001379 \times($ counts $/$ day $\times 5))+1.113$
Tracmor $^{29}: \quad$ TEE $=-1.259+(1.552 \times$ REE $)+(0.076 \times$ counts $/ \mathrm{min})$
$\mathrm{PAL}=\mathrm{TEE} / \mathrm{REE}$

In which TEE is total energy expenditure (MJ/d) and REE is resting energy expenditure (MJ/d). The different accelerometers were randomized over the two groups. Half of the subjects in the capsaicin group and the placebo group received the CSA, the other half received the Tracmor. Subjects received the same accelerometers every time.

\section{Energy intake}

Energy intake (EI) was calculated as TEE plus energy storage (ES). Energy storage was calculated from the composition of the energy stored. For usual energy storage of fat mass and fat free mass $30 \mathrm{MJ}$ per kilogram body weight gain was taken (A). If body weight gain consisted of only fat free mass while fat mass decreased, $52 \mathrm{MJ}$ per kilogram fat free mass gain ${ }^{30}$ and $30 \mathrm{MJ}$ per kilogram fat mass loss was used (B).
(A)
ES $(\mathrm{MJ} / \mathrm{d})=(\Delta$ body weight $(\mathrm{kg}) \times 30) /$ number of days
$\mathrm{ES}(\mathrm{MJ} / \mathrm{d})=((\Delta \mathrm{FFM}(\mathrm{kg}) \times 52)-(\Delta \mathrm{FM}(\mathrm{kg}) \times 30)) /$ number of days

\section{VLED period}

After the subject's baseline measurements a very low energy diet (VLED) intervention followed for four weeks, in order to let the subjects lose weight. The VLED (Modifast $(B)$, Novartis Nutrition, Breda, The Netherlands) was supplied in three sachets daily, dissolved in water to obtain a milk shake, pudding, soup or muesli. Vegetables and fruit were allowed in addition to the VLED. The aim was a body weight loss of at least $4 \mathrm{~kg}$ over 4 weeks.

After this weight loss period, the measurements described under baseline measurements were repeated (table 1).

\section{Weight maintenance period}

Then the weight maintenance phase started. During the weight maintenance phase the subjects, divided over two matched groups, received capsaicin or placebo. The capsaicin capsules contained $22.5 \mathrm{mg}$ capsaicin (Naturex, France) and $202.5 \mathrm{mg}$ of vegetable oil. The placebo capsules contained $225 \mathrm{mg}$ of vegetable oil. Subjects in both groups had to take 2 capsules during breakfast, 2 during lunch and 2 during diner. So, the total dosage of capsaicin was $135 \mathrm{mg} /$ day for the capsaicin group and $0 \mathrm{mg}$ capsaicin/day for the placebo group. This dosage of capsaicin was based upon the maximal dosage shown in 
the literature ${ }^{16-19}$. Other dosages and types used are minimally $3 \mathrm{mg}$ per experiment and maximally $126 \mathrm{mg} / \mathrm{day}^{16-19}$.

Subjects were stratified for gender, BMl, age, eating behavior (TFEQ, factor 1), resting energy expenditure, and divided into two groups. A double-blind administration of the supplementation was carried out. Thus, finally 42 (30 female, 12 male) subjects participated during the whole experiment in the capsaicin group and 49 ( 38 female, 11 male) subjects in the placebo group. With respect to the group with intensive measurements 30 subjects participated during the whole experiment in the capsaicin group and 36 subjects in the placebo group. Ten of the subjects complained about the capsules on the first or second day. They were seen by the responsible medical doctor and advised to use half the dosage. After disclosure of the blinding it occurred that all these subjects were part of the capsaicin group. Measurements as described under baseline measurements were executed again three months (i.e. 13 weeks) later. In addition, body weight was determined 1 month and 2 months after the start of the weight maintenance phase.

\section{Data analysis}

Data are presented as means \pm standard deviation (SD). A two-factor repeated measures ANOVA was carried out to determine possible differences between the capsaicin and placebo group in all measured parameters over time. When appropriate a factorial ANOVA was used for analyzing differences between the treatment groups. Post hoc analyses were done with the Scheffe F-test. A P value $<0.05$ was regarded as statistically significant. Statistical procedures were performed by using Statview SE+ Graphics (Abacus Concepts, Berkeley, CA, 1988).

\section{RESULTS}

No different effects for men or women were observed. Therefore these data have been taken together.

\section{VLED period}

During the VLED period the following changes occurred, which did not differ between the subsequent treatment and placebo group (table 1). With respect to body weight loss, the subjects lost a significant amount of body weight, i.e. $6.6 \pm$ $2.0 \mathrm{~kg}(\mathrm{SD})$, or $7.8 \pm 1.8 \%(\mathrm{SD})$ of their original body weight $(\mathrm{P}<0.001)$. This consisted of $4.1 \pm 1.6 \mathrm{~kg} \mathrm{FM}$ and $2.5 \pm 1.7 \mathrm{~kg}$ FFM. The body weight data of both groups are presented in figure 1 . 


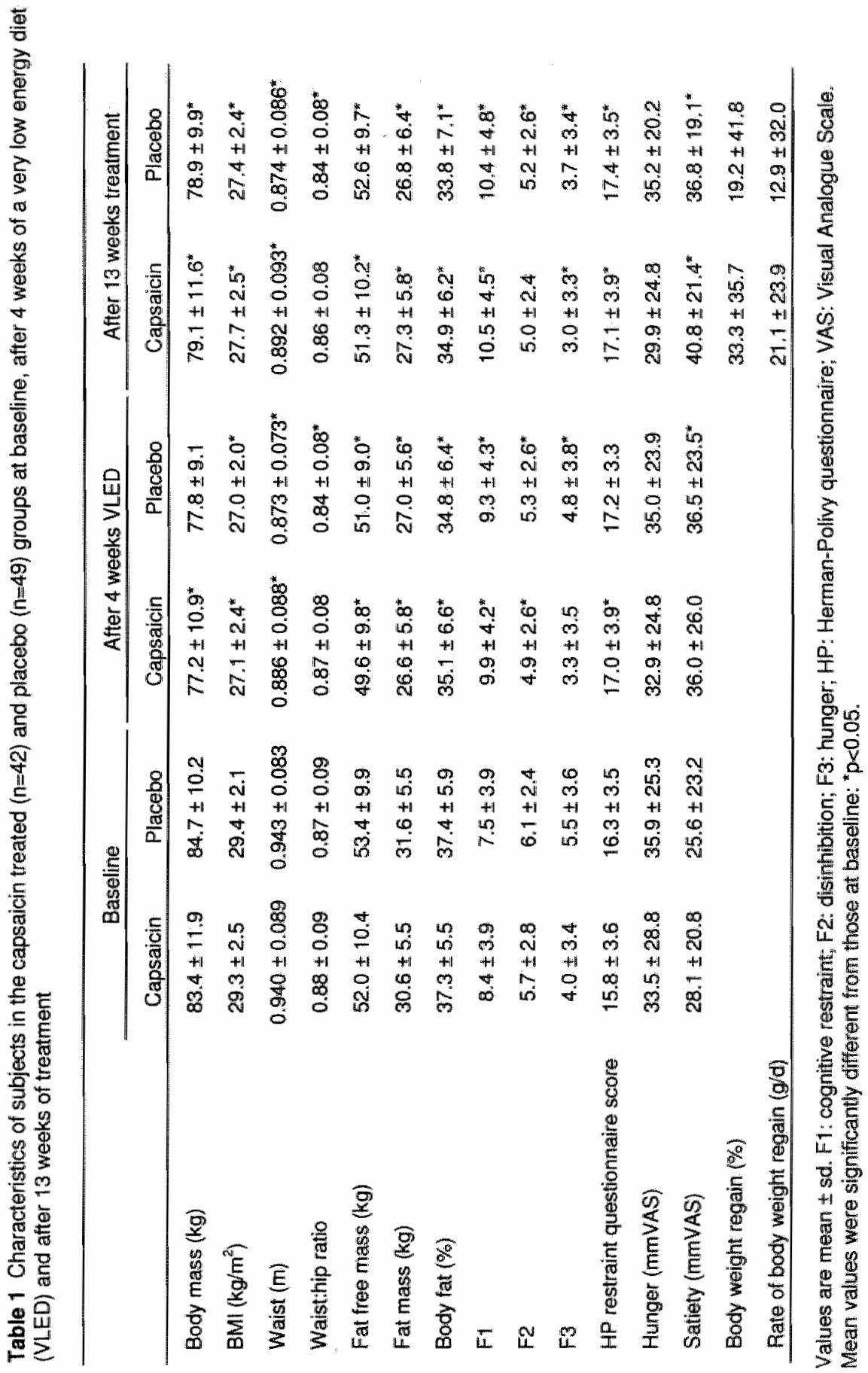


Also wailst circumference was significantly reduced over time. Attitude towards eating showed some significant changes over time (table 1). Cognitive restraint (factor 1, TFEQ) increased significantly, disinhibition (factor 2, TFEQ) and general hunger scores (factor 3 , TFEQ) decreased during weight loss (table 1). REE and RQ decreased during weight loss (table 2). TEE decreased in both groups, but only reached significance in the placebo group. The fasting blood parameters glucose, insulin, triacylglycerol and leptin showed a decrease with weight loss, and $\beta$-hydroxybutyrate, glycerol (not significantly) and free fatty acids showed an increase with weight loss (table 3 ).

\section{Weight maintenance period}

During weight maintenance, body weight regain, expressed as percentage of body mass loss, as well as rate of regain was not significantly different between treatments (table 1). Cognitive restraint scores stayed significantly higher during weight maintenance compared to baseline in both groups. Disinhibition stayed lowered in the placebo group; and general hunger decreased in both groups. Satiety in the fasted state before breakfast increased during weight maintenance in the placebo and in the capsaicin group (table 1). The hunger scores in the fasted state before breakfast did not change over time in both groups. The increase in $\mathrm{RQ}$ during weight maintenance was significantly smaller in the capsaicin compared with the placebo group $(0.04 \pm 0.06$ vs. 0.07 $\pm 0.05, P<0.05$ ), indicating a smaller decrease in fat oxidation in the capsaicin group than in the placebo group. The increase in $R Q$ was not related to weight regain ( $P>0.05$ ). Fat oxidation $(g / h)$ after weight maintenance was higher in the capsaicin group compared to placebo ( $4.2 \pm 1.1$ vs $3.5 \pm 0.9 ; P<0.05)$ (figure 2 ). The increase in REE during weight maintenance was significantly higher in the capsaicin compared to placebo group $(0.7 \pm 0.5 \mathrm{MJ} / \mathrm{d}$ vs. $0.2 \pm 0.5 \mathrm{MJ} / \mathrm{d}$, $\mathrm{P}<0.005)$, although increases in FFM showed no differences between both groups. REE in the placebo group after weight maintenance was still significantly lower compared to baseline, but FFM was also lower. In the capsaicin group the REE returned to baseline, while FFM was still reduced.

To assess possible differences in REE adjusted for FFM between groups we analyzed the residuals of the regression of REE on FFM (figure 3 ). The residual analysis was done by factorial ANOVA after three months treatment, and showed a trend for a significant difference between the capsaicin and placebo group after treatment $(P=0.07)$. Total energy expenditure stayed significantly lower during weight maintenance compared to baseline in the placebo group, but FFM was lower as well.

Energy intake, calculated from energy expenditure and energy storage, was not significantly different between both groups during weight maintenance. 


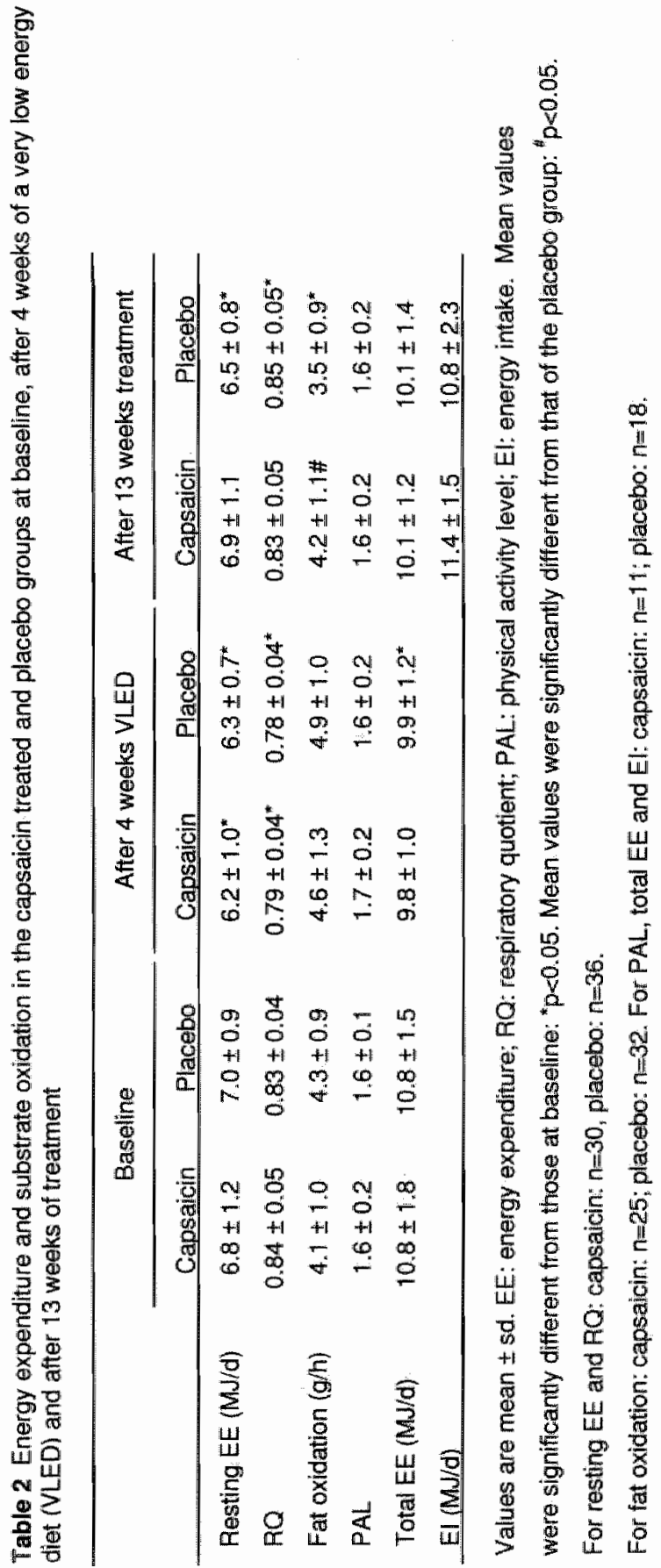




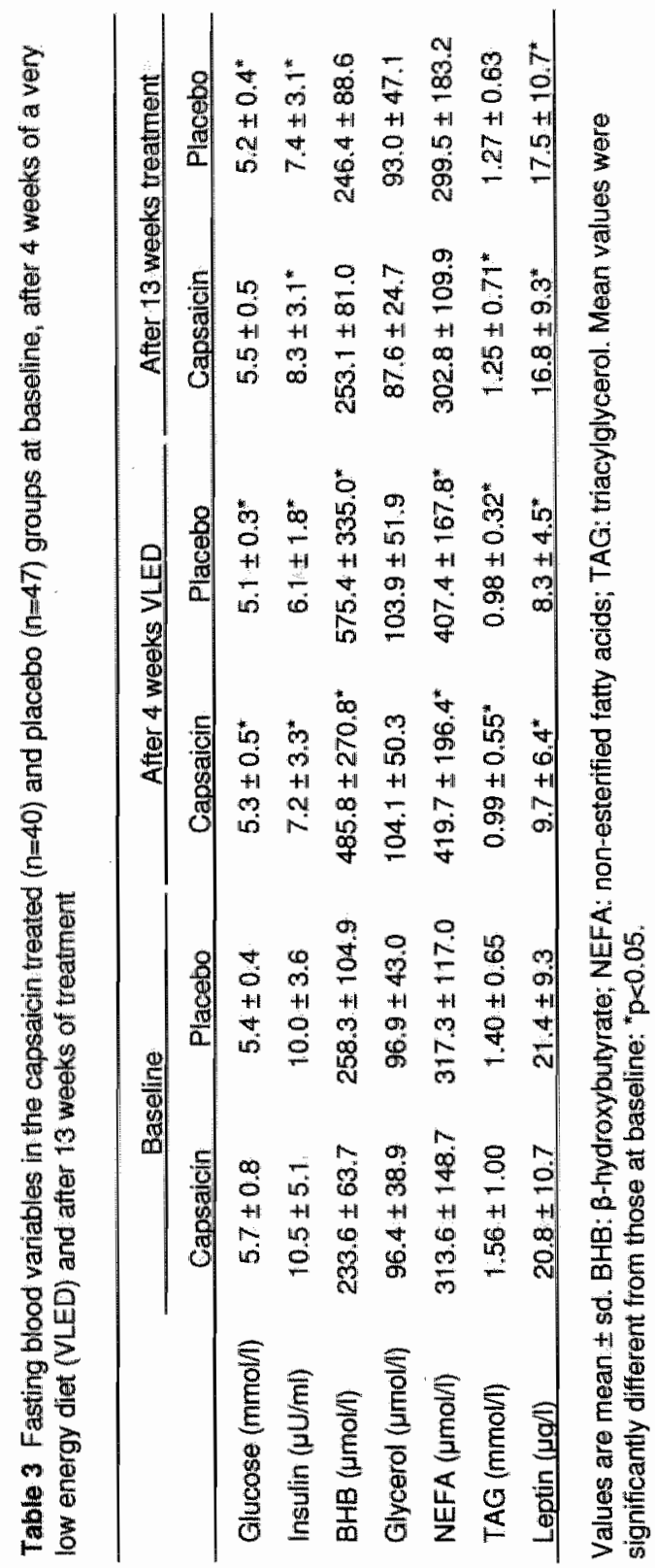


Insulin and leptin levels stayed significantly lower after treatment compared to baseline in both groups (table 3). Glucose levels in the placebo group and triacylglycerol levels in the capsaicin group stayed significantly lower after treatment compared to baseline. $\beta$-hydroxybutyrate, glycerol and free fatty acids levels returned to almost baseline values during weight regain (table 3 ). No effect of treatment $x$ time interaction appeared.

No other adverse events then the ten subjects who complained about the capsules and were advised to use half the dosage, were reported. Results of subjects receiving the half dosage or the complete dosage of capsaicin did not differ significantly.

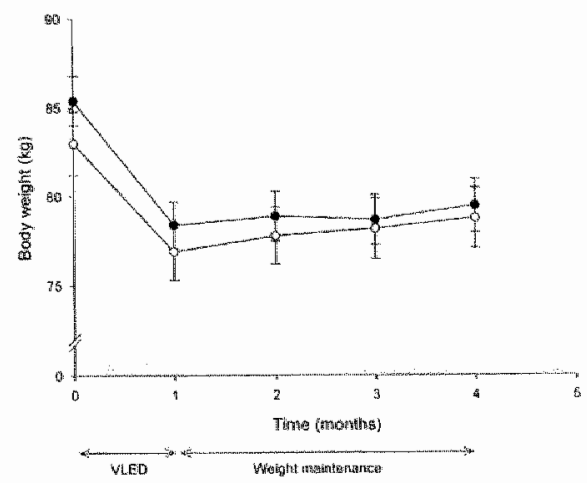

Figure 1 Change in body weight over time in the capsaicin treated (open circles, $n=42$ ) and placebo (filled circles, $n=49$ ) groups. VLED: very low energy diet. Values are mean \pm s.e.m. shown by vertical bars. No significant differences were seen between both group at any time.

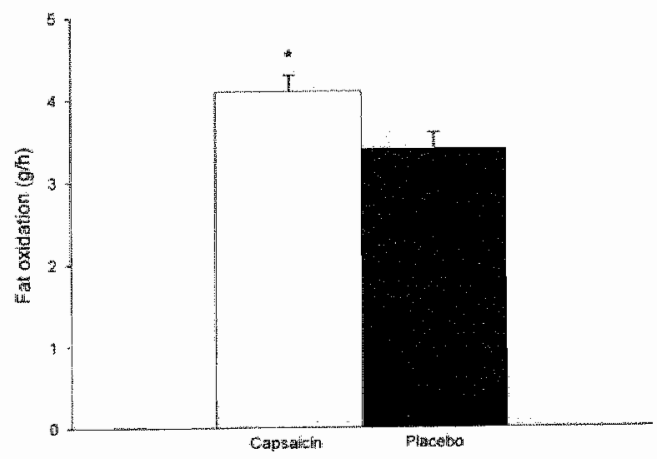

Figure 2 Fat oxidation $(g / h)$ after 3-months weight maintenance in the capsaicin treated $(n=25)$ and placebo $(n=32)$ groups. Values are mean \pm s.e.m. shown by vertical bars. Mean value for the capsaicin group was significantly different from that of the placebo group: " $p<0.05$. 


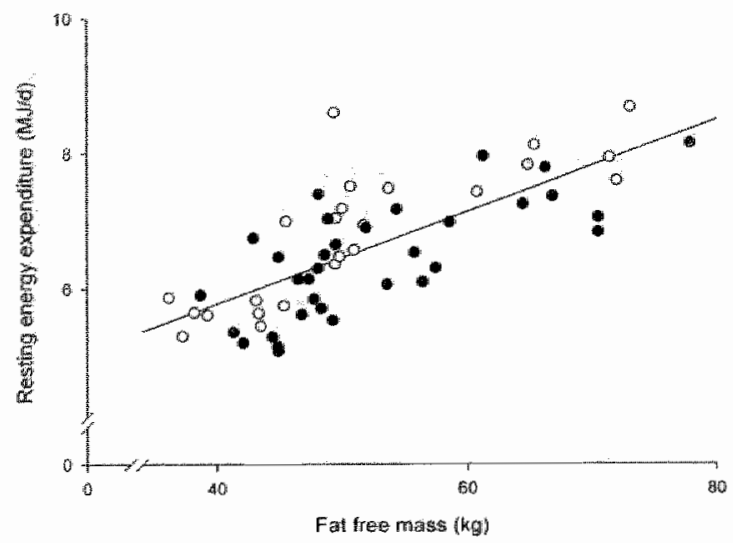

Figure 3 Resting energy expenditure after weight maintenance as a function of fat free mass after weight maintenance in the capsaicin treated (open circles, $n=21$ ) and placebo (filled circles, $n=28$ ) groups. The regression equation is: Resting energy expenditure $(\mathrm{M} / \mathrm{J} / \mathrm{d})=0.07 \mathrm{fat}$ free mass $(\mathrm{kg})+$ $3.1(p<0.0001, r=0.74)$.

\section{DISCUSSION}

The actual experiment on body weight maintenance after body weight loss showed that $135 \mathrm{mg}$ capsaicin/day vs. placebo, did not improve body weight maintenance in originally moderately overweight men and women, after a modest weight loss of $7.8 \%$. However, we showed that with similar weight regain, substrate oxidation was affected by capsaicin. During weight regain the increase in RQ was smaller in the capsaicin group, so the decrease in fat oxidation was smaller compared to placebo. The net fat oxidation $(\mathrm{g} / \mathrm{h})$ after weight maintenance was also higher in the capsaicin group compared to placebo. This is in line with the suggestion by Yoshioka et al. ${ }^{17}$, who showed a shift in lipid balance during a short-term experiment with capsaicin in Japanese women.

Measurements of habitual food intake are difficult, especially in obese subjects, because of underreporting energy and fat intake ${ }^{31-33}$ and this may lead to incorrect conclusions ${ }^{33}$. Therefore, in the present study the energy intake during weight maintenance was not recorded, but calculated from energy expenditure and energy storage.

Previously, we also observed a lack of a relationship between increase of $\mathrm{RQ}$ and body weight regain after weight loss ${ }^{34}$. It seems that the vulnerability for weight gain predicted by a relatively high $R Q$, as was indicated by Ravussin et $a l^{35}$, Zurlo et $a l^{36}$, Seidell et $a l^{37}{ }^{37}$. Schutz ${ }^{38}$, does not necessarily hold for the situation of weight regain. 
REE after weight maintenance returned to baseline in the capsaicin group (although FFM was still lowered), and in the placebo group REE was still significantly lowered compared to baseline (while FFM was lower too). Since the main determinant of REE is FFM $^{39}$, the REE has to be adjusted for FFM. Therefore the residuals of the regression of REE on FFM were analyzed. This resulted in showing a trend for an increased REE as a function of FFM in the capsaicin group, compared to placebo. Yoshioka et al. ${ }^{16}$ reported an increase in energy expenditure after a meal containing red pepper, which was probably explained by $\beta$-adrenergic stimulation. A low metabolic rate after weight reduction is a risk factor for subsequent weight regain ${ }^{39}$. However, here the normalized resting metabolic rate in the capsaicin group could not prevent weight regain.

The lack of a relationship between body weight regain and RQ might explain the lack of a difference in regain between the groups. This emphasizes again that a relatively low $\mathbb{R Q}$ may prevent weight gain ${ }^{35-38}$, which does not mean that an artificially lowered RQ during regain prevents or limits weight regain. Moreover, the relative increase of REE as a function of FFM also could not limit weight regain. The relatively lower $R Q$ and higher $R E E$ did not result in a relatively higher FFM and lower FM in the capsaicin group. It may be that the capsaicin effects, although clearly present, were too small to limit regain of body weight. Furthermore, the regain data showed large individual differences. Even after removing the outliers, the variance of the regain data remains relatively high.

The question whether subjects get accustomed to capsaicin on the long-term is of interest. The Japanese women studied by Yoshioka et al. ${ }^{17}$ were used to spicy foods, but still showed an increase in fat oxidation following red pepper ingestion. The present observations are also in line with this, i.e. continuing capsaicin supplementation for three months, in subjects who were not used to capsaicin in their habitual diet, still appeared to stimulate fat oxidation. Also, similar to Yoshioka's observations ${ }^{10-19}$ we did not find different results between different dosages of capsaicin. Compliance to capsaicin consumption in our study was shown in that all subjects who appeared to have consumed the capsaicin capsules had mentioned a somewhat burning feeling in their stomach every time they came to the university. Here a subject specific sensitivity may play a role ${ }^{17}$. Because the use of capsaicin on the long term may cause habituation, we used a higher dosage compared to the short-term experiments by Yoshioka ${ }^{16-19}$. Since all our subjects reported not to use red pepper frequently in their diet, our dosage might have been relatively high.

The hunger scores in the fasted state before breakfast did not change over time in both groups. Yoshioka et al. ${ }^{18}$ found a decrease in hunger after breakfast with red pepper and before lunch. Therefore a decrease in hunger due to capsaicin 
consumption might rather be a short-term than a long-term effect. Here habituation might have played a role.

Eating behavior, as measured by the TFEQ, showed an improved profile, i.e. more cognitive restraint; less disinhibition and hunger after the weight loss period, which is similar to previous observations ${ }^{13 ; 34 ; 40 ; 41}$. Previously, we showed an inverse relationship between increase in cognitive restraint during weight loss and weight regain thereafter ${ }^{13}$. However, this relationship failed to reach significance (capsaicin group: $P=0.1$, placebo group: $P=0.06$ ) in the present study.

Regarding the beneficial effects of weight loss, after the treatment period body mass, percentage body fat and waist circumference were still significantly reduced compared to baseline. As often seen during weight loss the fasting blood parameters glucose, insulin, triacylglycerol and leptin showed a decrease with weight loss, and $\beta$-hydroxybutyrate, glycerol and free fatty acids showed an increase with weight loss. The beneficial effects of weight loss were still present after treatment for glucose, insulin, triacylglycerol and leptin, whereas the levels of $\beta$-hydroxybutyrate, glycerol and free fatty acids returned to baseline.

In conclusion, the short-term observation by Yoshioka et al. ${ }^{17}$, i.e. a larger fat oxidation due to consumption of capsaicin also holds on the long term, i.e. during weight regain. The short-term effect on appetite reported by Yoshioka et al. ${ }^{18}$ did not appear on the long term. However, the effects of capsaicin on the longer term did not sustain weight maintenance in comparison to placebo, probably because an effect on body composition was not achieved.

\section{ACKNOWLEDGMENTS}

We thank Ilse Nijs, Joan Senden, Wendy Sluijsmans and Loek Wouters for their contributions to the study. This study was supported by Novartis $\mathrm{CH}$, Consumer Health Ltdl. (Nyon, Switzerland).

\section{REFERENCES}

1. Seidell JC (1995) Obesity in Europe. Obes Res 3 Suppl 2, 249s-259s.

2. Noppa $H$ (1980) Body weight change in relation to incidence of ischemic heart disease and change in risk factors for ischemic heart disease. $A m J$ Epidemiol 111, 693-704. 


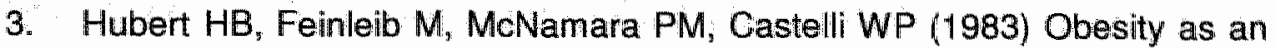
independent risk factor for cardiovascular disease: a 26-year follow-up of participants in the Framingham Heart Study. Circulation 67, 968-977.

4. Kromhout D (1983) Body weight, diet, and serum cholesterol in 871 middle-aged men during 10 years of follow-up (the Zutphen Study). Am J Clin Nutr 38, 591-598.

5. Van Gaal LF, Wauters MA, De Leeuw IH (1997) The beneficial effects of modest weight loss on cardiovascular risk factors. Int $J$ Obes Relat Metab Disord 21 Suppl 1, S5-9.

6. Goldstein DJ (1992) Beneficial health effects of modest weight loss. Int $J$ Obes Relat Metab Disord 16, 397-415.

7. Wing RR, Jeffery RW, Burton LR, Thorson C, Kuller LH, Folsom AR (1992) Change in waist-hip ratio with weight loss and its association with change in cardiovascular risk factors. Am J Clin Nutr 55, 1086-1092.

8. Wadden TA, Stunkard AJ, Liebschutz J (1988) Three-year follow-up of the treatment of obesity by very low calorie diet, behavior therapy, and their combination. J Consult Clin Psychol 56, 925-928.

9. Kramer FM, Jeffery RW, Forster JL, Snell MK (1989) Long-term follow-up of behavioral treatment for obesity: patterns of weight regain among men and women. Int J Obes 13, 123-136.

10. Pasman WJ, Westerterp-Plantenga MS, Muls E, Vansant G, van Ree J, Saris WH (1997) The effectiveness of long-term fibre supplementation on weight maintenance in weight-reduced women. Int $J$ Obes Relat Metab Disord 21, 548-555.

11. Pasman WJ, Westerterp-Plantenga MS, Saris WH (1997) The effectiveness of long-term supplementation of carbohydrate, chromium, fibre and caffeine on weight maintenance. Int $J$ Obes Relat Metab Disord 21, 1143-1151.

12. Pasman WJ, Saris WH, Muls E, Vansant G, Westerterp-Plantenga MS (1999) Effect of exercise training on long-term weight maintenance in weight- reduced men. Metabolism 48, 15-21.

13. Westerterp-Plantenga MS, Kempen KP, Saris WH (1998) Determinants of weight maintenance in women after diet-induced weight reduction. Int $J$ Obes Relat Metab Disord 22, 1-6.

14. Kawada T, Hagihara K, Iwai K (1986) Effects of capsaicin on lipid metabolism in rats fed a high fat diet. J Nutr 116, 1272-1278.

15. Kawada $T$, Sakabe $S$, Watanabe $T$, Yamamoto M, Iwai K (1988) Some pungent principles of spices cause the adrenal medulla to secrete catecholamine in anesthetized rats. Proc Soc Exp Biol Med 188, 229-233. 
16. Yoshioka M, Lim K, Kikuzato S, Kiyonaga A, Tanaka $H$, Shindo M, Suzuki $M$ (1995) Effects of red-pepper diet on the energy metabolism in men. $J$ Nutr Sci Vitaminol (Tokyo) 41, 647-656.

17. Yoshioka M, St-Pierre S, Suzuki M, Tremblay A (1998) Effects of red pepper added to high-fat and high-carbohydrate meals on energy metabolism and substrate utilization in Japanese women. Br J Nutr 80 , 503-510.

18. Yoshioka M, St-Pierre S, Drapeau V, Dionne I, Doucet E, Suzuki M, Tremblay A (1999) Effects of red pepper on appetite and energy intake. $\mathrm{Br}$ $J$ Nutr 82, 115-123.

19. Yoshioka M, Doucet E, Drapeau V, Dionne I, Tremblay A (2001) Combined effects of red pepper and caffeine consumption on $24 \mathrm{~h}$ energy balance in subjects given free access to foods. Br J Nutr 85, 203-211.

20. Schoeller DA, van Santen E, Peterson DW, Dietz W, Jaspan J, Klein PD (1980) Total body water measurement in humans with 180 and $2 \mathrm{H}$ labeled water. Am J Clin Nutr 33, 2686-2693.

21. van Marken Lichtenbelt WD, Westerterp KR, Wouters L (1994) Deuterium dilution as a method for determining total body water: effect of test protocol and sampling time. Br J Nutr 72, 491-497.

22. Stunkard AJ, Messick S (1985) The three-factor eating questionnaire to measure dietary restraint, disinhibition and hunger. J Psychosom Res 29, 71-83.

23. Westerterp-Plantenga MS, Rolland V, Wilson SA, Westerterp KR (1999) Satiety related to $24 \mathrm{~h}$ diet-induced thermogenesis during high protein/carbohydrate vs high fat diets measured in a respiration chamber. Eur J Clin Nutr 53, 495-502.

24. Herman CP, Polivy J (1980) Restrained eating. In Obesity, pp. 208-224 [AJ Stunkard, editor]. Philadelphia: W.B. Saunders.

25. Schoffelen PF, Westerterp KR, Saris WH, Ten Hoor F (1997) A dualrespiration chamber system with automated calibration. J App/ Physiol 83, 2064-2072.

26. Weir JB (1949) New Methods for calculating metabolic rate with special reference to protein metabolism. Journal of Physiology 109, 1-9.

27. Peronnet F, Massicotte D (1991) Table of nonprotein respiratory quotient: an update. Can J Sport Sci 16, 23-29.

28. Ekelund U, Yngve A, Sjostrom M, Westerterp K (2000) Field evaluation of the Computer Science and Application's Inc. Activity monitor during running and skating training in adolescent athletes. Int $J$ Sports Med 21, 586-592. 
29. Goris AH, Meijer EP, Kester $A_{n}$ Westerterp KR (2001) Use of a triaxial accelerometer to validate reported food intakes. Am J Clin Nutr 73, 549 . 553.

30. Pullar JD, Webster AJ (1977) The energy cost of fat and protein deposition in the rat. Br J Nutr 37, 355-363.

31. Goris $\mathrm{AH}$, Westerterp KR (1999) Underreporting of habitual food intake is explained by undereating in highly motivated lean women. J Nutr 129, 878882.

32. Goris AH, Westerterp KR (2000) Improved reporting of habitual food intake after confrontation with earlier results on food reporting. $B r J$ Nutr 83,363 369.

33. Goris AH, Westerterp-Plantenga MS, Westerterp KR (2000) Undereating and underrecording of habitual food intake in obese men: selective underreporting of fat intake. Am J Clin Nutr 71, 130-134.

34. Pasman WJ, Saris WH, Westerterp-Plantenga MS (1999) Predictors of weight maintenance. Obes Res 7, 43-50.

35. Ravussin E, Fontvieille AM, Swinburn BA, Bogardus C (1993) Risk factors for the development of obesity. Ann N Y Acad Sci 683, 141-150.

36. Zurlo F, Lillioja S, Esposito-Del Puente A, Nyomba BL, Raz I, Saad MF, Swinburn BA, Knowler WC, Bogardus C, Ravussin E (1990) Low ratio of fat to carbohydrate oxidation as predictor of weight gain: study of 24-h RQ. Am J Physiol 259, E650-657.

37. Seidell JC, Muller DC, Sorkin JD, Andres R (1992) Fasting respiratory exchange ratio and resting metabolic rate as predictors of weight gain: the Baltimore Longitudinal Study on Aging. Int J Obes Relat Metab Disord 16, 667-674.

38. Schutz Y (1995) Abnormalities of fuel utilization as predisposing to the development of obesity in humans. Obes Res 3 Suppl 2, 173S-1178S.

39. Ravussin E, Bogardus C (1989) Relationship of genetics, age, and physical fitness to daily energy expenditure and fuel utilization. Am $J$ Clin Nutr 49 , 968-975.

40. Clark MM, Marcus BH, Pera $V$, Niaura RS (1994) Changes in eating inventory scores following obesity treatment. Int J Eat Disord 15, 401-405.

41. Pekkarinen T, Takala $I$, Mustajoki $P$ (1996) Two year maintenance of weight loss after a VLCD and behavioural therapy for obesity: correlation to the scores of questionnaires measuring eating behaviour. Int $J$ Obes Relat Metab Disord 20, 332-337. 


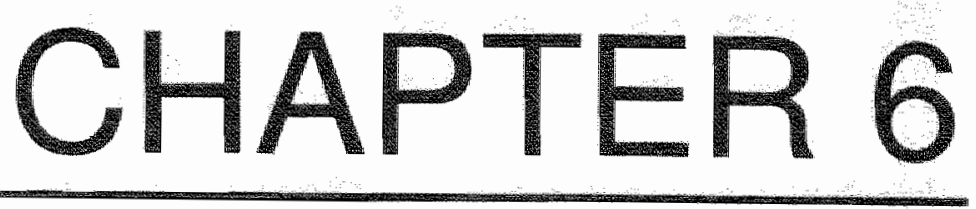

\section{Effects of green tea on weight maintenance after body weight loss}

EMR Kovacs, MPGM Lejeune, I. Nijs, MS Westerterp-Plantenga Br J Nutr 2004; 91: 431-437 


\section{ABSTRACT}

This study was conducted to investigate whether green tea may improve weight maintenance by preventing or limiting weight regain after weight loss of 5 to $10 \%$ in overweight and moderately obese subjects. The study had a randomized, parallel, placebo-contralled design. 104 overweight and moderately obese male and female subjects (age, 18-60 y; BMl, $25-35 \mathrm{~kg} / \mathrm{m}^{2}$ ) participated in a very low energy diet intervention (VLED, $2.1 \mathrm{MJ} / \mathrm{d}$ ) of 4 weeks followed by a weight maintenance period of 13 weeks in which they received green tea (caffeine, $104 \mathrm{mg} / \mathrm{d}$; catechins, $573 \mathrm{mg} / \mathrm{d}$. epigallocatechin gallate, $323 \mathrm{mg} / \mathrm{d}$ ) or placebo. Subjects lost (mean \pm SD) $6.4 \pm 1.9 \mathrm{~kg}$ or $7.5 \pm 2.2 \%$ of their original body weight during VLED $(p<0.001)$. Body weight regain was not significantly different between the green tea and the placebo group ( $30.5 \pm$ $61.8 \%$ and $19.7 \pm 56.9 \%$, respectively). In the green tea treatment, habitual high caffeine consumption was associated with a higher weight regain compared to habitual low caffeine consumption $(39 \pm 17 \%$ and $16 \pm 11 \%$, respectively; $p<0.05)$. We conclude that weight maintenance after $7.5 \%$ body weight loss was not affected by green tea treatment and that habitual caffeine consumption affected weight maintenance in the green tea treatment.

Keywords: caffeine, epigallocatechin gallate, energy expenditure, substrate oxidation, obesity 


\section{INTRODUCTION}

The increasing incidence of obesity is a recognized medical problem in developed countries ${ }^{1}$. Obesity is associated with an increased risk of developing serious disorders, including hypertension, dyslipidemia ${ }_{\text {, cardiovascular disease, }}$ non-insulin dependent diabetes mellitus, gallbladder disease, respiratory dysfunction, gout and osteoarthritis ${ }^{2}$. Factors suggested to be related to the development of obesity are increased energy intake, especially from increased energy density through increased fat intake ${ }^{3}$ and decreased energy expenditure, particularly from reduced physical activity ${ }^{3}$. Body weight and fat loss can thus be achieved by reducing energy intake and/or increasing energy expenditure. Treatment of obesity is beneficial. Modest weight loss, i.e. 5 to $10 \%$ of the initial body weight, which is a realistic goal for most individuals, is associated with marked health improvement ${ }^{4 ; 5}$. However long-term maintenance of the body weight lost can be described as unsuccessful. Most studies on weight maintenance show that weight regain is usually the case ${ }^{6-10}$, indicating that subjects are not able to change their eating and activity behavior adequately ${ }^{11}$. Intervention strategies for promoting long-term weight maintenance are therefore needed in order to treat obesity effectively. The limited long-term effectiveness of conventional weight management (dietary intervention, physical activity and behavioral therapy) leads to the development of alternative weight reduction strategies. A rapidly growing therapeutic area, largely embraced by the general public, is the use of natural ingredients.

One of these ingredients is green tea. Green tea, rich in catechin polyphenols, especially epigallocatechin gallate, and caffeine, has been shown to increase 24-h energy expenditure and fat oxidation ${ }^{12}$. Therefore, we hypothesized that green tea would have a limiting effect on body weight regain after weight loss, probably through a thermogenic effect. The aim of the present study was to investigate whether green tea may improve weight maintenance by preventing or limiting weight regain after weight loss of 5 to $10 \%$ in overweight and moderately obese subjects.

\section{SUBJECTS AND METHODS}

\section{Subjects}

140 male and female subjects, aged between 18 and 60 years, were recruited for this study. They underwent a medical screening. Selection resulted in 120 subjects who were in good health, non-smokers, not using medication and at most moderate alcohol users $(<2$ glasses/d), with a body mass index (BMI) 
between 25 and $35 \mathrm{~kg} / \mathrm{m}^{2}$. They all gave their written informed consent. The Medical Ethics Committee of the Academic Hospital in Maastricht approved of the study. Subjects were randomized to an intensive $(n=80)$ or an extensive group $(n=40)$. The intensive group underwent all the measurements. The extensive group underwent the same measurements as the intensive group, except for resting energy expenditure, substrate oxidation and physical activity. During the first four weeks, 16 subjects dropped out, due to various reasons: moving house, changing jobs, or not being able to cope with the first diet, or to continue the schedule with visits to the University. Finally 104 subjects fulfilled in the study, i.e. 70 in the intensive group and 34 in the extensive group.

\section{Experimental design: baseline measurements}

\section{Body weight and body mass index}

Body weight was measured on a digital balance (Seca, model 707, Hamburg Germany; weighing accuracy of $0.1 \mathrm{~kg}$ ) with subjects in underwear, in the fasted state and after voiding their bladder. Height was measured using a wallmounted stadiometer (Seca, model 220, Hamburg, Germany). Body mass index was calculated as $B W /$ height ${ }^{2}\left(\mathrm{~kg} / \mathrm{m}^{2}\right)$.

\section{Body composition}

The distribution of fat was investigated by measuring the waist and hip circumferences and calculation of the waist-hip ratio (WHR). The waist circumference was measured at the site of the smallest circumference between the rib cage and the ileac crest, with the subjects in standing position. The hip circumference was measured at the site of the largest circumference between the waist and the thighs. The WHR was calculated by dividing the waist circumference by the hip circumference.

Total body water (TBW) was measured using the deuterium dilution technique ${ }^{13: 14}$. In the evening, the subjects ingested a dose of deuterium enriched water after collecting a background urine sample. After consumption of the deuterium-enriched water no more fluid and food was consumed. The following morning a urine sample from the second voiding was collected between 8:00 h and 10:00 h. Deuterium concentration in the urine samples was measured using an isotope ratio mass spectrometer (Micromass Optima, Manchester, UK). TBW was obtained by dividing the measured deuterium dilution space by 1.0413. Fat free mass (FFM) was calculated by dividing the TBW by the hydration factor 0.73 . By subtracting FFM from BW, fat mass (FM) was obtained. FM expressed as a percentage of BW is body fat percentage. 


\section{Attitude towards eating}

To determine whether attitude towards food intake changed during the experiment, a Dutch translation of the Three Factor Eating Questionnaire (TFEQ) was used ${ }^{15 ; 16}$. In addition, the Herman Polivy questionnaire $(\mathrm{HP})^{17}$ was used to determine the frequency of dieting.

Caffeine intake

Habitual caffeine intake was determined during an interview using a questionnaire specific for caffeine containing products. Subjects were asked about the type and the amount of caffeine containing products that they were normally consuming during one week.

\section{Post-absorptive appetite profile}

To determine the post-absorptive appetite profile, hunger and satiety were rated on anchored $100 \mathrm{~mm}$ Visual Analogue Scales in the morning before breakfast.

\section{Blood parameters}

A fasted blood sample of $10 \mathrm{ml}$ was taken and mixed with EDTA to prevent clotting. Plasma was obtained by centrifugation $\left(4^{\circ} \mathrm{C}, 3000 \mathrm{rpm}, 10 \mathrm{~min}\right)$, frozen in liquid nitrogen and stored at $-80^{\circ} \mathrm{C}$ until further analysis. Plasma glucose concentrations were determined using the hexokinase method (Glucose HK 125 kit, ABX diagnostics, Montpellier, France). The Wako NEFA C-kit (Wako chemicals, Neuss, Germany) was used to determine free fatty acid concentrations. Insulin concentrations were measured using the RIA-kit (Insulin RIA-100, Kabi-Pharmacia). The glycerolkinase method was used to determine glycerol concentrations (Boehringer Mannheim GmbH, Mannheim, Germany). Triglycerides were measured using the GPO-trinder kit (Sigma Diagnostics Inc., St. Louis, USA). The $\beta$-hydroxybutyrate dehydrogenase method (Sigma Diagnostics Inc., St. Louis, USA) was used to determine $\beta$-hydroxybutyrate concentrations. Leptin concentrations were measured using the human leptin RIA-kit (Linco Research Inc., St. Charles, USA).

\section{Adverse events}

Adverse events during treatment were recorded using a specified questionnaire.

\section{Resting energy expenditure and substrate oxidation}

Resting energy expenditure (REE) and substrate oxidation were measured by means of an open circuit ventilated hood system. REE was measured in the morning with subjects in a fasted state while lying supine for $30 \mathrm{~min}$. Gas analysis was performed by a paramagnetic oxygen analyzer and an infrared carbon dioxide Servomex type 500A, Crowborough Sussex, UK), similar to the 
analysis system described by Schoffelen et al. ${ }^{18}$. Calculation of REE was based upon the Weir's formulas ${ }^{19}$. Respiratory quotient $(R Q)$ was calculated as $\mathrm{CO}_{2}$ produced/ $\mathrm{O}_{2}$ consumed.

Physical activity

Physical activity level (PAL) and total energy expenditure (TEE) were determined using an uniaxial accelerometer $(C S A)^{20}$ or a tri-axial accelerometer for movement registration (Tracmor) ${ }^{21}$ during one week. Subjects were wearing the CSA or Tracmor during waking hours in a belt at the back of the waist. PAL and TEE were calculated using the following equations:

$$
\begin{array}{ll}
\mathrm{CSA}^{20}: & \mathrm{PAL}=(0.000001379 \times(\text { counts } / \text { day } \times 5))+1.113 \\
\text { Tracmor }^{21}: & \text { TEE }=-1.259+(1.552 \times \mathrm{REE})+(0.076 \times \text { counts } / \mathrm{min}) \\
& \text { PAL }=\text { TEE } / \text { REE }
\end{array}
$$

\section{Experimental design: body weight loss period}

A very low energy diet (VLED, 2.1 MJ/d) intervention was offered during four weeks; in order to let all subjects lose weight. The VLED (Modifast $\Theta_{\text {; }}$; Novartis Nutrition, Breda, the Netherlands) was supplied in three sachets daily, dissolved in water to obtain a milk shake, pudding, soup or muesli. Vegetables and fruit were allowed in addition to Modifastie. The aim was a body weight loss of at least $4 \mathrm{~kg}$. After this body weight loss period, the measurements described under baseline measurements were repeated (table 1).

\section{Experimental design: weight maintenance period}

For assessment during the weight maintenance period of 13 weeks, subjects, stratified for gender, BMI, age, cognitive restraint (factor 1, TFEQ) and resting energy expenditure, were divided into two groups. The subjects received 450 mg green tea or placebo (6 capsules/d; i.e. 2 capsules with breakfast, lunch, and dinner). The composition of the green tea capsule was analyzed by highperformance liquid chromatography and is given in table 2. Consequently, ingestion of capsules containing green tea provided daily a total of $104 \mathrm{mg}$ caffeine and $573 \mathrm{mg}$ catechins, of which $323 \mathrm{mg}$ was epigallocatechin gallate. The administration of the supplementation was double-blind. The green tea capsules and the placebo capsules were not distinguishable from each other. Finally 51 ( 36 female, 15 male) subjects participated in the 'green tea' group and 53 (42 female, 11 male) subjects participated in the placebo group. With respect to the intensive group, 33 subjects belonged to the 'green tea' group and 37 subjects to the placebo group. 


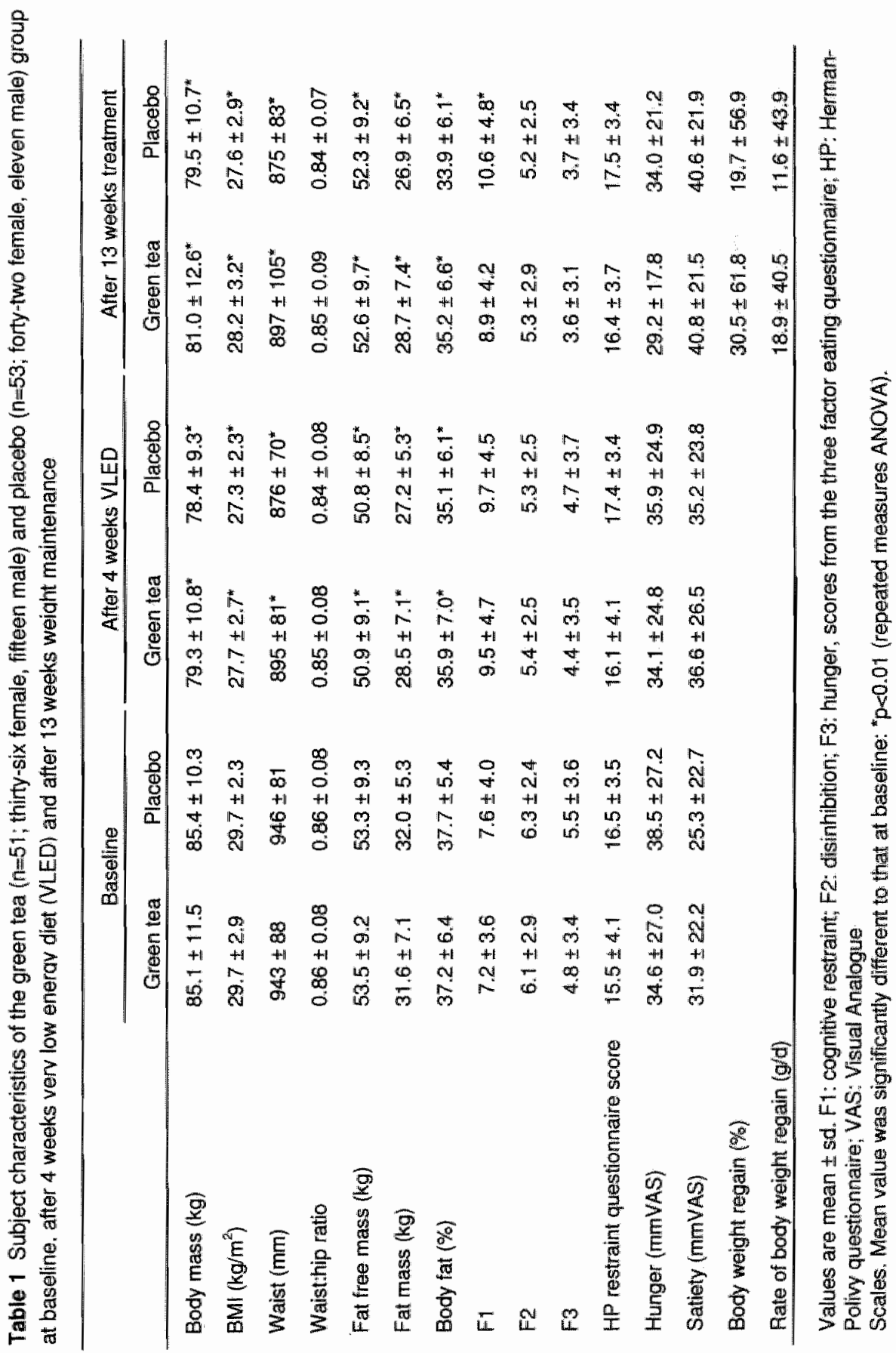


After this weight maintenance period, the measurements described under baseline measurements were repeated (table 1). In addition, body weight was determined 4 and 7 weeks after the start of the weight maintenance period.

\section{Data analysis}

Data are presented as means \pm standard deviation (SD). A two-factor repeated measures ANOVA was carried out to determine possible differences between the green tea and placebo group in all measured parameters over time. When appropriate a factorial ANOVA was used for analyzing differences between the treatment groups. Post hoc analyses were done with the Scheffe F-test. A $\mathrm{P}<0.05$ was regarded as statistically significant. Statistical procedures were performed by using Statview SE+ Graphics (Abacus Concepts, Berkeley, CA, 1988).

\section{RESULTS}

For all parameters measured, no different treatment effect was observed between men and women. Therefore data were taken together. Habitual caffeine consumption did not differ between the green tea $(369 \pm 227 \mathrm{mg} / \mathrm{d}$, range $1-991 \mathrm{mg} / \mathrm{d}, \mathrm{n}=19$ with $<300 \mathrm{mg} / \mathrm{d}$ caffeine, $\mathrm{n}=32$ with $>300 \mathrm{mg} / \mathrm{d}$ caffeine) and the placebo group (358 $\pm 190 \mathrm{mg} / \mathrm{d}$, range $39-996 \mathrm{mg} / \mathrm{d}, \mathrm{n}=19$ with $<300 \mathrm{mg} / \mathrm{d}$ caffeine, $n=32$ with $>300 \mathrm{mg} / \mathrm{d}$ caffeine).

Table 2 Composition of the green tea and placebo capsules (mg/capsule)

\begin{tabular}{|c|c|c|}
\hline & green lea & placobo \\
\hline Cafleine & 17.25 & \\
\hline Total catechins & 95.46 & \\
\hline Catechin & 1.01 & \\
\hline Epicatechin & 5.76 & \\
\hline Gallocatechin & 1.111 & \\
\hline Epigallocatechin & 3.77 & \\
\hline Catechin gallate & 0.81 & \\
\hline Eplcatechin gallate & 20.74 & \\
\hline Gallocatech in gallata & 8.45 & \\
\hline Epigallocatochin gallate & 53.81 & \\
\hline Placebo & 337.29 & 450.00 \\
\hline Total & 450.00 & 450,00 \\
\hline
\end{tabular}




\section{Body weight loss period}

During the body weight loss period subjects lost $6.4 \pm 1.9 \mathrm{~kg}$ or $7.5 \pm 2.2 \%$ of their original body weight $(p<0.01)$. This loss consisted of $4.0 \pm 6.2 \mathrm{~kg} \mathrm{FM}$ and of $2.4 \pm 2.2 \mathrm{~kg}$ FFM. Waist circumference decreased during body weight loss. Attitude towards eating did not change significantly. Also hunger and satiety in the fasted state before breakfast did not change significantly (table 1). REE decreased during body weight loss. Also RQ decreased, indicating increased fat oxidation. No significant changes were observed for PAL and TEE (table 3). Fasted plasma glucose, insulin, triacylglycerol and leptin decreased, while plasma $\beta$-hydroxybutyrate, free fatty acids and glycerol increased with body weight loss (table 4). No differences were observed between the two groups that followed different treatments during the weight maintenance period.

\section{Weight maintenance period}

During the weight maintenance period body weight regain, expressed as percentage of body weight loss, and the rate of regain were not significantly different between treatments (table 1). Body weight regain was mainly due to increased fat free mass, while fat mass almost did not change.

Cognitive restraint (factor 1 , TFEQ) increased during weight regain in the placebo group $(p<0.01)$, but not in the green tea group. However, cognitive restraint at the end of the weight maintenance period was not different between treatments. Hunger and satiety in the fasted state before breakfast did not change significantly. REE and RQ were not significantly different from baseline values at the end of the weight maintenance period (table 3). Also all fasted plasma parameters almost returned to baseline concentrations after the weight maintenance period. Post-hoc we looked whether the magnitude of habitual caffeine intake might have affected the effectiveness of green tea administration. Therefore we discriminated within the green tea group between low ( $<300 \mathrm{mg} / \mathrm{d}$ ) and high ( $>300 \mathrm{mg} / \mathrm{d}$ ) caffeine consumers. A level of $300 \mathrm{mg} / \mathrm{d}$, corresponding to 3-4 cups of coffee per day, was chosen as it corresponds approximately to the mean value of caffeine consumption in the Dutch population.

We observed higher satiety in the fasted state $(p<0.05)$ and lower plasma leptin concentration $(p<0.001)$ in the high caffeine consumers compared to the low caffeine consumers at baseline (table 5 ), but not after weight loss or weight regain. Body weight regain was higher in the high caffeine consumers compared to the low caffeine consumers $(p<0.05$; table 5$)$. Body weight regain in the low caffeine consumers was not significantly different from placebo. Habitual caffeine consumption was not related to body composition or REE. 


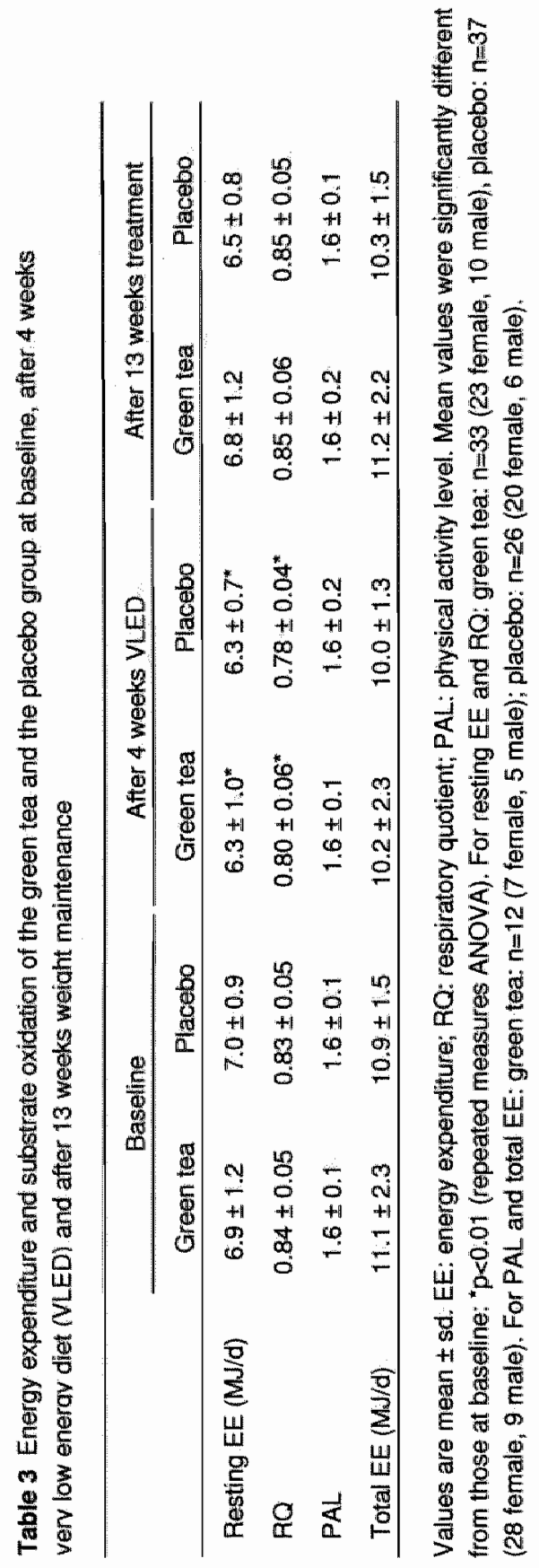




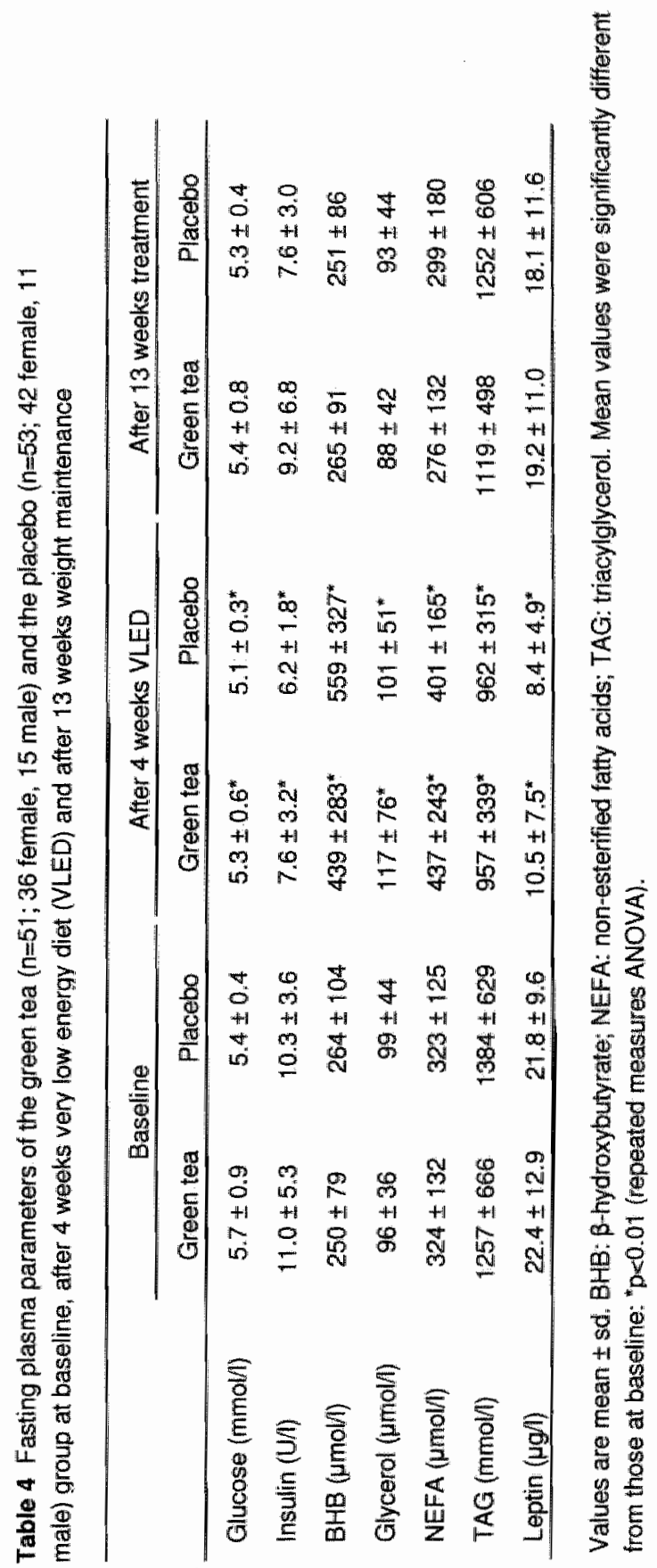


Table 5 Habitual caffeine consumption, satiety and leptin at baseline, and \%body weight regain of the green tea group divided over high $(n=32)$ and low $(n=19)$ habitual caffeine consumers

\begin{tabular}{lccl}
\hline & High caffeine consumers & Low caffeine consumers & p-value \\
\hline Caffeine consumption (mg/d) & $511 \pm 167$ & $149 \pm 90$ & $<0.0001$ \\
Baseline satiety (mmVAS) & $35 \pm 14$ & $28 \pm 8$ & $<0.05$ \\
Baseline leptin $(\mu \mathrm{g} /)$ & $18.8 \pm 9.8$ & $27.6 \pm 15.2$ & $<0.001$ \\
\%body weight regain & $39 \pm 17$ & $16 \pm 11$ & $<0.05$ \\
\hline
\end{tabular}

Values are mean $\pm \mathrm{sd}$.

\section{DISCUSSION}

The present experiment showed that green tea did not improve body weight maintenance after $7.5 \%$ body weight loss compared to placebo in originally overweight and moderately obese men and women. Moreover, no differences in metabolic and blood parameters were found between the green tea and the placebo group.

The lack of finding a positive effect of green tea on weight maintenance contradicts our hypothesis based upon the results of Dulloo et al. ${ }^{12}$. Dulloo et al. ${ }^{12}$ showed that green tea (caffeine, $150 \mathrm{mg} / \mathrm{d}$; catechins, $375 \mathrm{mg} / \mathrm{d}$ : epigallocatechin gallate: $270 \mathrm{mg} / \mathrm{d}$ ) stimulated $24 \mathrm{~h}$ energy expenditure and fat oxidation. This effect was attributed to the content of caffeine and tea catechins. Caffeine acts through inhibition of phosphodiesterase, an enzyme that degrades intracellular cyclic AMP, and through antagonism of the negative modulatory effect of adenosine on increased norepinephrine release ${ }^{22}$. Tea catechins have been shown to inhibit catechol O-methyltransferase ${ }^{23}$, the enzyme that degrades norepinephrine. Taken together, both caffeine and catechins would result in increased and/or prolonged effect of norepinephrine on energy and lipid metabolism. In this respect, Dulloo et al. ${ }^{12}$ showed that the effect of green tea on energy expenditure and fat oxidation was greater than can be attributed to its caffeine content, indicating that the action of the catechins was necessary to elicit a response of the relatively low dose of caffeine. However, Rumpler et al. ${ }^{24}$ showed that oolong tea, also rich in caffeine and catechins (caffeine, 270 $\mathrm{mg} / \mathrm{d}$; catechins, $668 \mathrm{mg} / \mathrm{d}$ : epigallocatechin gallate, $244 \mathrm{mg} / \mathrm{d}$ ), increased $24 \mathrm{~h}$ energy expenditure and fat oxidation, but its effect was solely due to its caffeine content. The discrepancy in the results of these studies and in the mechanisms behind the effect of green and oolong tea can be attributed to differences in the dose of caffeine $(150 \mathrm{mg} / \mathrm{d}$ vs. $270 \mathrm{mg} / \mathrm{d}$ ), the number of administrations ( $3 \mathrm{vs}$. 5 times), the period of administration (from breakfast until dinner vs. from 8:30 
to $14: 30 \mathrm{~h}$ ) or the way of administration (capsules vs. tea drink) in the studies of Dulloo et al. ${ }^{12}$ and Rumpler et al. ${ }^{24}$, respectively.

In the present study, we used a similar daily dose of green tea, the same number of administrations, the same time period, and the same way of administration as reported by Dulloo et $a l^{12}$. However, we did not observe the expected effect of green tea on energy expenditure and fat oxidation. This can be explained by several factors.

Dulloo et al. ${ }^{12}$ investigated the effects of green tea on the short term (24h) using a protocol, in which the subjects had to withdraw from caffeine-containing foods and beverages from $24 \mathrm{~h}$ before until the end of the experiment. Moreover, the subjects in that study were relatively low caffeine consumers $(100-200 \mathrm{mg} / \mathrm{d})$. On the contrary, the subjects in our experiment were investigated in a free-living condition, in which they had no restrictions, e.g. with respect to caffeine consumption. This means that next to the treatment, the subjects had their habitual caffeine intake, varying approximately from 0 to $1000 \mathrm{mg} / \mathrm{d}$. It is therefore likely that the magnitude of the habitual caffeine intake may have overruled the effectiveness of green tea. In this regard, the low caffeine consumers showed a stronger weight maintenance compared to the high caffeine consumers. This could possibly indicate that supplementation with green tea may only be effective when habitual caffeine intake is low and that a much higher dose is required when habitual caffeine intake is high. With respect to this, it is possible that the greater weight regain observed in the high caffeine consumers can be attributed to some saturation of the ability of green tea to further stimulate norepinephrine-related mechanisms, as both green tea and caffeine seem to produce at least part of their effect through mechanisms involving norepinephrine. Another possible explanation for failing to extrapolate the short-term findings of Dulloo et $a l^{12}$ on the long term may be habituation to green tea (or caffeine) during prolonged administration. Furthermore, the placebo group showed increased cognitive restraint eating during the weight maintenance period. This increase was not observed in the green tea group. This might explain why the placebo group showed similar effects on weight regain as the green tea group, although the green tea group was expected to result in stronger weight maintenance. In this respect, it has been previously shown that increased cognitive restraint is related to weight maintenance 11. However, we have no explanation about the increase in cognitive restraint in the placebo group as both groups underwent the same protocol and received the same instructions.

A last possible explanation for failing to confirm the findings of Dulloo et $a l^{12}$ is that in the present study the majority of the subjects consisted of women. It is possible that the impact of green tea on energy expenditure and fat oxidation is greater in men than in women. In the present study, we did not observe an 
effect of green tea when looking at men alone. However, this might also be explained by a lack of power when considering men and women apart.

Body weight regain during the weight maintenance period was mainly due to fat free mass. During rapid body weight loss, substantial amounts of glycogen and water are lost together with fat, especially during the first phase of weight loss. It is therefore possible that during body weight regain glycogen and water are recovered first, while recovery of fat occurs at a later moment.

Interestingly, high caffeine consumers had a lower plasma leptin concentration at baseline, indicating that habitual use of caffeine may reduce leptin levels. This was independent of resting energy expenditure or fat free mass, since these were not related to caffeine consumption. Also, fasted satiety at baseline was higher in the high caffeine consumers. However, it is not clear whether these differences in circulating leptin and satiety at baseline may explain the difference in weight regain observed in the high and low caffeine consumers.

We conclude that green tea did not improve weight maintenance after weight loss of $7.5 \%$ in originally overweight and moderately obese subjects. The stronger weight maintenance with green tea in the low caffeine consumers compared to the high caffeine consumers indicates that the magnitude of habitual caffeine intake may affect the effectiveness of green tea administration.

\section{ACKNOWLEDGMENTS}

We thank llse Nijs, Joan Senden, Wendy Sluijsmans and Loek Wouters for their contributions to the study. This study was supported by Novartis $\mathrm{CH}$, Consumer Health Ltd. (Nyon, Switzerland).

\section{REFERENCES}

1. Seidell JC (1995) Obesity in Europe. Obes Res 3 Suppl 2, 249s-259s.

2. Pi-Sunyer FX (1993) Medical hazards of obesity. Ann Intern Med 119, 655660.

3. Westerterp-Plantenga MS (2001) Analysis of energy density of food in relation to energy intake regulation in human subjects. $B r J$ Nutr 85,351 361.

4. Goldstein DJ (1992) Beneficial health effects of modest weight loss. Int $J$ Obes Relat Metab Disord 16, 397-415.

5. Van Gaal LF, Wauters MA, De Leeuw IH (1997) The beneficial effects of modest weight loss on cardiovascular risk factors. Int $J$ Obes Relat Metab Disord 21 Suppl 1, S5-9. 
6. Wadden TA, Stunkard Ad, Liebschutz J (1988) Three-year follow-up of the treatment of obesity by very low calorie diet, behavior therapy, and their combination. J Consult Clin Psychol 56, 925-928.

7. Kramer FM, Jeffery RW, Forster JL, Snell MK (1989) Long-term follow-up of behavioral treatment for obesity: patterns of weight regain among men and women. Int $J$ Obes 13, 123-136.

8. Pasman WJ, Westerterp-Plantenga MS, Muls E, Vansant G, van Ree J, Saris WH (1997) The effectiveness of long-term fibre supplementation on weight maintenance in weight-reduced women. Int $J$ Obes Relat Metab Disord 21, 548-555.

9. Pasman WJ, Westerterp-Plantenga MS, Saris WH (1997) The effectiveness of long-term supplementation of carbohydrate, chromium, fibre and caffeine on weight maintenance. Int $J$ Obes Relat Metab Disord 21, 1143-1151.

10. Pasman WJ, Saris WH, Muls E, Vansant G, Westerterp-Plantenga MS (1999) Effect of exercise training on long-term weight maintenance in weight- reduced men. Metabolism 48, 15-21.

11. Westerterp-Plantenga MS, Kempen KP, Saris WH (1998) Determinants of weight maintenance in women after diet-induced weight reduction. Int $J$ Obes Relat Metab Disord 22, 1-6.

12. Dulloo AG, Duret C, Rohrer D, Girardier L, Mensi N, Fathi M, Chantre $P$, Vandermander $J$ (1999) Efficacy of a green tea extract rich in catechin polyphenols and caffeine in increasing 24-h energy expenditure and fat oxidation in humans. Am J Clin Nutr 70, 1040-1045.

13. Schoeller DA, van Santen E, Peterson DW, Dietz W, Jaspan J, Klein PD (1980) Total body water measurement in humans with $18 \mathrm{O}$ and $2 \mathrm{H}$ labeled water. Am J Clin Nutr 33, 2686-2693.

14. van Marken Lichtenbelt WD, Westerterp KR, Wouters L (1994) Deuterium dilution as a method for determining total body water: effect of test protocol and sampling time. $\mathrm{Br} J$ Nutr 72, 491-497.

15. Stunkard AJ, Messick $S$ (1985) The three-factor eating questionnaire to measure dietary restraint, disinhibition and hunger. J Psychosom Res 29, $71-83$.

16. Westerterp-Plantenga MS, Rolland V, Wilson SA, Westerterp KR (1999) Satiety related to $24 \mathrm{~h}$ diet-induced thermogenesis during high protein/carbohydrate vs high fat diets measured in a respiration chamber. Eur J Clin Nutr 53, 495-502.

17. Herman CP, Polivy J (1980) Restrained eating. In Obesity, pp. 208-224 [AJ Stunkard, editor]. Philadelphia: W.B. Saunders. 
18. Schoffelen PF, Westerterp KR, Saris WH, Ten Hoor F (1997) A dualrespiration chamber system with automated calibration. J App/ Physiol 83, 2064-2072.

19. Weir JB (1949) New Methods for calculating metabolic rate with special reference to protein metabolism. Journal of Physiology 109, 1-9.

20. Ekelund U, Yngve A, Sjostrom M, Westerterp K (2000) Field evaluation of the Computer Science and Application's Inc. Activity monitor during running and skating training in adolescent athletes. Int $J$ Sports Med 21, 586-592.

21. Goris AH, Meijer EP, Kester A, Westerterp KR (2001) Use of a triaxial accelerometer to validate reported food intakes. Am J Clin Nutr 73, 549553.

22. Dulloo AG, Seydoux J, Girardier $L$ (1992) Potentiation of the thermogenic antiobesity effects of ephedrine by dietary methylxanthines: adenosine antagonism or phosphodiesterase inhibition? Metabolism 4.1, 1233-1241.

23. Borchardt RT, Huber JA (1975) Catechol O-methyltransferase. 5. Structure-activity relationships for inhibition by flavonoids. J Med Chem 18 , 120-122.

24. Rumpler $W$, Seale J, Clevidence $B$, Judd J, Wiley $E$, Yamamoto $S$, Komatsu T, Sawaki T, Ishikura $Y$, Hosoda K (2001) Oolong tea increases metabolic rate and fat oxidation in men. J Nutr 131, 2848-2852. 


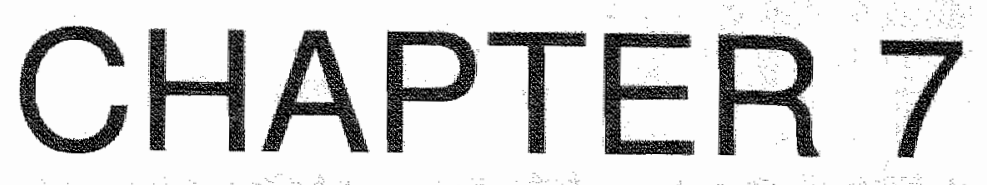

\section{Additional protein intake limits weight regain after weight loss in humans}

MPGM Lejeune, EMR Kovacs, MS Westerterp-Plantenga

$\mathrm{Br}$ I Nutr 2005; 93: 281-289 


\section{ABSTRACT}

Since long-term weight maintenance is a major problem, interventions to improve weight maintenance (WM) are needed. The aim of the study was to investigate whether addition of protein to the diet may limit weight regain after weight loss of 5 to $10 \%$ in overweight subjects. In a randomized parallel study design, 113 overweight subjects (BML: $29.3 \pm 2.5 \mathrm{~kg} / \mathrm{m}^{2}$; age: $45.1 \pm 10.4 \mathrm{yr}$ ) followed a very low energy diet (VLED) for 4 weeks after which a 6-month WM period followed. During WM subjects were randomized into either a protein group or a control group. The protein group received $30 \mathrm{~g} / \mathrm{d}$ protein in addition to their own usual diet. During VLED no differences between the groups were observed. During WM, compared to the control group, the protein group showed a higher protein intake ( $18 \%$ vs, $15 \%, p<0.05)$, a lower weight regain $(0.8$ vs. $3.0 \mathrm{~kg}, p<0.05)$, a decreased waist circumference $(-1.2 \pm 0.7$ vs. $0.5 \pm 0.5 \mathrm{~cm}$, $p<0.05)$, and a smaller increase in $R Q(0.03 \pm 0.01$ vs. $0.07 \pm 0.01, p<0.05)$. Weight regain in the protein group consisted of only fat free mass, while the control group gained fat mass as well. Satiety in the fasted state before breakfast increased significantly more in the protein group compared to the control group. After 6 months follow-up, body weight showed a significant group $x$ time interaction. A protein intake of $18 \%$ versus $15 \%$ resulted in improved WM in overweight subjects after weight loss of $7.5 \%$. This improved WM implied several factors, i.e. improved body composition, fat distribution, substrate oxidation and satiety.

Key words: substrate oxidation, weight maintenance, body composition, high protein 


\section{INTRODUCTION}

A common treatment for obesity is weight reduction. Although short term weight loss programs have been proven to be successful, long-term weight maintenance is a major problem ${ }^{1-5}$. Successful weight maintenance is of importance for lowering risk factors for cardiovascular and other diseases ${ }^{6-8}$. To improve the metabolic profile, it is not necessary to achieve the ideal body weight; a weight reduction of 5 to $10 \%$ is often sufficient to induce a clinically relevant effect ${ }^{6}$. To preserve these beneficial effects of weight reduction, improvement of long-term weight maintenance is necessary. Pasman et al. ${ }^{9}$ showed that weight regain was slower when the body composition of the weight regained consisted of a greater fat free mass due to physical activity. We hypothesize that weight regain may be limited if the inevitable increase in body weight consists of a larger fat free mass, for instance achieved by consumption of an appropriate substrate. For this we suggest an increased protein intake, because of its potential to increase fat free mass ${ }^{10}$. Furthermore, it is known that from all the macronutrients protein seems to be the most satiating. Protein consumption suppresses short-term food intake more than fats or carbohydrates, even more than is expected from its energy content alone ${ }^{11}$. Several studies showed that a high protein lunch decreased later food intake more than a lunch low in protein ${ }^{12-14}$. Westerterp-Plantenga et al. ${ }^{15}$ showed an increased satiety effect of a high protein diet despite similar energy intake. Finally, protein has also been shown to have low energy efficiency during overfeeding $^{16: 17}$, a situation that is comparable to a weight regain situation. Although the effect of dietary protein has been examined in weight loss studies $^{18-20}$, the effect of additional protein intake on weight maintenance has not been studied yet. The aim of this study was to investigate whether addition of protein to the diet may limit weight regain after a weight loss of 5 to $10 \%$ in moderately overweight subjects.

\section{SUBJECTS AND METHODS}

\section{Subjects}

140 moderately overweight male and female subjects (body mass index (BMI) between 25 and $35 \mathrm{~kg} / \mathrm{m}^{2}$, aged between 18 and 60 years) were recruited for this study by advertisements in local newspapers. They underwent a medical screening. All subjects were in good health, non-smokers, not using medication and at most moderate alcohol users. A written informed consent was obtained from all participants. The Medical Ethics Committee of the Academic Hospital in 
Maastricht approved the study. Twenty subjects did not start the study due to relocation, changing jobs, or inability to fulfill the schedule with visits to the university. Intention to treat applied for 120 subjects. During the first week 7 subjects dropped out due to difficulty maintaining the very low energy diet. They were aimed to participate in the additional protein group. Their baseline characteristics did not affect the averages of the baseline measurements of the treatment group. Thus, 113 subjects completed the study. Subject characteristics are shown in table 1.

\section{Experimental design}

After determining the subjects' baseline characteristics they were divided into two similar groups, stratified for gender, BMl, age, eating behavior (Three Factor Eating Questionnaire ${ }^{15 ; 21}$ and resting energy expenditure. Both groups followed a very low energy diet (VLED) intervention for 4 weeks, in order to initiate weight loss. After this weight loss period a weight maintenance period of 6 months followed. Subjects in both groups visited the University six times. During these visits the measurements were done as described in the Measurements section. Moreover, they were asked by a dietician how they felt, how they considered taking part in the study, and whether they had specific questions themselves. Furthermore, dietary counseling was provided upon request for all subjects. One of the groups was provided with additional protein (protein group, $n=53$ ), while the other group did not receive this additional protein (control group, $n=60$ ). Since, similar to previous meal-replacement studies $^{22-26}$, no placebo was used for this control group, we included repeated measurements of dietary restraint to check whether additional dietary protein would affect attitudes towards eating differently. After 6 months weight maintenance, the additional protein intake was stopped. Six months after weight maintenance all subjects were asked to return to the university for a follow-up measurement of body weight. For this measurement 31 subjects in the protein group and 39 subjects in the control group returned.

\section{Measurements}

The following measurements were executed to determine subject characteristics (table 1).

Body weight and body mass index

Body weight was measured on a digital balance (Seca, model 707, Hamburg Germany; weighing accuracy of $0.1 \mathrm{~kg}$ ) with subjects in underwear, in a fasted 
state and after voiding their bladder. Height was measured using a wallmounted stadiometer (Seca, model 220, Hamburg, Germany).

Body mass index was calculated as body weight height ${ }^{2}\left(\mathrm{~kg} \cdot \mathrm{m}^{-2}\right)$.

\section{Waist-hip ratio}

The distribution of fat was investigated by measuring the waist and hip circumferences, then calculating the waist-hip ratio (WHR). The waist circumference was measured at the site of the smallest circumference between the rib cage and the ileac crest, with the subjects in standing position. The hip circumference was measured at the site of the largest circumference between the waist and the thighs. The WHR was calculated by dividing the waist circumference by the hip circumference.

\section{Body composition}

Total body water (TBW) was measured using the deuterium $\left({ }^{2} \mathrm{H}_{2} \mathrm{O}\right)$ dilution technique ${ }^{27 ; 28}$. In the evening the subjects collected a background urine sample, and then ingested a dose of deuterium enriched water $\left({ }^{2} \mathrm{H}_{2} \mathrm{O}\right)$, after which they refrained from consumption of fluid and food. The following morning a urine sample from the second voiding was collected between 8:00 h and 10:00 h. Deuterium concentration in the urine samples was measured using an isotope ratio mass spectrometer (Micromass Optima, Manchester, UK). TBW was obtained by dividing the measured deuterium dilution space by 1.0427 . Fat free mass (FFM) was calculated by dividing the TBW by the constant hydration factor 0.73 , which can be used for adult subjects ${ }^{29}$. The weight loss and weight maintenance periods were long enough to establish a stable hydration of fat free mass. Fat mass (FM) was calculated by subtracting FFM from body weight. FM expressed as a percentage of total body mass is body fat percentage.

\section{Attitude towards eating}

To determine whether attitude towards food intake changed during the experiment, a Dutch translation of the Three Factor Eating Questionnaire (TFEQ) was used ${ }^{15 ; 21}$. The first factor of the TFEQ (F1) measures cognitive restrained eating: control of food intake by thought and will power. The second factor (F2) represents disinhibition: an incidental inability to resist eating cues, or inhibition of dietary restraint, and emotional eating. The third factor (F3) examines the subjective feeling of general hunger.

In addition the Herman Polivy questionnaire (HP) was used to determine the frequency of dieting ${ }^{30}$. 


\section{Post-absorptive appetite profile}

To determine the post-absorptive appetite profile, hunger and satiety were rated on anchored $100 \mathrm{~mm}$ Visual Analogue Scales (mmVAS) in the morning before breakfast.

\section{Blood parameters}

A fasting blood sample of $10 \mathrm{ml}$ was taken and mixed with EDTA to prevent clotting. Plasma was obtained by centrifugation (at $3000 \mathrm{U} / \mathrm{min}$ for 10 minutes by $-4^{\circ} \mathrm{C}$ ), frozen in liquid nitrogen and stored at $-80^{\circ} \mathrm{C}$ until further analysis. Plasma glucose concentrations were determined using the hexokinase method (Glucose HK 125 kit, ABX diagnostics, Montpellier, France). The Wako NEFA C-kit (Wako chemicals, Neuss, Germany) was used to determine free fatty acid concentrations. Insulin concentrations were measured using the RIA-kit (Insulin RIA-100, Kabi-Pharmacia). The glycerolkinase method was used to determine glycerol concentrations (Boehringer Mannheim GmbH, Mannheim "Germany). Triacylglycerol was measured using the GPO-trinder kit (Sigma Diagnostics Inc.; St. Louis, USA). The $\beta$-hydroxybutyrate dehydrogenase method (Sigma Diagnostics Inc., St. Louis, USA) was used to determine $\beta$-hydroxybutyrate concentrations. Leptin concentrations were measured using the human leptin RIA-kit (Linco Research Inc., St. Charles, USA).

\section{Adverse events}

Adverse events during treatment were recorded and the severity and outcome specified.

\section{Resting energy expenditure and substrate oxidation}

In a random subset of subjects $(n=75)$ resting energy expenditure (REE) and substrate oxidation were measured by means of an open circuit ventilated hood system. REE was measured in the morning with subjects in a fasted state whille lying supine for $30 \mathrm{~min}$. Gas analyses were performed by a paramagnetic oxygen analyzer (Servomex type 500A, Crowborough Sussex, UK) and an infrared carbon dioxide analyzer (Servomex type 500A), similar to the analysis system described by Schoffelen et al. ${ }^{31}$. Calculation of REE was based upon the Weir's formulas ${ }^{32}$. RQ was calculated as $\mathrm{CO}_{2}$ produced $/ \mathrm{O}_{2}$ consumed.

\section{Physical activity}

The same subset of subjects who underwent metabolic testing was used to measure physical activity level (PAL). PAL was determined using an uniaxial accelerometer $(\mathrm{CSA})^{33}$, or a tri-axial accelerometer for movement registration $\left(\right.$ Tracmor) ${ }^{34}$ during one week. Subjects wore the CSA or Tracmor during waking hours in a belt at waist level on the back. The different accelerometers were 
randomized over the two groups. Half of the subjects in the protein group and the control group received the CSA the other half received the Tracmor. Subjects received the same accelerometers every time.

PAL was calculated using the following equations:

$\mathrm{CSA}^{33}: \quad \mathrm{PAL}=(0.000001379 \times($ counts/day $\times 5))+1.113$

Tracmor $^{34}: \quad$ TEE $=-1.259+(1.552 \times$ REE $)+(0.076 \times$ counts $/ \mathrm{min})$ $\mathrm{PAL}=\mathrm{TEE} / \mathrm{REE}$

In which TEE is total energy expenditure (MJ/d) and REE is resting energy expenditure $(\mathrm{MJ} / \mathrm{d})$.

\section{Protein intake}

Compliance to additional protein intake was checked by taking $24 \mathrm{~h}$ urine samples after 3 months weight maintenance and analyzing these for nitrogen. Energy intake from protein was calculated from the $24 \mathrm{~h}$ nitrogen output according to the formula of Isaksson ${ }^{35}$ :

Protein intake $(\mathrm{g})=($ nitrogen output in $24 \mathrm{~h}$ urine $(\mathrm{g} / \mathrm{d})+2 \mathrm{~g}) \times 6.25$

\section{Energy intake and energy efficiency}

Energy intake (El) was calculated as TEE plus energy storage (ES). Energy storage was calculated from the composition of the energy stored. For usual energy storage of fat mass and fat free mass $30 \mathrm{MJ}$ per kilogram body weight gain was taken ${ }^{36}$ (A). If body weight gain consisted of only fat free mass while fat mass decreased, $52 \mathrm{MJ}$ per kilogram fat free mass gain ${ }^{36}$ and $30 \mathrm{MJ}$ per kilogram fat mass loss was used (B).
(A)
ES $(\mathrm{MJ} / \mathrm{d})=(\Delta$ body weight $(\mathrm{kg}) \times 30) /$ number of days
$E S(M J / d)=((\Delta F F M(\mathrm{~kg}) \times 52)-(\Delta F M(\mathrm{~kg}) \times 30)) /$ number of days

To see whether a higher percentage of energy as protein in the diet could lower the energy efficiency, which is known already as the 'Stock' hypothesis ${ }^{16 ; 17}$, we used the following equation to calculate energy efficiency:

Eeff $(\mathrm{kg} / \mathrm{MJ})=$ body weight regain $(\mathrm{kg}) /(\mathrm{El}(\mathrm{MJ} / \mathrm{d}) \times$ number of days $)$

\section{VLED period}

The VLED provided $2.1 \mathrm{MJ} / \mathrm{d}$ (En\% carbohydrate/protein/fat: 42/44/14) (Modifast $(\Theta$, Novartis Nutrition, Breda, The Netherlands) and was supplied in three sachets daily that were dissolved in water to obtain a milk shake, pudding, soup or muesli. Vegetables and fruit were allowed in addition to Modifast. The aim was a body weight loss of at least $4 \mathrm{~kg}$ over 4 weeks. 


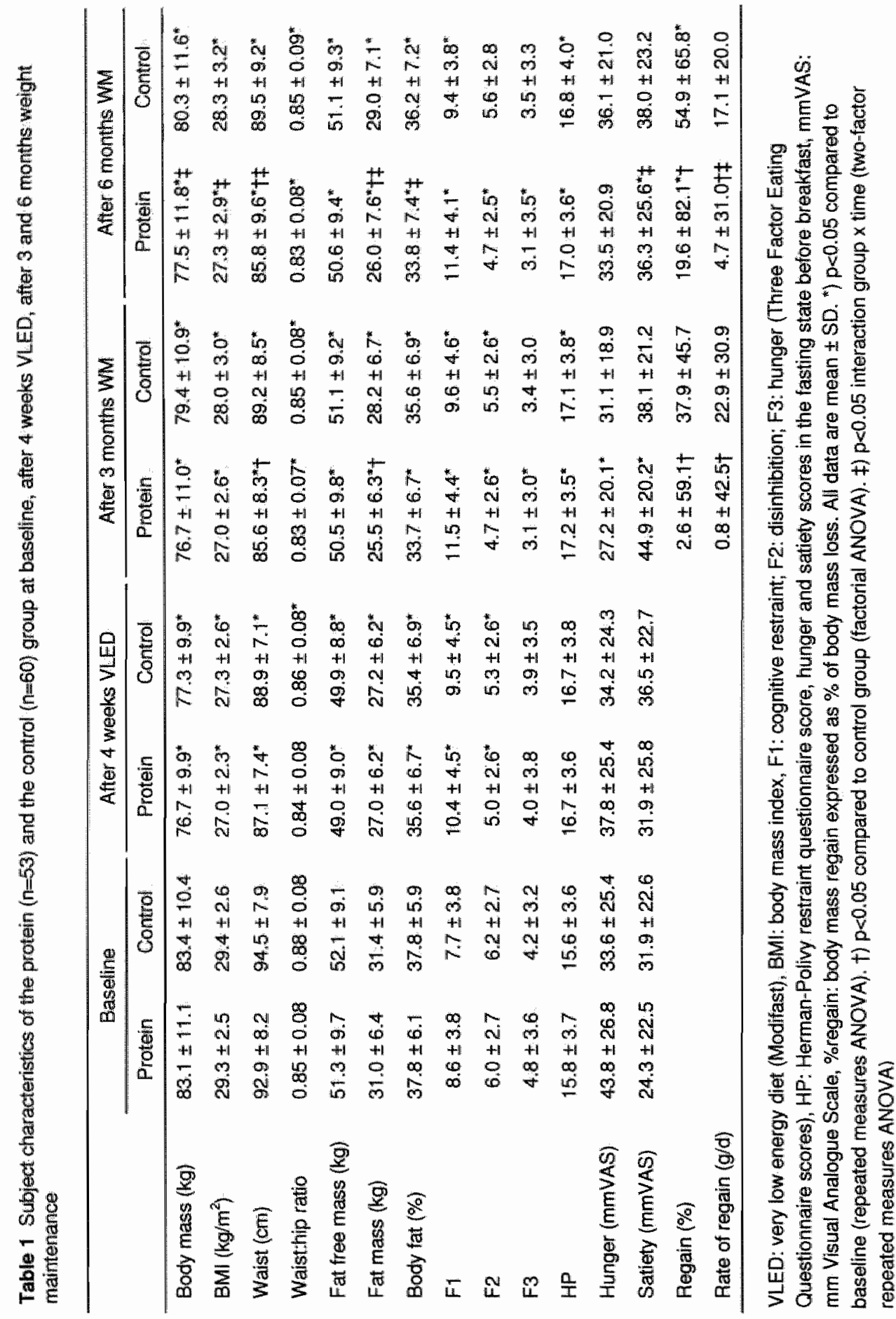




\section{Weight maintenance period}

After the VLED period, the weight maintenance period started in which all subjects were allowed to eat their habitual diet again. During the weight maintenance phase the subjects in the protein group received $30 \mathrm{~g}$ additional protein per day. This was provided as a sachet of pure protein (protein source Ca-caseinate, $1.4 \%$ calcium) per day to be dissolved in water resulting in a vanilla-drink. The protein drink contained no carbohydrate or fat. Subjects were required to consume the protein drink at lunch or in the afternoon. This way we aimed at an energy intake comprised of 18-20 percent protein per day, depending on the subject's usual protein intake.

\section{Data analysis}

Data are presented as means \pm standard deviation (SD). A two-factor repeated measures ANOVA was carried out to determine possible differences between the protein and control group in all measured parameters over time. When appropriate a factorial ANOVA was used for analyzing differences between the two groups. Post hoc analyses were done with the Scheffe F-test. A P value $<0.05$ was regarded as statistically significant. Statistical procedures were performed by using Statview SE+ Graphics (Abacus Concepts, Berkeley, CA, 1988).

\section{RESULTS}

No different effects for men or women were observed. Therefore data from both genders were analyzed together. No adverse events occurred. Subjects reported continuously to feel positive about taking part in the study. They confirmed that ample attention was given to their questions.

\section{VLED period}

During the VLED period the changes described below occurred, which did not differ between the subsequent protein and control group (table 1). Subjects lost a significant amount of body weight, i.e. $6.3 \pm 2.0 \mathrm{~kg}$ (SD), or $7.5 \pm 2.0 \%$ (SD) of their original body weight $(p<0.0001)$. The mean change in body weight for both groups over time is shown in figure 1. This consisted of $4.0 \pm 1.7 \mathrm{~kg} \mathrm{FM}$ and 2.3 $\pm 1.7 \mathrm{~kg}$ FFM. Waist circumference was also significantly reduced over time. Attitude towards eating showed some significant changes over time (table 1). Cognitive restraint (factor 1, TFEQ) increased significantly, disinhibition (factor 
2, TFEQ) and general hunger scores (factor 3, TFEQ) decreased during weight loss (table 1). REE and RQ decreased during weight loss (table 2). TEE decreased in both groups, but only reached significance in the control group. Fasting blood glucose, insulin, triacylglycerol and leptin showed a significant decrease with weight loss, and $\beta$-hydroxy butyrate, glycerol and free fatty acids showed a significant increase with weight loss (table 3 ).

\section{Weight maintenance period}

Compliance to the additional protein was shown by a higher amount of nitrogen in $24 \mathrm{~h}$ urine in the protein group compared to the control group $(14.3 \pm 3.5 \mathrm{~g} / \mathrm{d}$ vs. $11.2 \pm 3.5 \mathrm{~g} / \mathrm{d}, \mathrm{p}<0.05)$. The protein intake in the protein group was $101.7 \pm$ $22.2 \mathrm{~g} / \mathrm{d}$, which was significantly higher than the $82.7 \pm 22.0 \mathrm{~g} / \mathrm{d}$ in the control group $(p<0.05)$. When expressed as percentage energy intake from protein, significant differences persisted, with $18 \%$ in the protein group, and $15 \%$ in the control group $(p<0.05)$.

During weight maintenance, percentage body weight regain, as well as rate of regain was significantly lower in the protein group compared to the control group (table 1, figure 2). The net percentage body mass lost after the weight maintenance period compared to baseline was significantly higher in the protein group compared to the control group $(6.7 \pm 7.2 \%$ vs. $3.8 \pm 4.8 \%, p<0.05)$. The protein group showed a decrease in waist circumference during weight maintenance, whereas the control group showed an increase $(-1.2 \pm 0.7 \mathrm{~cm}$ vs. $0.5 \pm 0.5 \mathrm{~cm} ; \mathrm{p}<0.05)$. FFM stayed significantly lower during weight maintenance compared to baseline in both groups. FM in the protein group continued to decrease during weight maintenance, while FM increased in the control group $(-0.9 \pm 0.7 \mathrm{~kg}$ vs. $1.7 \pm 0.4 \mathrm{~kg} ; \mathrm{p}<0.005$ ) (figure $3 \mathrm{a}$ and $3 \mathrm{~b}$ ). Cognitive restraint scores stayed significantly higher during weight maintenance compared to baseline in both groups. No differences were seen in the change in cognitive restraint during the study between the groups. Disinhibition stayed significantly lower in both groups and general hunger decreased in both groups. Satiety in the fasted state before breakfast increased significantly during weight maintenance in the protein group, but not in the control group (table 1). The increase in satiety was significantly higher in the protein group compared to the control group. The hunger scores in the fasted state before breakfast did not change over time in both groups.

REE returned to almost baseline values in both groups during weight maintenance (table 2). To assess possible differences in REE adjusted for FFM between groups, we analyzed the residuals of the regression of REE on FFM. The residual analysis showed no significant group $x$ time interaction. The increase in $R Q$ during weight maintenance was significantly smaller in the 
protein group compared with the control group (0.03 \pm 0.01 vs. $0.07 \pm 0.01$, $\mathrm{p}<0.05$ ), indicating a smaller decrease in fat oxidation in the protein group than in the control group. The increase in $R Q$ was not related to weight regain $(p>0.05)$. No changes in PAL were seen over time and between groups (table 2). A trend for a lower energy efficiency of the protein group compared to the control group was found after 6 months weight maintenance $(3.0 \times 10-4 \pm 0.003$ $\mathrm{kg} / \mathrm{MJ}$ vs. $0.001 \pm 0.002 \mathrm{~kg} / \mathrm{MJ}, \mathrm{p}=0.12$ ).

Leptin concentrations stayed significantly lower after treatment compared to baseline in the protein group (table 3). Glucose concentrations stayed significantly lower after treatment compared to baseline in the control group. Insulin concentrations stayed significantly lower after treatment compared to baseline in both groups. B-hydroxybutyrate, glycerol and free fatty acid concentrations returned to almost baseline values during weight regain (table 3). Triacylglycerol concentrations during weight maintenance were significantly lower in the protein group compared to the control group.

The change in body weight of the subset of subjects (protein: $n=31$; control: $\mathrm{n}=39$ ) who were also measured after 6 months follow-up is shown in figure 4 . The analysis of the follow-up measurement of body weight showed a significant group $\mathrm{x}$ time interaction.

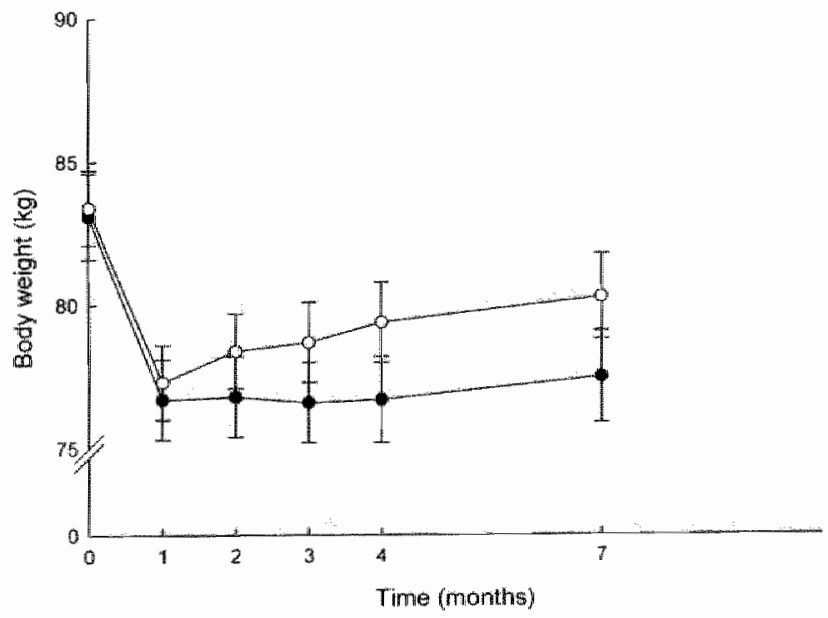

Figure 1 The change in body weight over time for the protein group $(\cdot)(n=53)$ and the control group (o) $(n=60)$. Values are means with standard errors of the mean shown by vertical bars. 


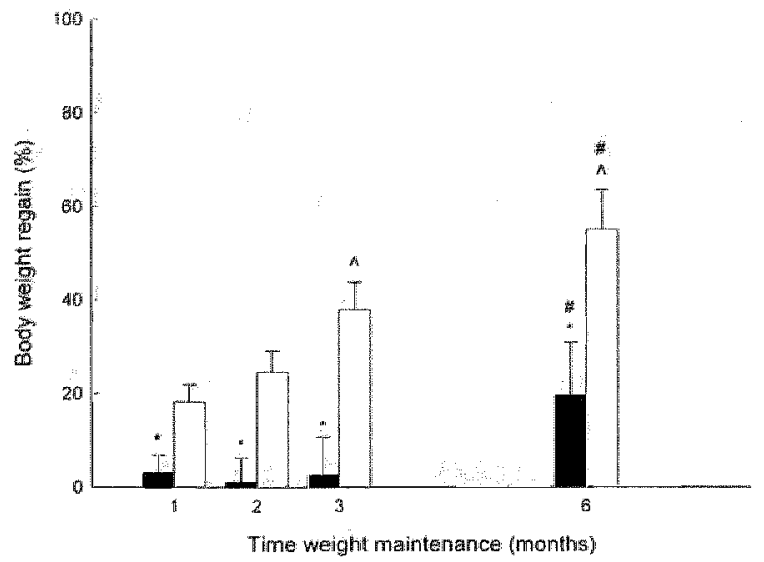

Figure 2 The weight regain during weight maintenance (expressed as percentage of the weight loss) for the protein $(a)(n=53)$ and the control group $(i)(n=60)$. Values are means with standard errors of the mean shown by vertical bars. " $p<0.05$ compared to control group, ${ }^{\wedge} p<0.05$ compared to 1 month weight maintenance, $\# p<0.05$ compared to 2 months weight maintenance.

(a)

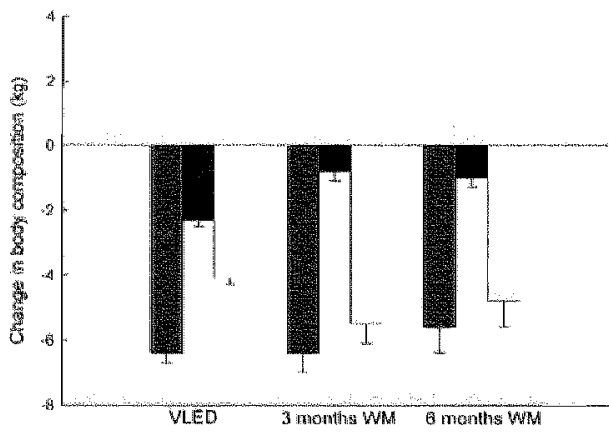

(b)

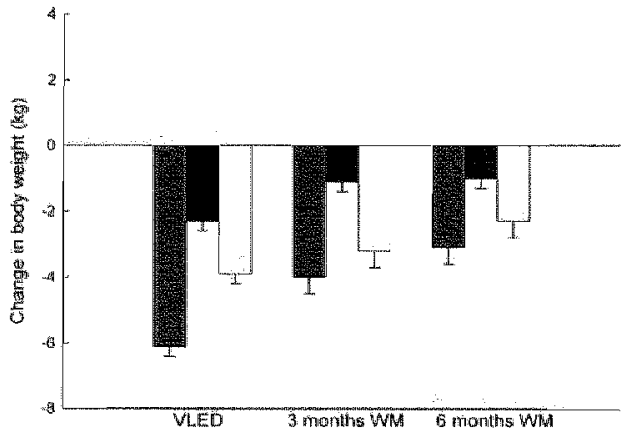

Figure 3 The changes in body weight, fat free mass and fat mass for the protein group (a) (n=53) and the control group (b) $(n=60)$ during the studly compared to baseline. Values are means with standard errors of the mean shown by vertical bars. VLED: change after the very low energy diet period 3 months WM: change after 3 months weight maintenance, 6 months WM: change after 6 months weight maintenance. $\Delta$ body weight: $\square \Delta$ fat free mass; $\square \Delta$ fat mass. 


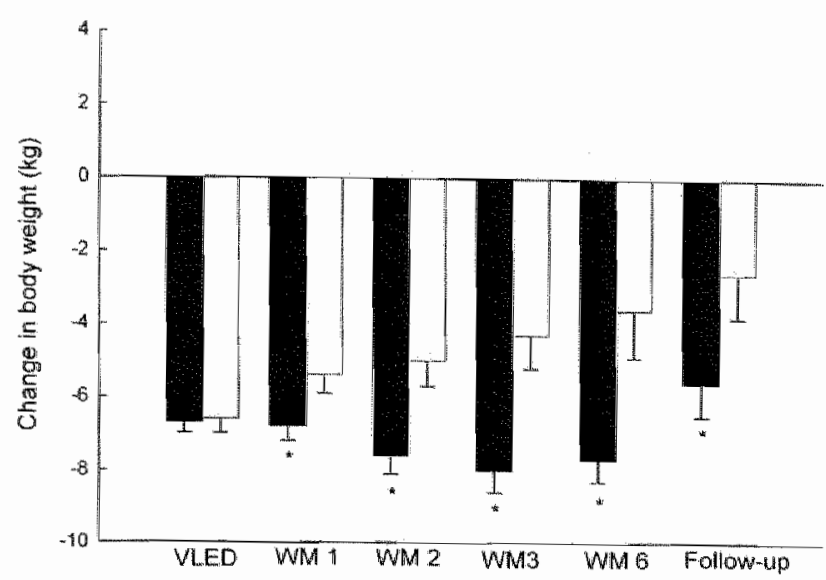

Figure 4 The change in body weight for the subjects with follow-up in the protein group (m) (m=31) and the control group (c) $(n=39)$ during the study compared to baseline. Values are means with standard errors of the mean shown by vertical bars.

" $\mathrm{p}<0.05$ compared to the control group. VLED: change after the very low energy diet period, WM 1: change after 1 month weight maintenance, WM 2: change after 2 months weight maintenance, WM 3. change after 3 months weight maintenance, WM 6: change after 6 months weight maintenance, Follow-up: change after 6 months follow-up.

\section{DISCUSSION}

In the present study, we investigated whether addition of protein to the diet may limit weight regain after a weight loss of 5 to $10 \%$ in moderately overweight men and women. The results show that subjects who consumed $18 \%$ of energy intake as protein regained less weight during 6 months weight maintenance, i.e. $0.8 \mathrm{~kg}$, compared to the subjects who consumed $15 \%$ of energy intake as protein, i.e. $3.0 \mathrm{~kg}$. This was independent of changes in cognitive restraint, physical activity, resting energy expenditure, total energy expenditure and hunger scores since these parameters did not differ between groups.

The composition of the body mass regained was different for the protein and the control group. The body mass regained in the protein group consisted only of fat free mass, whereas the fat mass still decreased during weight maintenance which resulted in a lower percentage body fat. In the control group the composition of the body mass regain was fat mass as well as fat free mass. The observation that body mass regain consisting only of fat free mass results in a slower weight regain, is in line with our hypothesis that when the composition of the weight regained consists of a greater fat free mass the inevitable increase in body mass will be slower. 


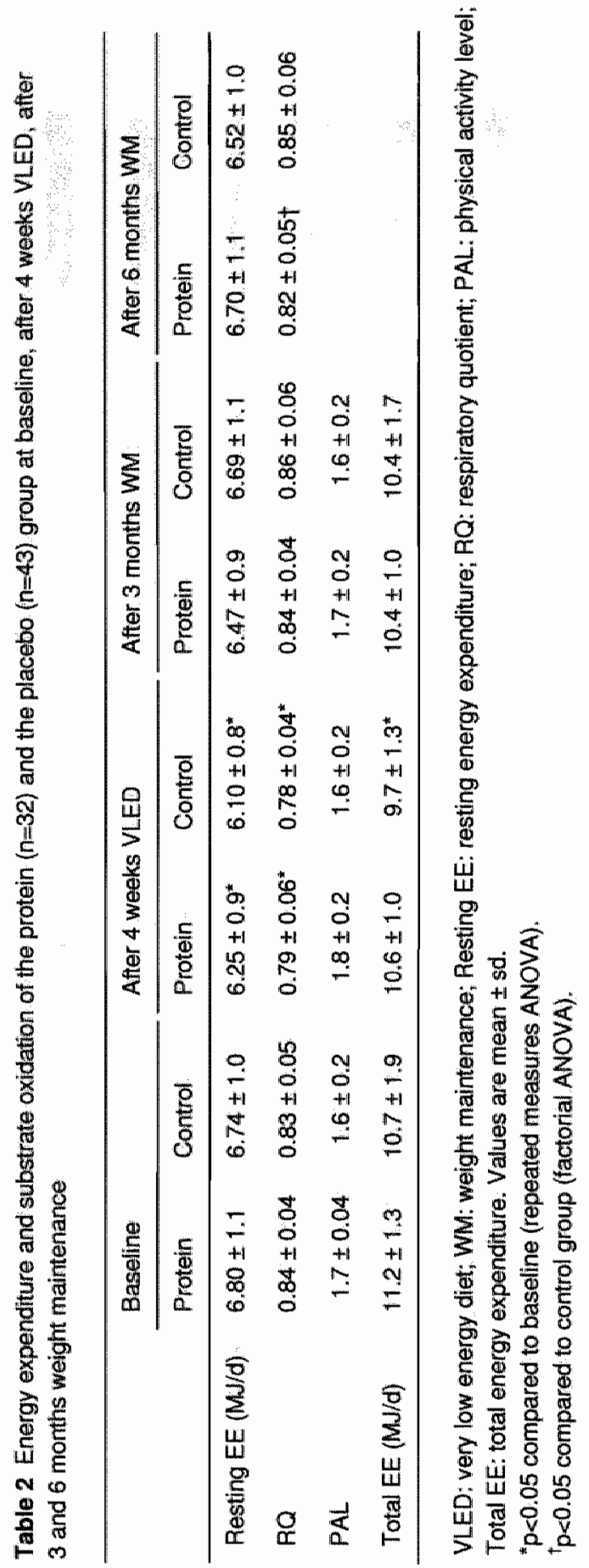




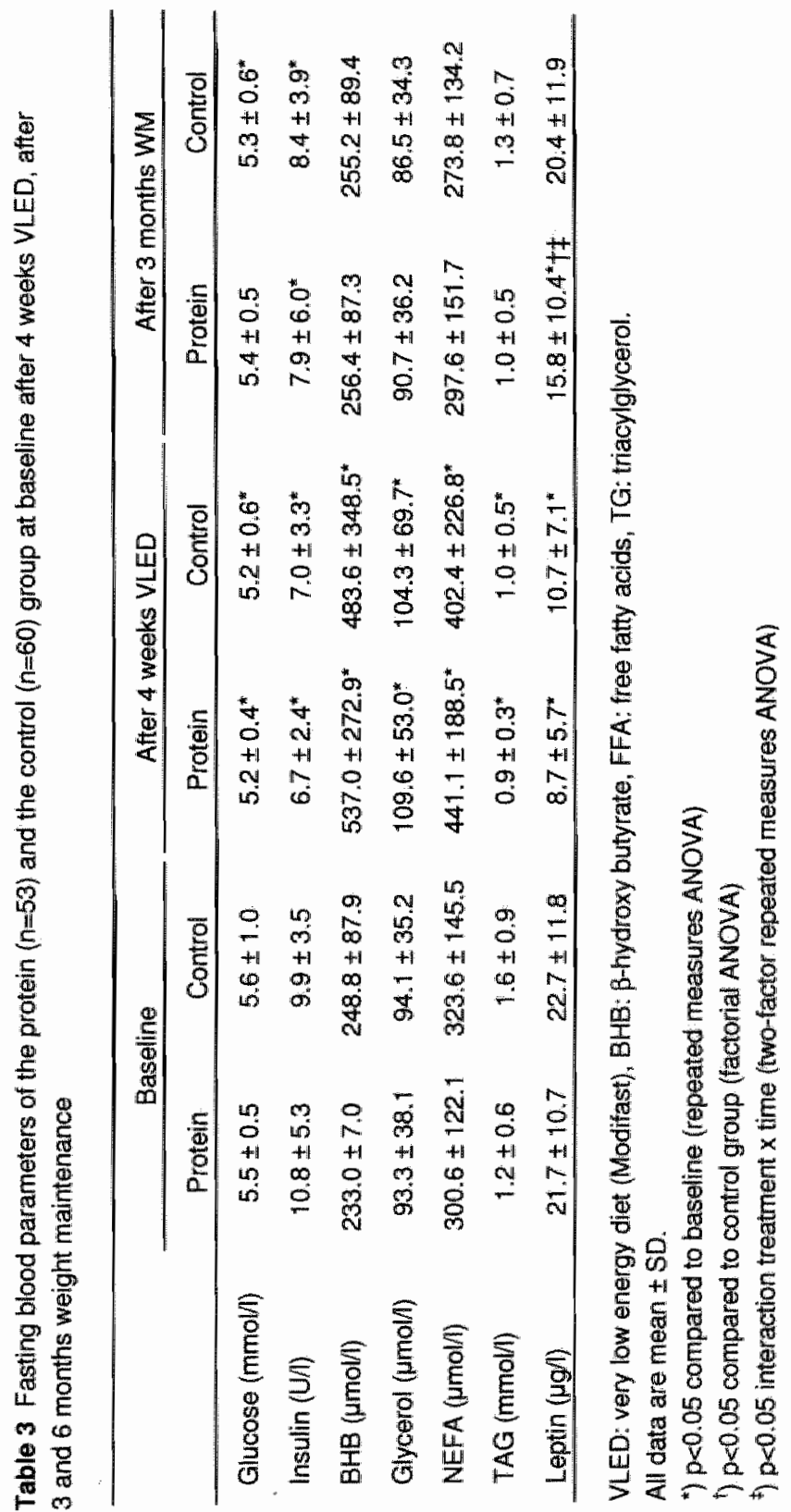


However, here we have shown that this was due to increased protein intake without a change in physical activity, whereas in the study of Pasman et al. ${ }^{9}$ the cause appeared to be increased physical activity.

In addition to a beneficial effect of dietary protein during weight loss ${ }^{18-20 ; 37}$, protein also appears to support weight maintenance. Although subjects were asked to consume $30 \mathrm{~g} / \mathrm{d}$ of protein in addition to their usual diet, the analysis of the results showed a mean difference of $19 \mathrm{~g} / \mathrm{d}$ between the protein and control group. This could imply that subjects in the protein group replaced part of their usual protein intake by the protein that was provided to them. Since this was a study under free-living conditions, the carbohydrate and fat content of the weight maintenance diet remains unknown.

With respect to satiety, we found a greater increase in post-absorptive satiety in the protein group during weight maintenance although their energy intake did not differ significantly from the control group. Short term differences in digestion, absorption and energy expenditure between different protein sources have been shown ${ }^{38 ;}$;9. Boirie et $a l^{38}$ introduced the concept of 'fast' and "slow' proteins, based upon the differences in digestion and absorption of these proteins. These short term effects may be related to increases in concentrations of gut hormones, such as GLP-1 ${ }^{40-42}$ and $\mathrm{CCK}^{43-45}$. However, this probably does not apply to post-absorptive satiety. Animal protein has been shown to introduce a higher energy expenditure ${ }^{39}$, and in the longer term, the higher postabsorptive satiety and thermogenesis were sustained with high protein diets consisting of a variety of proteins from different sources ${ }^{15 ; 17 ; 19 ; 46}$. Moreover, a relationship between satiety and thermogenesis has been shown ${ }^{15 ; 47}$ with using high protein diets. Therefore we suggest that the higher post-absorptive satiety is due to increased thermogenesis.

The observation that the increase in resting energy expenditure as a function of fat free mass during weight maintenance did not differ significantly might be due to the lack of a significant difference in the increase of fat free mass.

The slower increase in RQ in the protein group reflects a more favorable body composition.

Although the treatment with respect to number of visits, measurements, and attention was identical in both groups, there was no placebo used for the additional protein, similar to previous meal-replacement studies ${ }^{22-26}$. The issue of the placebo is a difficult one. It would be possible to exchange the protein drink with a carbohydrate or fat drink, but then one needs a more complete study which also addresses the specific carbohydrate and fat effect. This was beyond the scope of the present study. However, we checked whether the results in both groups could be differently related to changes in eating behavior. The increase in cognitive restraint during the study did not differ between the protein and control group. So, this cannot explain the limited body weight regain 
during weight maintenance in the protein group compared to the control group. It shows that without a difference in increase in cognitive restraint, the protein group maintained the weight loss better.

Since reporting of food intake in humans cannot be expected to be completely reliable because of reasons of privacy ${ }^{48}$ and thus often leads to incorrect conclusions $^{49-5 t}$, we chose to calculate energy intake from energy expenditure and energy storage. The calculated energy intake was not significantly different between both groups and can therefore not explain the difference in body weight regain.

Zemel et $a l^{52}$ showed that a low calcium intake $(400 \mathrm{mg} / \mathrm{d})$ leads to a smaller body weight loss compared to a high calcium intake. Since the average calcium intake in the Dutch population is already rather high $(800-1600 \mathrm{mg} / \mathrm{d})^{53}$, the additional calcium intake in the protein group $(420 \mathrm{mg} / \mathrm{d})$ could have contributed to the difference in body weight regain in the present study, yet is unlikely to explain it completely.

The analysis of the follow-up measurement of body weight showed a significant difference between both groups after 3 and 6 months weight maintenance. The change in body weight over time in the control group appeared to continue as during the first 6 months, while the body weight over time in the protein group appeared to be maintained. Unfortunately, body composition was not determined during follow-up. This needs to be repeated, to be able to indicate whether body composition is still a main factor in determining the difference in weight maintenance between the groups. With respect to metabolic syndrome risk factors, weight maintenance as well as waist circumference was more favorable in the protein group than in the control group.

In conclusion, a protein intake of $18 \%$ versus $15 \%$ resulted in improved weight maintenance during 6 to 12 months in moderately overweight subjects after a weight loss of $7.5 \%$. This improved weight maintenance implied several factors, i.e. improved body composition, fat distribution, substrate oxidation and satiety. The result suggests that improved weight maintenance is possible when it is supported multi-factorially.

\section{ACKNOWLEDGMENTS}

We thank Ilse Nijs, Joan Senden, Wendy Sluijsmans and Loek Wouters for their contributions to the study. This study was supported by Novartis $\mathrm{CH}$, Consumer Health Ltd. (Nyon, Switzerland). 


\section{REFERENCES}

1. Kramer FM, Jeffery RW, Forster JL, Snell MK (1989) Long-term follow-up of behavioral treatment for obesity: patterns of weight regain among men and women. Int J Obes 13, 123-136.

2. Wadden TA, Foster GD, Letizia KA (1994) One-year behavioral treatment of obesity: comparison of moderate and severe caloric restriction and the effects of weight maintenance therapy. $J$ Consult Clin Psychol 62, 165-171.

3. Pasman WJ; Westerterp-Plantenga MS, Muls E, Vansant G, van Ree J, Saris WH (1997) The effectiveness of long-term fibre supplementation on weight maintenance in weight-reduced women. Int $J$ Obes Relat Metab Disord 21, 548-555.

4. Pasman WJ, Westerterp-Plantenga MS, Saris WH (1997) The effectiveness of long-term supplementation of carbohydrate, chromium, fibre and caffeine on weight maintenance. Int $J$ Obes Relat Metab Disord 21, 1143-1151.

5. Westerterp-Plantenga MS, Kempen KP, Saris WH (1998) Determinants of weight maintenance in women after diet-induced weight reduction. Int $J$ Obes Relat Metab Disord 22, 1-6.

6. Goldstein DJ (1992) Beneficial health effects of modest weight loss. Int $J$ Obes Relat Metab Disord 16, 397-415.

7. Wing RR, Jeffery RW, Burton LR, Thorson C, Kuller LH, Folsom AR (1992) Change in waist-hip ratio with weight loss and its association with change in cardiovascular risk factors. Am J Clin Nutr 55, 1086-1092.

8. Van Gaal LF, Wauters MA, De Leeuw IH (1997) The beneficial effects of modest weight loss on cardiovascular risk factors. Int $J$ Obes Relat Metab Disord 21 Suppl 1, S5-9.

9. Pasman WJ, Saris WH, Muls E, Vansant G, Westerterp-Plantenga MS (1999) Effect of exercise training on long-term weight maintenance in weight- reduced men. Metabolism 48, 15-21.

10. Jean $\mathrm{C}$, Rome $\mathrm{S}$, Mathe $\mathrm{V}$, Huneau JF, Aattouri $\mathrm{N}$, Fromentin $\mathrm{G}$, Achagiotis $\mathrm{CL}$, Tome D (2001) Metabolic evidence for adaptation to a high protein diet in rats. $J$ Nutr 131, 91-98.

11. Anderson GH (1994) Regulation of food intake. In Modern nutrition in health and disease, pp. 524-536 [M Shils, J Olson, M Shike, editors]. Malvern: Lea and Febiger.

12. Booth DA, Chase A, Campbell AT (1970) Relative effectiveness of protein in the late stages of appetite suppression in man. Physiol Behav 5, 12991302.

13. Barkeling B, Rossner S, Bjorvell H (1990) Effects of a high-protein meal (meat) and a high-carbohydrate meal (vegetarian) on satiety measured by 
automated computerized monitoring of subsequent food intake, motivation to eat and food preferences. Int J Obes 14, 743-751.

14. Latner JD, Schwartz M (1999) The effects of a high-carbohydrate, highprotein or balanced lunch upon later food intake and hunger ratings. Appetite 33, 119-128.

15. Westerterp-Plantenga MS, Rolland V, Wilson SA, Westerterp KR (1999) Satiety related to $24 \mathrm{~h}$ diet-induced thermogenesis during high protein/carbohydrate vs high fat diets measured in a respiration chamber. Eur J Clin Nutr 53, 495-502.

16. Stock MJ (1999) Gluttony and thermogenesis revisited. Int $J$ Obes Relat Metab Disord 23, 1105-1117.

17. Dulloo $A G$, Jacquet $J$ (1999) Low-protein overfeeding: a tool to unmask susceptibility to obesity in humans. Int $J$ Obes Relat Metab Disord 23, 1118-1121.

18. Skov AR, Toubro S, Ronn B, Holm L, Astrup A (1999) Randomized trial on protein vs carbohydrate in ad libitum fat reduced diet for the treatment of obesity. Int J Obes Relat Metab Disord 23, 528-536.

19. Dumesnil JG, Turgeon J, Tremblay A, Poirier P, Gilbert M, Gagnon L, StPierre S, Garneau C, Lemieux I, Pascot A, Bergeron J, Despres JP (2001) Effect of a low-glycaemic index--low-fat--high protein diet on the atherogenic metabolic risk profile of abdominally obese men. Br J Nutr 86 , 557-568.

20. Layman DK, Boileau RA, Erickson DJ, Painter JE, Shiue $H$, Sather C, Christou DD (2003) A reduced ratio of dietary carbohydrate to protein improves body composition and blood lipid profiles during weight loss in adult women. $J$ Nutr 133, 411-417.

21. Stunkard AJ, Messick S (1985) The three-factor eating questionnaire to measure dietary restraint, disinhibition and hunger. I Psychosom Res 29, $71-83$.

22. Ditschuneit HH, Flechtner-Mors M, Johnson TD, Adler G (1999) Metabolic and weight-loss effects of a long-term dietary intervention in obese patients. Am J Clin Nutr 69, 198-204.

23. Flechtner-Mors $M$, Ditschuneit $H H$, Johnson TD, Suchard MA, Adler G (2000) Metabolic and weight loss effects of long-term dietary intervention in obese patients: four-year results. Obes Res 8, 399-402.

24. Rothacker DQ (2000) Five-year self-management of weight using meal replacements: comparison with matched controls in rural Wisconsin. Nutrition 16, 344-348.

25. Ashley JM, St Jeor ST, Perumean-Chaney S, Schrage J, Bovee V (2001) Meal replacements in weight intervention. Obes Res 9 Suppl 4, 312S$320 \mathrm{~S}$. 
26. Allison DB, Gadbury G, Schwartz LG, Murugesan R, Kraker JL, Heshka S, Fontaine KR, Heymsfield SB (2003) A novel soy-based meal replacement formula for weight loss among obese individuals: a randomized controlled clinical trial. Eur J Clin Nutr 57, 514-522.

27. Schoeller DA, van Santen E, Peterson DW, Dietz W, Jaspan J, Klein PD (1980) Total body water measurement in humans with 180 and $2 \mathrm{H}$ labeled water. Am J Clin Nutr 33, 2686-2693.

28. van Marken Lichtenbelt WD, Westerterp KR, Wouters L (1994) Deuterium dilution as a method for determining total body water: effect of test protocol and sampling time. Br J Nutr 72, 491-497.

29. Schoeller DA (1996) Hydrometry. In Human Body Composition, pp. 25-43 [AF Roche, SB Heymsfield, TG Lohmans, editors]. Champaign, USA: Braun-Brumfield.

30. Herman CP, Polivy $J(1980)$ Restrained eating. In Obesity, pp. 208-224 [AJ Stunkard, editor]. Philadelphia: W.B. Saunders.

31. Schoffelen PF, Westerterp KR, Saris WH, Ten Hoor F (1997) A dualrespiration chamber system with automated calibration. J Appl Physiol 83, 2064-2072.

32. Weir JB (1949) New Methods for calculating metabolic rate with special reference to protein metabolism. Journal of Physiology 109, 1-9.

33. Ekelund U, Yngve A, Sjostrom M, Westerterp K (2000) Field evaluation of the Computer Science and Application's Inc. Activity monitor during running and skating training in adolescent athletes. Int $J$ Sports Med 21, 586-592.

34. Goris AH, Meijer EP, Kester A, Westerterp KR (2001) Use of a triaxial acceierometer to validate reported food intakes. Am J Clin Nutr 73, 549553.

35. Isaksson B (1980) Urinary nitrogen output as a validity test in dietary surveys. Am J Clin Nutr 33, 4-5.

36. Pullar JD, Webster AJ (1977) The energy cost of fat and protein deposition in the rat. Br I Nutr 37, 355-363.

37. Astrup A (2001) Healthy lifestyles in Europe: prevention of obesity and type Il diabetes by diet and physical activity. Public Health Nutr 4, 499-515.

38. Boirie $Y$, Dangin $M$, Gachon $P$, Vasson MP, Maubois $\mathrm{JL}$, Beaufrere $B$ (1997) Slow and fast dietary proteins differently modulate postprandial protein accretion. Proc Natl Acad Sci U S A 94, 14930-14935.

39. Mikkelsen $\mathrm{PB}$, Toubro $\mathrm{S}$, Astrup $\mathrm{A}(2000)$ Effect of fat-reduced diets on 24$\mathrm{h}$ energy expenditure: comparisons between animal protein, vegetable protein, and carbohydrate. Am J Clin Nutr 72, 1135-1141. 
40. Flint As Raben A, Astrup A, Holst JJ (1998) Glucagon-like peptide 1 promotes satiety and suppresses energy intake in humans. $J$ Clin Invest $101,515-520$.

41. Gutzwiller JP, Drewe J, Goke B, Schmidt H, Rohrer B, Lareida J, Beglinger C (1999) Glucagon-like peptide-1 promotes satiety and reduces food intake in patients with diabetes mellitus type 2. Am J Physiol 276, R1541-1544.

42. Naslund $E$, Barkeling $B$, King $N$, Gutniak $M$, Blundell JE, Holst $\mathrm{JJ}$, Rossner S, Hellstrom PM (1999) Energy intake and appetite are suppressed by glucagon-like peptide-1 (GLP-1) in obese men. Int $J$ Obes Relat Metab Disord 23, 304-311.

43. Schick RR, Schusdziarra V, Mossner J, Neuberger J, Schroder B, Segmuller R, Maier V, Classen M (1991) Effect of CCK on food intake in man: physiological or pharmacological effect? Z Gastroenterol 29, 53-58.

44. Burton-Freeman B, Davis PA, Schneeman BO (2002) Plasma cholecystokinin is associated with subjective measures of satiety in women. Am J Clin Nutr 76, 659-667.

45. Kissileff HR, Carretta JC, Geliebter A, Pi-Sunyer FX (2003) Cholecystokinin and stomach distension combine to reduce food intake in humans. Am J Physiol Regul Integr Comp Physiol 285, R992-998.

46. Westerterp-Plantenga MS, Lejeune MP, Nijs I, van Ooijen M, Kovacs EM (2004) High protein intake sustains weight maintenance after body weight loss in humans. Int $J$ Obes Relat Metab Disord 28, 57-64.

47. Crovetti $R$, Porrini M, Santangelo A, Testolin G (1998) The influence of thermic effect of food on satiety. Eur J Clin Nutr 52, 482-488.

48. Blundell JE (2000) What foods do people habitually eat? A dilemma for nutrition, an enigma for psychology. Am J Clin Nutr 71, 3-5.

49. Goris AH, Westerterp KR (1999) Underreporting of habitual food intake is explained by undereating in highly motivated lean women. I Nutr 129, 878882.

50. Goris $\mathrm{AH}$, Westerterp KR (2000) Improved reporting of habitual food intake after confrontation with earlier results on food reporting. Br J Nutr 83, 363369.

51. Goris AH, Westerterp-Plantenga MS, Westerterp KR (2000) Undereating and underrecording of habitual food intake in obese men: selective underreporting of fat intake. Am J Clin Nutr 71, 130-134.

52. Zemel MB (2003) Mechanisms of dairy modulation of adiposity. I Nutr 133, 252S-256S.

53. Hulshof KF, Brussaard JH, Kruizinga AG, Telman J, Lowik MR (2003) Socio-economic status, dietary intake and 10 y trends: the Dutch National Food Consumption Survey. Eur J Clin Nutr 57, 128-137. 


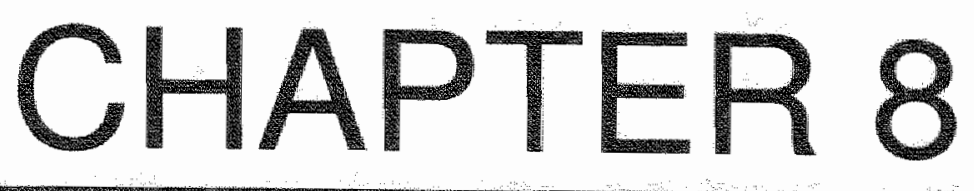

\section{4h satiety, GLP-1, ghrelin, energy- and substrate} metabolism during a high-protein diet measured in a respiration chamber

MPGM Lejeune, KR Westerterp, TCM Adam, ND Luscombe-Marsh, MS Westerterp-Plantenga

Submitted for publication 


\section{ABSTRACT}

Background: The mechanism of protein-induced satiety remains unclear.

Objective: To investigate $24 \mathrm{~h}$ satiety and related hormones, and energy- and substrate metabolism during a high-protein diet in a respiration chamber.

Design: Subjects were twelve healthy females (BMI: $20-25 \mathrm{~kg} / \mathrm{m}^{2}$, age: $18-40 \mathrm{y}$ ). They were fed in energy balance with a normal-protein (NP: $10 / 60 / 30 \%$ of energy protein/carbohydrate/fat) or a high-protein (HP: $30 / 40 / 30 \%$ of energy protein/carbohydrate/fat) diet in a randomized cross-over design. 24h energy expenditure, substrate oxidation, appetite profile, and ghrelin and GLP-1 concentrations were measured.

Results: Sleeping metabolic rate $(6.40 \pm 0.47$ versus $6.12 \pm 0.40 \mathrm{MJ} / \mathrm{d} ; p<0.05)$, DIT $(0.91 \pm 0.25$ versus $0.69 \pm 0.24 \mathrm{MJ} / \mathrm{d} ; p<0.05)$ and satiety were significantly higher during the HP diet, whereas activity-induced energy expenditure (1.68 \pm 0.32 versus $1.86 \pm 0.41 ; p<0.05), R Q(0.84 \pm 0.02$ versus $0.88 \pm 0.03$; $p<0.0005)$, and hunger were significantly lower. There was a tendency for a greater $24 \mathrm{~h}$ energy expenditure during the HP diet $(p=0.05)$. While energy intake was not different, the subjects were in energy balance during the HP diet and in positive energy balance during the NP diet. Satiety was related to $24 \mathrm{~h}$ energy expenditure $\left(p<0.05 ; r^{2}=0.40\right)$ and energy intake $\left(p<0.01 ; r^{2}=0.53\right)$ during the HP diet, while in energy balance. Ghrelin concentrations were not different between diets whereas GLP-1 concentrations after dinner were higher in the HP than NP diet condition $(p<0.05)$.

Conclusion: A HP diet compared to a NP diet when fed at energy balance during 4 days increased $24 \mathrm{~h}$ satiety, which was related to energy-metabolism, and not to ghrelin or GLP-1 concentrations.

Keywords: satiety, high-protein, ghrelin, GLP-1, energy balance 


\section{INTRODUCTION}

With respect to energy expenditure, it is known that protein has the highest and most prolonged thermic effect of the separate macronutrients $(20-30 \%)$, followed by carbohydrate $(5-15 \%)$ and fat $(0-3 \%)^{1}$. Studies measuring dietinduced thermogenesis (DIT) over 24 hours $^{2}$, over several hours ${ }^{3}$ or, after a single preload ${ }^{4}$ have all showed that diets higher in protein exert a greater effect on energy expenditure compared to diets lower in protein. This suggests that protein has a lower energy efficiency than carbohydrate or fat.

Protein has been observed to increase satiety to a greater extent than carbohydrate and fat and can therefore reduce energy intake ${ }^{5}$. Differences in $24 \mathrm{~h}$ satiety have been related to differences in DIT ${ }^{6}$. Based upon these observations for protein-related satiety, thermogenesis and energy inefficiency, we previously reported that a protein intake of $18 \%$ of energy versus $15 \%$ of energy resulted in improved weight maintenance which could partly be explained by an increased post-absorptive satiety, decreased energy efficiency and improved body composition favoring the maintenance of fat free mass ${ }^{7,8}$. The release of hormones such as ghrelin and glucagon-like peptide $\uparrow$ (GLP-1) are thought to influence post-ingestive satiety. Stimulation of endogenous ghrelin and GLP-1 production seems to be nutrient-specific ${ }^{9}, 10,11,12,13,14,15,16,17$. In the present highly controlled study we assessed simultaneously several mechanisms of satiety when carbohydrate was exchanged for protein isoenergetically over a period of 4 days, thus keeping energy density constant. We hypothesize that satiety is related to energy inefficiency (an elevated thermogenesis) and/or, the satiety hormones (ghrelin and GLP-1). In order to further unravel the favorable effect that a high-protein intake appears to have on body composition, i.e. increasing fat free mass at the expense of fat mass ${ }^{\theta_{1}, 7_{1}}{ }^{18}$, ${ }^{19}$, special attention was paid to $24 \mathrm{~h}$ fat oxidation during a high-protein versus a normal-protein diet.

\section{SUBJECTS AND METHODS}

\section{Subjects}

Twelve healthy female volunteers (BMI: $20-25 \mathrm{~kg} / \mathrm{m}^{2}$, age: $18-40 \mathrm{y}$ ) were recruited by advertisements placed on notice-boards at the university. All subjects underwent a medical screening and all were in good health, nonsmokers, not using medication and at most moderate alcohol users. Baseline characteristics of the subjects are presented in table 1. Written informed 
consent was obtained from all participants. The Medical Ethics Committee of the Academic Hospital in Maastricht approved of the study.

\section{Experimental sessions}

\section{Protocol}

The study had a single-blind, randomized; cross-over design. Subjects underwent two $36 \mathrm{~h}$ sessions in a respiration chamber for measurements of energy expenditure and substrate oxidation. The two sessions were conducted 4 weeks apart to ensure that each subject was in the same phase of their menstrual cycle. Three days prior to each session, subjects were provided with a diet to consume at home. The normal-protein diet (NP) and the high-protein diet (HP) were randomized over both sessions. The macronutrient composition ( $\%$ of energy Protein/Carbohydrate/Fat) of the diets was 10/60/30 for the normal-protein diet, and $30 / 40 / 30$ for the high-protein diet. A detailed composition of the diets is presented in table 2 .

Table 1. Subject characteristics at baseline.

\begin{tabular}{lc}
\hline & Mean $\pm \mathrm{sd}$ \\
\hline Age $(\mathrm{yr})$ & $21 \pm 3$ \\
Body weight $(\mathrm{kg})$ & $60.6 \pm 4.4$ \\
Height $(\mathrm{m})$ & $1.70 \pm 0.07$ \\
BMI $\left(\mathrm{kg} / \mathrm{m}^{2}\right)$ & $21.1 \pm 1.5$ \\
Fat mass $(\mathrm{kg})$ & $14.7 \pm 2.2$ \\
Fat free mass $(\mathrm{kg})$ & $45.8 \pm 3.1$ \\
Body fat $(\%)$ & $24.3 \pm 2.7$ \\
Dietary restraint $(\mathrm{Fl})$ & $5 \pm 4$ \\
\hline
\end{tabular}

Table 2 Composition of the high-protein (HP) and normal-protein (NP) diet.

\begin{tabular}{lll}
\hline Breakfast: & \multicolumn{1}{c}{ HP } & \multicolumn{1}{c}{ NP } \\
& $\begin{array}{l}\text { Bread, Butter, Chicken filet, Milk, } \\
\text { Merengue }\end{array}$ & $\begin{array}{l}\text { Bread, Butter, Coco for on bread, } \\
\text { Orange juice }\end{array}$ \\
\hline Lunch: & $\begin{array}{l}\text { Bread, Soy milk, Fruit yoghurt, Tuna in } \\
\text { water, Tomato, Cucumber, Feta } \\
\text { cheese, Salad dressing }\end{array}$ & $\begin{array}{l}\text { Bread, Orange juice, Soy dessert, } \\
\text { Tuna in oil, Tomato, Cucumber, } \\
\text { Cottage cheese, Salad dressing, Com, } \\
\text { Banana, Fruit cocktail }\end{array}$ \\
\hline Diner: & $\begin{array}{l}\text { Rice dish with ham, Soup, Soy milk, } \\
\text { Muesli bar }\end{array}$ & $\begin{array}{l}\text { Rice with curry chicken, Soup, Orange } \\
\text { juice, Muesli bar }\end{array}$ \\
\hline
\end{tabular}




\section{Energy intake}

During each experimental session subjects were fed in energy balance. The energy content of the diet that the subjects consumed at home was based on Basal Metabolic Rate (BMR) as calculated with the equation of HarrisBenedict ${ }^{20}$. BMR was multiplied by an activity index of $1.7^{21}$. To determine the appropriate level of energy intake for attaining energy balance in the respiration chamber, the Sleeping Metabolic Rate (SMR) was measured during the first night and multiplied by an activity index of $1.5^{21}$. Energy intake was divided over the meals as $20 \%$ for breakfast (09:00h), $40 \%$ for lunch (13:45h), and $40 \%$ for dinner (19:30h).

\section{Blood sampling}

On the morning of day 4, a Teflon catheter was placed in the antecubital vein for blood sampling. During each respiration chamber session 9 blood samples (08:45h, 09:30h, 10:15h, 13:30h, 14:15h, 15:00h, 19:15h, 20:00h, and 20:45h) were taken to determine plasma ghrelin and GLP-1 concentrations. In addition, a blood sample for determination of fasting serum cortisol and growth hormone concentrations were taken at the first blood sampling time-point (08:45h). The blood for the serum measurements was allowed to clot at room temperature for $20 \mathrm{~min}$. Immediately after clotting the samples were put on ice and serum was extracted by centrifugation. The blood for plasma measurements was centrifuged immediately. All obtained samples were frozen in liquid nitrogen and stored at $-80^{\circ} \mathrm{C}$ until analyzed. Plasma concentrations of active ghrelin were measured by RIA (Linco Research Inc., St. Charles, Missouri, USA). Plasma active GLP-1 samples were analyzed using ELISA (EGLP-35K; Linco Research Inc., St Charles, Missouri, USA). Serum growth hormone concentrations were assayed using the DELFIA method (Wallac Oy, Turku, Finland). Serum cortisol was determined by a direct radioimmunossay after denaturation of trancortin by heating at $60^{\circ} \mathrm{C}$ as described by Sulon et al. ${ }^{22}$.

\section{Appetite profile}

Appetite profile was measured using anchored $100-\mathrm{mm}$ visual analogue scales (VAS). During each respiration chamber session these questionnaires were completed before and after every meal. The questions were "How hungry are you?" and "How satiated are you?" (these questions were anchored with: "not at all" to "very"). For the calculation of the $24 \mathrm{~h}$ area under the curve (AUC) the VAS ratings were interpolated from the latest measurement at night until the first measurement in the morning ${ }^{6}$. 


\section{Body composition}

Body composition was determined by the three compartment model, using the hydrodensitometry and deuterium dilution $\left({ }^{2} \mathrm{H}_{2} \mathrm{O}\right)$ technique ${ }^{23 ; 24}$, and was calculated using the combined equation of $\mathrm{Sir}^{25}$.

\section{Indirect calorimetry}

Oxygen consumption and carbon dioxide production were measured in the respiration chamber ${ }^{26}$. The respiration chamber is a $14 \mathrm{~m}^{3}$ room which is furnished with a bed, chair, computer, television, radio-cassette player, telephone, intercom, sink and toilet. The room was ventilated with fresh air at a rate of $70-80 \mathrm{l} / \mathrm{min}$. The ventilation rate was measured with a dry gas meter (type 4, Schlumberger, Dordrecht, the Netherlands). The concentrations of oxygen and carbon dioxide were measured using a paramagnetic $\mathrm{O}_{2}$ analyzer (Magnos 6G, Hartmann and Braun, Frankfurt, Germany; and type OA184A, Servomex, Crowborough, United Kingdom) and an infrared $\mathrm{CO}_{2}$ analyzer (Uras 3G, Hartmann and Braun, Frankfurt, Germany). During each 15-min period, six samples of outgoing air for each chamber, and one sample of fresh air, zero gas, and calibration gas were measured. The gas samples to be measured were selected by a computer that also stored and processed the data ${ }^{26}$.

\section{Energy expenditure and substrate oxidation}

24h energy expenditure consists of SMR, diet-induced thermogenesis (DIT), and activity-induced energy expenditure. 24h energy expenditure and $24 \mathrm{~h}$ respiratory quotient (RQ) were measured from $08: 00 \mathrm{~h}$ on day 4 to $08: 00 \mathrm{~h}$ on day 5. Activity was monitored using a radar system which is based on the Doppler principle. SMR was defined as the lowest mean energy expenditure measured over three consecutive hours between 00:00h and 07:00h. DIT was calculated by plotting energy expenditure against radar output; both averaged over $30-\mathrm{min}$ periods. The intercept of the regression line at the lowest radar output represents the energy expenditure in the inactive state (Resting Metabolic Rate; RMR), consisting of SMR and $\mathrm{DIT}{ }^{2}$. DIT was determined by subtracting SMR from RMR. Activity-induced energy expenditure (AEE) was determined by subtracting SMR and DIT from $24 \mathrm{~h}$ energy expenditure. Carbohydrate, fat, and protein oxidation were calculated from the measurements of $\mathrm{O}_{2}$ consumption, $\mathrm{CO}_{2}$ production and urinary nitrogen excretion, using the formula of Brouwer ${ }^{27}$. 24h urine was collected from the second voiding on day 4 until the first voiding on day 5 . Samples were collected in containers with $10 \mathrm{ml} \mathrm{H}_{2} \mathrm{SO}_{4}$ to prevent nitrogen loss through evaporation. Volume and nitrogen concentration were measured, the latter using a nitrogen analyzer (Elemental Analyzer, CHN-O-Rapid, Heraeus). 


\section{Physical activity}

To measure physical activity on day 4 , the subjects were asked to wear a triaxial accelerometer (Tracmor; Philips Research, Eindhoven, The Netherlands) ${ }^{28}$ during the waking hours. The average counts per day were calculated.

\section{Statistical analysis}

Data are presented as mean \pm standard deviation, unless otherwise indicated. A repeated measures ANOVA was carried out to determine possible differences between both conditions. Regression analyses were performed to determine the relationships between selected variables. Significance was defined as $p<0.05$. All statistical tests were performed using SPSS for Windows, version 11.5 (SPSS, Chicago, USA).

\section{RESULTS}

There was no difference in total energy intake between both conditions (HP: $9.10 \pm 0.70$ vs. NP: $9.15 \pm 0.77 \mathrm{MJ} / \mathrm{d}$ ). The results on $24 \mathrm{~h}$ energy expenditure are shown in table 3 . There was a trend $(p=0.05)$ for a greater total energy expenditure during the HP condition. Sleeping metabolic rate and diet-induced thermogenesis were significantly greater during the HP condition, while the activity-induced energy expenditure was significantly smaller in the HP condition. No differences between both conditions were found in physical activity measured with the accelerometers, expressed as counts per day. During the HP condition the energy balance was not significantly different from zero, whereas during the NP condition the subjects were slightly in a positive energy balance (HP: $0.11 \pm 0.30$ vs NP: $0.47 \pm 0.63 \mathrm{MJ} / \mathrm{d}$; $p<0.05$ ). RQ was significantly lower in the HP condition, indicating a higher fat oxidation (table 3). The separate macronutrient balances are shown in figure 1 and there was a significant difference in protein and fat balances between both diet conditions. During the HP condition subjects were in a positive protein and a negative fat balance, the protein and fat balances were significantly different between the two diets.

The 24h-AUC for hunger was significantly smaller in the HP condition (HP: 822 \pm 304 vs. NP: $1101 \pm 256 \mathrm{mmVAS} .24 \mathrm{~h} ; \mathrm{p}<0.005$ ), whereas the $24 \mathrm{~h}-\mathrm{AUC}$ for satiety was significantly larger in this condition (HP: $973 \pm 178$ vs. NP: $765 \pm$ $304 \mathrm{~mm} .24 h ; p<0.01)$. The hunger and satiety ratings during day 4 are shown in figure $2 \mathrm{a}$ and $2 \mathrm{~b}$. During the HP condition as compared to the NP condition, the hunger scores were significantly lower and the satiety scores were significantly higher before and after dinner. In the HP condition the $24 \mathrm{~h}$ satiety (AUC) 
appeared to be a function of both $24 \mathrm{~h}$ energy expenditure (figure $3 \mathrm{a}: \mathrm{p}<0.05$; $r^{2}=0.40$ ) and $24 h$ energy intake (figure $3 b: p<0.01 ; r^{2}=0.53$ ). These relationships were not found in the NP condition.

The results of the ghrelin and GLP-1 concentrations are shown in figure $4 \mathrm{a}$ and $4 \mathrm{~b}$. No differences were found in ghrelin concentrations between dietary conditions. However, in the NP condition the ghrelin concentrations decreased significantly after lunch and after dinner, while in the HP condition this was only seen after dinner. With respect to GLP-1, a significant increase in GLP-1 was seen 15 minutes after lunch and after dinner in both conditions and, they tended to stay higher for an hour afterwards. During the HP condition the GLP-1 concentration 15 minutes after dinner was significantly higher compared to the NP condition. After breakfast there was a trend $(p<0.1)$ for GLP-1 concentrations to be higher in the HP condition than in the NP condition. Fasting cortisol (HP: $287.0 \pm 86.6$ vs. NP: $283.9 \pm 124.0 \mu \mathrm{g} / \mathrm{L}$ ) and growth hormone (HP: $13.6 \pm 15.2$ vs. NP: $13.7 \pm 12.1 \mathrm{mU} / \mathrm{L}$ ) concentrations were not different between both conditions. During breakfast, the decrease in hunger was related to a decrease in ghrelin in both conditions (HP: $p<0.05, r^{2}=0.52$; NP: $p<0.05, r^{2}=0.45$ ). In addition, the increase in satiety was related to the decrease in ghrelin after the NP breakfast $\left(p<0.05, r^{2}=0.53\right)$. Only in the HP condition was the increase in satiety after dinner related to the increase in GLP-1 $(p<0.05$, $\left.r^{2}=0.41\right)$.

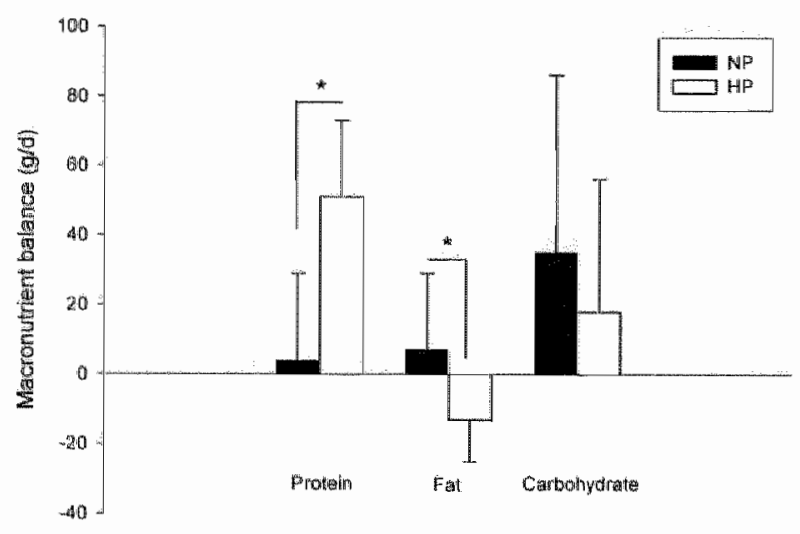

Figure 124 hacronutrient balances during day 4 on the high-protein (HP; $n=12$ ) and normalprotein $(N P ; n=12)$ diet condition. Values are means $\pm s d$. For differences between diet conditions (ANOVA repeated measures): " $p<0.005$. 
Table 3 Total energy expenditure, components of energy expenditure and RQ during the highprotein (HP; $n=12)$ and normall-protein (NP; $n=12$ ) condition.

\begin{tabular}{llll}
\hline & HP & NP & P-value \\
\hline SMR (MJ/d) & $6.40 \pm 0.47$ & $6.12 \pm 0.40$ & $<0.05$ \\
DIT (MJ/d) & $0.91 \pm 0.25$ & $0.69 \pm 0.24$ & $<0.05$ \\
DIT $(\% E I)$ & $10.1 \pm 2.7$ & $7.6 \pm 2.5$ & $<0.05$ \\
TEE (MJ/d) & $8.99 \pm 0.71$ & $8.67 \pm 0.73$ & $=0.05$ \\
AEE (MJ/d) & $1.68 \pm 0.32$ & $1.86 \pm 0.41$ & $<0.05$ \\
24h RQ & $0.84 \pm 0.02$ & $0.88 \pm 0.03$ & $<0.0005$ \\
\hline
\end{tabular}

(a)

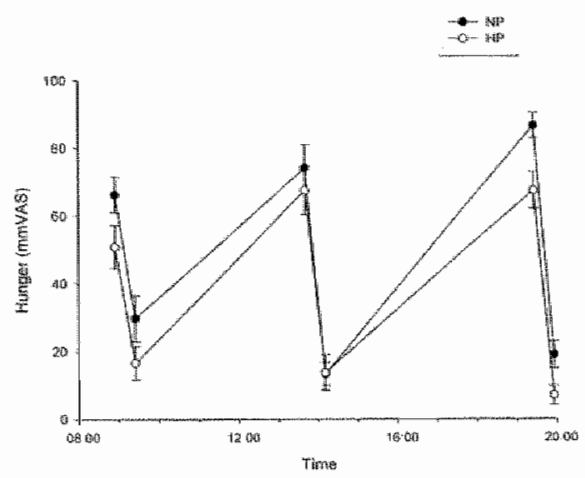

(b)

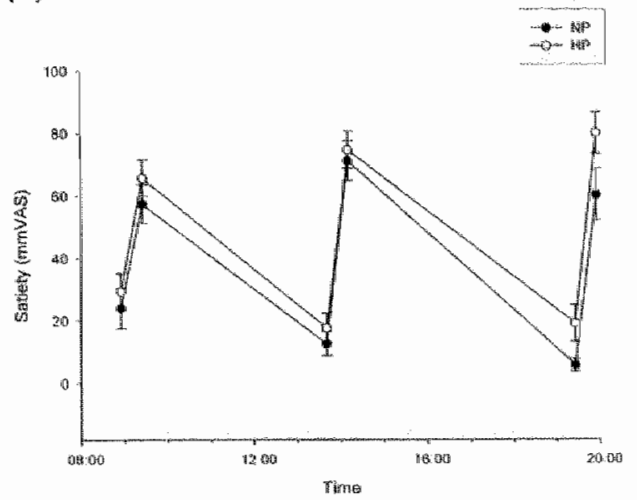

Figure 2 Hunger (a) and satiety (b) ratings measured using an anchored 100-mm visual analogue scale (mmVAS) during day 4 on the high-protein (HP; $n=12$ ) and normal-protein (NP; $n=12$ ) diet condition. Values are means \pm sem. For differences between diet conditions (ANOVA repeated measures): " $p<0.005$.

(a)

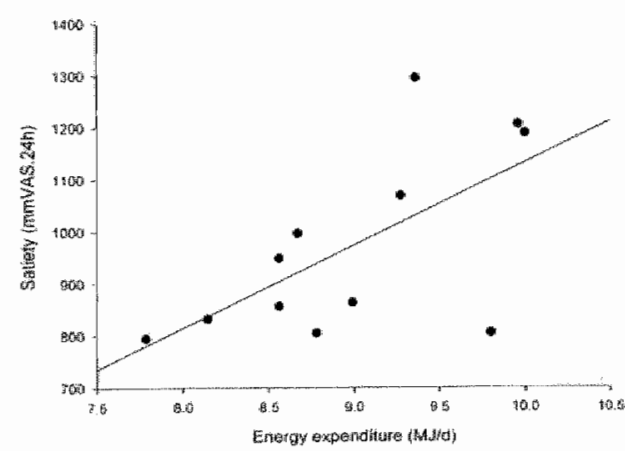

(b)

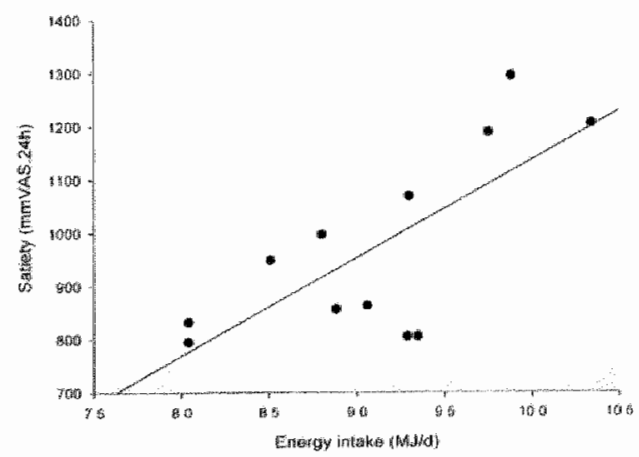

Figure 3 Correlation between (a) $24 \mathrm{~h}$ satiety (AUC) and $24 \mathrm{~h}$ energy expenditure ( $\mathrm{MJ} / \mathrm{d}$ ) in the highprotein condition (regression analysis: $p<0.05 ; r^{2}=0.40$ ) and (b) 24 h satiety (AUC) and 24 h energy intake $(\mathrm{MJ} / \mathrm{d})$ in the high-protein condition (regression analysis: $p<0.01 ; r^{2}=0.53$ ). 
(a)

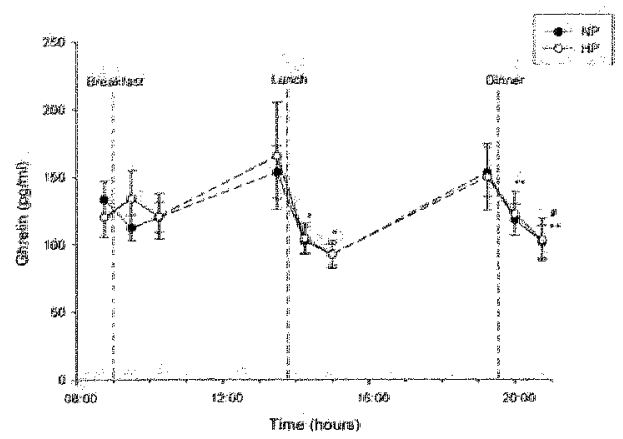

(b)

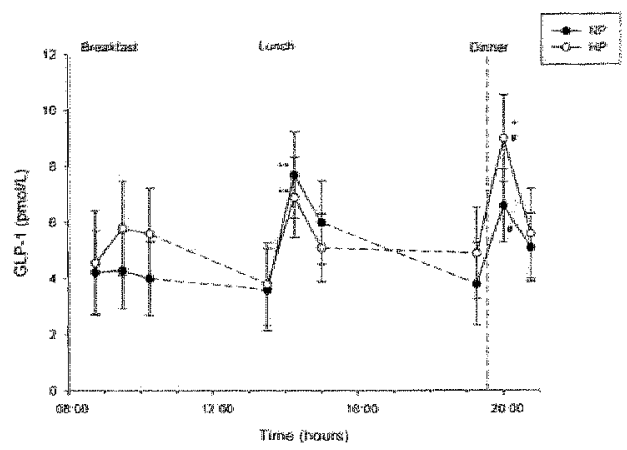

Figure 4 (a) Ghrelin concentrations during day 4 on the high-protein $(H P ; n=12)$ and normalprotein (NP; $n=12$ ) diet condition. Values are means \pm sem. For differences in time in the NP condition (ANOVA repeated measures): " $p<0.05$ compared to before lunch, *" $p<0.05$ compared to before dinner. For differences in time in the HP condition (ANOVA repeated measures): \# $p<0.05$ compared to before dinner. (b) GLP-1 concentrations during day 4 on the high-protein (HP; $n=12$ ) and normal-protein (NP; $n=12$ ) diet condition. Values are means \pm sem. For differences between treatments (ANOVA repeated measures): * $p<0.05$ compared to NP condition. For differences in time in both conditions (ANOVA repeated measures): ${ }^{* *} p<0.05$ compared to before lunch $\# p<0.05$ compared to before diner.

\section{DISCUSSION}

The present study shows that a high-protein diet compared to a normal-protein diet when eaten over 4 days increases $24 \mathrm{~h}$ satiety and decreases hunger, without differences in energy intake. These results support the hypothesis that protein increases satiety to a higher extent than carbohydrate and fat. The increased satiety in the HP diet was related to increased total energy expenditure. It is expected that satiety decreases if energy expenditure increases. Satiety ratings were also related to energy intake in the HP condition. Thus, with energy balance at a higher level, subjects were more satiated on the HP diet compared to the situation in which they were in a positive energy balance as on the NP diet. Crovetti et al. ${ }^{29}$ suggested that the thermic effect of food contributes to the satiating power of foods, which is inline with the results of the present study.

The protein intake in the NP diet was $1.0 \pm 0.1 \mathrm{~g} / \mathrm{kg}$, which should be enough to maintain nitrogen balance based on the current recommended dietary allowance for protein of $0.8 \mathrm{~g} / \mathrm{kg}^{30}$. This is reflected in the protein balance, which is not significantly different from zero in the NP condition. The protein intake in the HP diet was $2.6 \pm 0.3 \mathrm{~g} / \mathrm{kg}$, which resulted in a positive protein balance. The 
positive protein balance during the HP condition may in the long-term increase fat free mass. Although the fat content was kept constant at $30 \%$ of energy, the fat balance was different between the diets. The negative fat balance seen in the HP condition is in favor of fat loss in the long-term. These resuits are in line with the findings of our previous study in which subjects with an increased protein intake during weight maintenance showed an increased fat free mass and decreased fat mass as compared to subjects with a lower protein intake $e^{8,7}$. With respect to energy expenditure, a higher diet-induced thermogenesis and sleeping metabolic rate were found during the HP condition. It is suggested that the differences in diet-induced thermogenesis may be due to the body's small storage capacity for protein; hence it needs to be metabolized immediately. Furthermore, an increased protein synthesis; the high ATP cost of peptide bond synthesis, as well as the high cost of gluconeogenesis and urea production are often cited as the reason for the higher thermic effect of protein ${ }^{31 ;} 32$. In a respiration chamber experiment Dauncey et al. ${ }^{33}$ also showed that nutrient composition can have a marked influence on 24h energy expenditure. In that study a $12 \%$ increase after a high-protein intake was seen. Subjects being in energy balance on the HP diet and in a positive energy balance on the NP diet, showed that energy efficiency was lower in the HP condition. This is in line with the Stock hypothesis ${ }^{34}$ which states that a relatively high percentage of energy as protein during overfeeding decreases energy efficiency. Energy efficiency is expressed as the achieved body weight gain (in $\mathrm{kg}$ ) divided by the ingested energy (in MJ) necessary for that body weight gain. Therefore, a relatively low energy efficiency is a favorable situation because a higher energy intake is needed to gain 1 kilogram in body weight. The AEE in the HP condition was lower in comparison to the NP condition. This could be due to the fact that the NP diet was higher in carbohydrate compared to the HP diet, with the fat content being the same. Since carbohydrate has a lower DIT in comparison to protein', more energy remains for physical activity. However, the physical activity counts measured with the accelerometers showed no differences between both diet conditions. This means that subjects were not differently active during the day between both diets, but spent more energy on the same activities with the NP diet. In this respect, Segal et al..$^{35}$ showed that the thermic effect of food is not influenced by exercise.

It is thought that post-ingestive satiety is mediated, among other factors, by the release of hormones such as ghrelin, GLP-1, CCK, PYY, oxyntomodulin, and PP. Due to the frequent blood sampling, it was not possible to take all the afferent satiety factors into account. Therefore the present study focuses on ghrelin and GLP-1 only. A carbohydrate-rich meal has been reported to have a suppressive effect on plasma ghrelin concentrations ${ }^{14-16}$. Erdmann et al. ${ }^{16}$ proposed that this might be due to elevated glucose and insulin concentrations 
which can lead to suppression of plasma ghrelin. In the present study the decrease in ghrelin concentrations after a meal was seen during the NP diet, which was relatively high in carbohydrate. When $20 \%$ of energy of carbohydrate was exchanged for protein, the suppression of ghrelin after a meal could still be seen, although it only reached significance after dinner. This is in contrast to findings where ghrelin concentrations were increased after an oral protein load $^{14 ; " 16}$. However, in the present study the carbohydrate content of the HP diet was probably high enough to elicit an elevated glucose and insulin response, resulting in suppressed ghrelin concentrations. Endogenous GLP-1 production has been reported to be stimulated by meal ingestion, especially by carbohydrate and $\mathrm{fat}^{10: 11: 17}$. In contrast, if given in a mixed meal protein can increase GLP-1 concentrations to a greater extent compared to carbohydrate and fat $^{13}$. Results of the present study show an increase in GLP-1 concentrations in both diets after lunch and dinner. After dinner this increase was greater in the HP compared to the NP condition, which is in line with the results of Raben et al..$^{13}$.

With respect to additional regulatory circuit, it has been shown that the availability of nutrients can be sensed at central sites or directly in peripheral tissues $^{36}$. These complex feedback systems may play an important role in longterm body weight regulation in response to nutrient excess. In the present study where subjects were fed in energy balance the question remains whether nutrient sensing mechanisms are also of importance.

We conclude that a high-protein diet compared to a normal-protein diet, when consumed in energy balance over 4 days increased $24 \mathrm{~h}$ satiety, which was related to energy expenditure, energy intake, and not to ghrelin or GLP-1 concentrations.

\section{ACKNOWLEDGMENTS}

We gratefully acknowledge Ward Kolmans, Wendy Sluijsmans, Joan Senden, Loek Wouters and Paul Schoffelen for their assistance.

\section{REFERENCES}

1. Tappy $L$ (1996) Thermic effect of food and sympathetic nervous system activity in humans. Reprod Nutr Dev 36, 391-397. 
2. Westerterp KR, Wilson SA, Rolland V (1999) Diet induced thermogenesis measured over $24 \mathrm{~h}$ in a respiration chamber: effect of diet composition. Int $J$ Obes Relat Metab Disord 23, 287-292.

3. Johnston CS, Day CS, Swan PD (2002) Postprandial thermogenesis is increased $100 \%$ on a high-protein, low-fat diet versus a high-carbohydrate, low-fat diet in healthy, young women. J Am Coll Nutr 21, 55-61.

4. Luscombe ND, Clifton PM, Noakes M, Farnsworth E, Wittert G (2003) Effect of a high-protein, energy-restricted diet on weight loss and energy expenditure after weight stabilization in hyperinsulinemic subjects. Int $J$ Obes Relat Metab Disord 27, 582-590.

5. Poppitt SD, McCormack D, Buffenstein R (1998) Short-term effects of macronutrient preloads on appetite and energy intake in lean women. Physiol Behav 64, 279-285.

6. Westerterp-Plantenga MS, Rolland V, Wilson SA, Westerterp KR (1999) Satiety related to $24 \mathrm{~h}$ diet-induced thermogenesis during high protein/carbohydrate vs high fat diets measured in a respiration chamber. Eur J Clin Nutr 53, 495-502.

7. Westerterp-Plantenga MS, Lejeune MP, Nijs I, van Ooijen M, Kovacs EM (2004) High protein intake sustains weight maintenance after body weight loss in humans. Int $J$ Obes Relat Metab Disord 28, 57-64.

8. Lejeune MPGM, Kovacs EM, Westerterp-Plantenga MS (2005) Additional protein intake limits weight regain after weight loss in humans. $\mathrm{Br} J$ Nutr 95, 281-289.

9. Elliott RM, Morgan LM, Tredger JA, Deacon S, Wright J, Marks V (1993) Glucagon-like peptide-1 (7-36)amide and glucose-dependent insulinotropic polypeptide secretion in response to nutrient ingestion in man: acute postprandial and 24-h secretion patterns. J Endocrinol 138, 159-166.

10. Rocca AS, Brubaker PL (1995) Stereospecific effects of fatty acids on proglucagon-derived peptide secretion in fetal rat intestinal cultures. Endocrinology 136, 5593-5599.

11. Ritzel U, Fromme A, Ottleben M, Leonhardt U, Ramadori G (1997) Release of glucagon-like peptide-1 (GLP-1) by carbohydrates in the perfused rat ileum. Acta Diabetol 34, 18-21.

12. Cordier-Bussat $M$, Bernard $C$, Levenez $F$, Klages $N$, Laser-Ritz $B$, Philippe J, Chayvialle JA, Cuber JC (1998) Peptones stimulate both the secretion of the incretin hormone glucagon-like peptide 1 and the transcription of the proglucagon gene. Diabetes 47, 1038-1045.

13. Raben $A$, Agerholm-Larsen L, Flint A, Holst JJ, Astrup A (2003) Meals with similar energy densities but rich in protein, fat, carbohydrate, or alcohol have different effects on energy expenditure and substrate metabolism but not on appetite and energy intake. Am J Clin Nutr 77, 91-100. 
14. Erdmann J, Lippl $F$, Schusdziarra V (2003) Differential effect of protein and fat on plasma ghrelin levels in man. Regul Pept 116, 101-107.

15. Greenman Y, Golani N, Gillad S, Yaron M, Limor R, Stern N (2004) Ghrelin secretion is modulated in a nutrient- and gender-specific manner. Clin Endocrinol ( $10 \times f) 60,382-388$.

16. Erdmann J, Topsch R, Lippl F, Gussmann P, Schusdziarra V (2004) Postprandial response of plasma ghrelin levels to various test meals in relation to food intake, plasma insulin, and glucose. J Clin Endocrinol Metab 89, 3048-3054.

17. Adam TCM, Westerterp-Plantenga MS (2005) Nutrient-stimulated GLP-1 release in normal weight men and women. Horm Metab Res 37, 111-117.

18. Due A, Toubro S, Skov AR, Astrup A (2004) Effect of normal-fat diets, either medium or high in protein, on body weight in overweight subjects: a randomised 1-year trial. Int J Obes Relat Metab Disord 28, 1283-1290.

19. Lacroix M, Gaudichon C, Martin A, Morens C, Mathe V, Tome D, Huneau JF (2004) A long-term high-protein diet markedly reduces adipose tissue without major side effects in Wistar male rats. Am J Physiol Regul Integr Comp Physiol 287, R934-942.

20. Harris JA, Benedict FG (1919) A biometric study of basal metabolism in man. Washington: Carnegie Institution.

21. Westerterp KR (1999) Exercise and energy balance. In Regulation of food intake and energy expenditure, pp. 349-361 [MS Westerterp-Plantenga, AB Steffens, A Tremblay, editors]. Milano: EDRA.

22. Sulon $J$, Demey-Ponsart $L$, Beauduin P, Sodoyez JC (1978) Radioimmunoassay of corticosterone, cortisol and cortisone: their application to human cord and maternal plasma. J Steroid Biochem 9,671676.

23. van Marken Lichtenbelt WD, Westerterp KA, Wouters L (1994) Deuterium dilution as a method for determining total body water: effect of test protocol and sampling time. Br J Nutr 72, 491-497.

24. Schoeller DA, van Santen E, Peterson DW, Dietz W, Jaspan J, Klein PD (1980) Total body water measurement in humans with ${ }^{18} \mathrm{O}$ and ${ }^{2} \mathrm{H}$ labeled water. Am J Clin Nutr 33, 2686-2693.

25. Siri WE (1956) The gross composition of the body. Adv Biol Med Phys 4, 239-280.

26. Schoffelen PF, Westerterp KR, Saris WH, Ten Hoor F (1997) A dualrespiration chamber system with automated calibration. J App/ Physiol 83, 2064-2072.

27. Brouwer $E$ (1957) On simple formulae for calculating the heat expenditure and the quantities of carbohydrate and fat oxidized in metabolism of men 
and animals, from gaseous exchange (Oxygen intake and carbonic acid output) and urine-N. Acta Physiol Pharmacol Neerl 6, 795-802.

28. Plasqui $G$ (2005) Daily physical activity, energy expenditure and physical fitness; assessment and implications, Maastricht University.

29. Crovetti R, Porrini M, Santangelo A, Testolin G (1998) The influence of thermic effect of food on satiety. Eur J Clin Nutr 52, 482-488.

30. Netherlands HCot (2001) Dietary reference intakes: energy, proteins, fats and digestible carbohydrates. The Hague: Health Counsil of the Netherlands.

31. Robinson $S M$, Jaccard C, Persaud $C$, Jackson AA, Jequier $E$, Schutz $Y$ (1990) Protein turnover and thermogenesis in response to high-protein and high-carbohydrate feeding in men. Am J Clin Nutr 52, 72-80.

32. Mikkelsen PB, Toubro $S$, Astrup A (2000) Effect of fat-reduced diets on 24$\mathrm{h}$ energy expenditure: comparisons between animal protein, vegetable protein, and carbohydrate. Am J Clin Nutr 72, 1135-1141.

33. Dauncey MJ, Bingham SA (1983) Dependence of 24 h energy expenditure in man on the composition of the nutrient intake. Br J Nutr 50, 1-13.

34. Stock MJ (1999) Gluttony and thermogenesis revisited. Int $J$ Obes Relat Metab Disord 23, 1105-1117.

35. Segal KR, Gutin B, Nyman AM, Pi-Sunyer FX (1985) Thermic effect of food at rest, during exercise, and after exercise in lean and obese men of similar bady weight. J Clin Invest 76, 1107-1112.

36. Obici $S$, Rossetti $L$ (2003) Minireview: nutrient sensing and the regulation of insulin action and energy balance. Endocrinology 144, 5172-5178. 


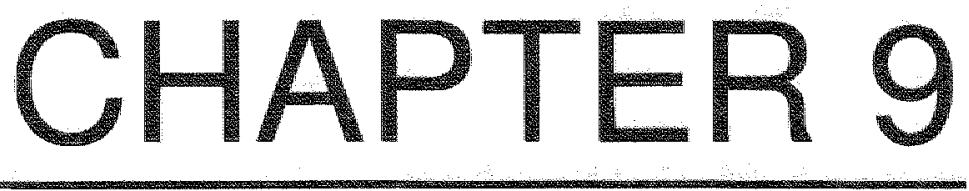

\section{General discussion}


The research in this thesis was focused on targets that may play a role in the prevention and long-term treatment of overweight and obesity. Both behavioral targets, i.e. eating behavior and physical activity, and metabolic targets, i.e. satiety, energy expenditure, substrate oxidation, body composition, and energy efficiency were focused on.

\section{DIETARY RESTRAINT AND WEIGHT MANAGEMENT}

Changing eating behavior is one of the behavioral targets for weight management. It has been shown that subjects, who can increase cognitive restrained eating during an energy restriction program, show less regain during weight maintenance thereafter ${ }^{1-6}$. Because of the presumed role of reduced physical activity in the development of obesity, increase of physical activity as a behavioral treatment of obesity, with or without a diet, often has been subject of research ${ }^{7}$. Although adding exercise to a diet program is usually unsuccessful in affecting the amount of weight lost ${ }^{8 ; 9}$, it has been shown that exercise-induced weight loss in obese subjects is possible, but only under extremely guided and controlled conditions ${ }^{10}$. Assessing simultaneously the role of dietary restraint and physical activity during weight maintenance, we showed that successful weight maintenance was explained by body mass loss and increase in dietary restraint during energy restriction, irrespective of possible exercise training effects ${ }^{6}$. Thus, the ability to change eating behavior contributes more to the long-term success of weight management than increased physical activity. However, regular physical activity does improve physical and psychological health and should therefore be encouraged as part of a healthy lifestyle.

It has been suggested that subjects who find it difficult to change their eating behavior adequately during dietary treatment of obesity, would benefit the most from a pharmacological treatment. Therefore the role of eating behavior during weight loss treatment with sibutramine, an anti-obesity drug enhancing satiety, has been investigated ${ }^{11}$. Results showed that the subjects, who were initially less restrained, thus being able to increase restraint, lost the most weight during the treatment period. The effects of another pharmacological treatment, e.g. PEG-OB, of obesity in the long-term was investigated in relation to the role of eating behavior during weight loss and the first period of weight maintenance thereafter ${ }^{12}$. Although treatment with PEG-OB protein led to a greater body weight loss relative to placebo, weight maintenance was not supported by this treatment. Contrarily, dietary restraint was more effective in the first period of weight maintenance in the placebo treated group, resulting in a slower regain of body weight. It may be that pharmacological treatment limits the change in lifestyle necessary for weight maintenance after weight loss. In conclusion, 
during pharmacological treatment of abesity subjects must also be stimulated to change their eating behavior.

The results reported above show that changing eating behavior is sometimes difficult. The failure to change eating behavior adequately may partly be explained by genetic background. Recently is has been reported that different polymorphisms of obesity related genes showed behavioral differences leading to dietary discipline, less emotional eating and less feelings of hunger, resulting in a better weight maintenance ${ }^{13}$. Future research should also take the genetic background into account when studying how to change eating behavior adequately.

\section{THERMOGENIC SUPPLEMENTS AND WEIGHT MANAGEMENT}

A wide selection of natural herbal products is currently being marketed as weight loss agents. Several of these supplements are proposed to act on energy expenditure via thermogenic properties. In this thesis we focused on the supplements capsaicin and green tea. The first agent, capsaicin, is the pungent principle of hot red pepper. In a series of human studies Yoshioka et al. ${ }^{14-47}$ showed an increase in diet-induced thermogenesis and a decrease in respiratory quotient immediately after a meal to which capsaicin was added, implying a shift in substrate oxidation from carbohydrate to fat oxidation. The increase in the facultative phase of diet-induced thermogenesis was probably due to $\beta$-adrenergic stimulation ${ }^{14}$. They also showed a decreased appetite, decreased cumulative food intake ${ }^{16}$ and increased energy expenditure after consumption of capsaicin ${ }^{15 ; 17}$. The reducing effect on energy intake could be due to the sensory effect or the post-ingestive, gastro-intestinal effect of capsaicin. The sensory and gastro-intestinal contributions of capsaicin have been assessed in humans by offering the same dosage of capsaicin in tomato juice (sensory and gastro-intestinal exposure) or in capsules (gastro-intestinal exposure) that were swallowed with tomato juice ${ }^{18}$. Results showed that the sensory perception of capsaicin reduced energy intake even further than the gastro-intestinal administration did. The short-term effect of capsaicin on fat oxidation, as reported by Yoshioka et al. ${ }^{15}$, also holds in the long-term during a period of weight maintenance ${ }^{19}$. The short-term effect on appetite reported by Yoshioka et al. ${ }^{16}$ did not appear in the long-term ${ }^{19}$. Although clearly present, the effects of capsaicin were too small to limit regain of body weight in the longterm. The strong pungency of capsaicin, which in the long-term may affect compliance, has to be taken into account when investigating the role of capsaicin in weight management. An effective application of the effects of 
capsaicin in the long-term may be the use of a non-pungent cultivar of pepper, named $\mathrm{CH}-19$ Sweet. It has been shown that $\mathrm{CH}-19$ Sweet increases oxygen consumption and body temperature in humans, suggesting a similar effect as hot red pepper on energy consumption ${ }^{20}$.

Another thermogenic ingredient that is of interest is green tea. Dulloo et al. ${ }^{21}$ showed that green tea, rich in catechin polyphenols and caffeine, increases $24 \mathrm{~h}$ energy expenditure and fat oxidation. This effect was attributed to the content of caffeine and tea catechins. Caffeine acts through inhibition of phosphodiesterase, an enzyme that degrades intracellular cyclic AMP, and through antagonism of the negative modulatory effect of adenosine on increased norepinephrine release ${ }^{22}$. Tea catechins have been shown to inhibit catechol 0 -methyltransferase ${ }^{23}$, the enzyme that degrades norepinephrine. Taken together, both caffeine and catechins would result in increased and/or prolonged effect of norepinephrine on energy and lipid metabolism. Taken the thermogenic properties of green tea into account, it has been suggested that green tea supplementation may offset the reduction in resting energy expenditure that is usually seen during a weight loss diet. However, a study assessing the effect of green tea supplementation during a low-energy diet showed no added beneficial effect on body weight or body composition due to higher resting energy expenditure ${ }^{24}$. A long-term study investigating the effects of green tea supplementation during weight maintenance failed to reproduce the short-term results on energy expenditure and fat oxidation, and weight maintenance was not improved ${ }^{25}$. Since the caffeine intake in this study population under free-living conditions was without restrictions, it is likely that the magnitude of the habitual caffeine intake may have overruled the effectiveness of green tea. In this regard, the low caffeine consumers showed a better weight maintenance compared to the high caffeine consumers. This is in line with results of several Japanese studies, which showed that tea catechins administration with limited caffeine intake, reduced body fat during weight maintenance $e^{26-29}$.

An advantage of thermogenic supplements is that they may affect energy expenditure, but have no effect on energy intake based on their minimal energy content. Although the effects of these ingredients on body weight are limited, the effects may be large enough to have an added beneficial effect when combined with other weight management strategies (e.g. changing eating behavior). 


\section{DIETARY PROTEIN AND WEIGHT MANAGEMENT}

The composition of the ideal weight loss and weight maintenance diet is subject of debate. In the past, dietary guidelines for prevention and treatment of overweight and obesity have mainly focused on low-fat, high-carbohydrate diets. Recently, there is a growing interest in high-protein diets. It is hypothesized that high-protein diets enhance weight loss due to an increased thermogenesis and satiety.

\section{Protein and thermogenesis}

The thermic effect of food seems to be influenced by the composition of the food consumed. It is known that protein has the highest and most prolonged thermic effect of the separate macronutrients $(20-30 \%)$, followed by carbohydrate $(5-15 \%)$ and fat $(0-3 \%)^{30}$. The difference in diet-induced thermogenesis (DIT) may be due to the fact that the body has no storage capacity for protein and thus needs to metabolize it immediately. Furthermore, the increased protein synthesis, the high ATP cost of peptide bond synthesis as well as the high cost of gluconeogenesis and urea production are often seen as the reason for the higher thermic effect of protein ${ }^{31 ;}{ }^{32}$. In other words, highprotein diets are less energy efficient compared to diets high in carbohydrate or fat. Many studies have assessed the effects of protein-rich foods on dietinduced thermogenesis. Medium term studies, measuring diet-induced thermogenesis over 24 hours in a respiration chamber ${ }^{33 ;}{ }^{34}$, and studies measuring over several hours ${ }^{35}$, or after a single preload ${ }^{36}$, all suggest that diets higher in protein exert a larger effect on energy expenditure compared to diets lower in protein. Although the increase in energy expenditure attributable to the larger thermic effect is probably too small to have an effect on body weight in the short-term, this increase may become beneficial for weight loss in the long term. The beneficial effect of a higher protein intake on body weight has been shown in long-term weight loss ${ }^{37}$ and weight maintenance studies ${ }^{33 ;}{ }^{39}$, which could partly be explained by an increased thermogenesis. The order in which macronutrients are oxidized is: protein, carbohydrate, fat. So, protein ingestion leads to a rapid thermic effect in comparison to carbohydrate and fat.

It is suggested that different protein sources elicit differences in diet-induced thermogenesis. Mikkelsen et $a l^{32}$ showed that substitution of carbohydrate with either pork or soy protein produced a significantly higher thermic effect. The measured difference in diet-induced thermogenesis between the pork and soy protein diets was significantly higher than the predicted difference, suggesting that the thermic effect of protein depends on the protein source and amino acid 
composition. In humans, it is shown that well-balanced amino acid mixtures produce a higher thermic effect compared to amino acid mixture with low biological value $e^{40}$. Animal studies have shown that leucine is especially thermogenic compared to other amino acids and that this effect is mediated through increased protein synthesis ${ }^{41}$. However, high-protein diets consisting of a variety of proteins from different sources have been shown to sustain a higher thermogenesis in the long-term ${ }^{33 ; 38 ;} 39 ; 42 ; 43$.

\section{Protein and satiety}

The macronutrients protein, carbohydrate and fat have different satiating properties. It is suggested that protein has the potential to enhance sensations of satiety to a larger extent than carbohydrate, which is more satiating than fat. Several studies have reported a higher satiety following a high-protein preload in comparison to a high-carbohydrate or high-fat preload ${ }^{44-46}$. A high-protein diet has also been reported to enhance $24 \mathrm{~h}$ satiety ${ }^{47}$, and post-absorptive satiety during a weight maintenance study in which subjects increased their protein intake for a period of 3 months ${ }^{38 ; 39}$.

The mechanism of protein-induced satiety remains unclear. In 1956 Mellinkoff et al..$^{48}$ proposed the aminostatic hypothesis, which states that changes in the concentration of plasma amino acids are detected by the brain and therefore may influence feelings of satiety. However, there is little evidence to support this hypothesis. It is suggested that different protein sources may differ in their satiating power. Boirie et al. ${ }^{49}$ introduced the concept of 'slow' and 'fast' proteins to describe the differences in digestion and absorption of casein and whey. They proposed that 'fast' proteins (such as whey) may be more satiating than 'slow' proteins (such as casein). To test this hypothesis, a short-term study was executed to investigate the differences of a whey and casein protein preload on appetite ratings ${ }^{50}$. Results showed that the desire to eat was reduced by the whey protein compared to the casein protein following a standard lunch with fixed energy intake. However, it is not clear whether the differences in satiating capacity between protein sources would persist in the longer term.

Post-ingestive satiety is also thought to be mediated by the release of hormones such as ghrelin and glucagon-like peptide 1 (GLP-1). Ghrelin is a peptide hormone that is predominantly secreted by the stomach. In humans, ghrelin concentrations are increased during short-term fasting, and decreased after food intake ${ }^{51 ; 52}$. It recently has been shown that the ghrelin response seems to differ according to the macronutrient ingested. A carbohydrate-rich meal has been reported to have a suppressive effect on plasma ghrelin levels, 
but results on fat- and protein-rich meals are not consistent ${ }^{53-55}$. Erdmann et $a l^{55}$ proposed that meal ingestion primarily stimulates gastric ghrelin secretion, and only when sufficient amounts of carbohydrate are ingested and absorbed leading to elevated glucose and insulin concentrations, ghrelin is subsequently suppressed. Another peripheral hormonal satiety signal is GLP-1, which is secreted by the endocrine $L$ cells in the ileum in response to the presence of nutrients $^{56}$. Intravenous administration of GLP-1 appeared to have satiating effects in humans ${ }^{57 ;}$. ${ }^{2}$. Stimulation of endogenous GLP-1 production seems to be nutrient-specific. Especially carbohydrate and fat have the ability to enhance GLP-1 secretion ${ }^{59-61}$ whereas proteins and amino acids show hardly any effect $^{62 ; 63}$. However, in a mixed meal proteins seem to stimulate GLP-1 production more than carbohydrate or $\mathrm{fat}^{64}$.

Possible mechanisms of protein-induced satiety have been assessed in a respiration chamber study, where carbohydrate was exchanged for protein isoenergetically over a period of 4 days, thus keeping energy density constant ${ }^{34}$. During a controlled situation, $24 \mathrm{~h}$ measurements of all components of energy expenditure and the blood plasma concentrations of ghrelin and GLP-1 before and after meals were executed. The mechanism of protein-induced satiety was hypothesized to be related to energy inefficiency (an elevated thermogenesis) and/or so-called satiety hormones (ghrelin and GLP-1). Results showed that a high-protein diet compared to a normal-protein diet consumed in energy balance over 4 days increased $24 \mathrm{~h}$ satiety, which was related to energy expenditure and energy intake, and not to ghrelin or GLP-1 concentrations. This is in line with several other studies showing a relationship between the thermic effect of food and satiety ${ }^{47}$ : 5 .

\section{Protein and weight loss diets}

When investigating the effects of high-protein diets on weight loss and weight maintenance, the safety of these diets should be taken into account. The current recommended daily allowance for protein is $0.8 \mathrm{~g} / \mathrm{kg}^{66}$. In well-trained body builders a protein intake up to $2.8 \mathrm{~g} / \mathrm{kg}$ showed no adverse effects on kidney function ${ }^{67}$. However, individuals most at risk of potential adverse effects (i.e. subjects with renal or cardiovascular diseases) should be careful with highprotein diets ${ }^{68}$. Protein intake may be expressed in grams, or as percentage of energy intake. When advising subjects a high-protein diet, the difference between these two measures should be taken into account. For instance a weight loss diet of $2.5 \mathrm{MJ} / \mathrm{d}$ with a protein content of $60 \mathrm{~g} / \mathrm{d}$ consist for $40 \mathrm{en} \%$ of protein, while an energy-balance diet of $10 \mathrm{MJ} / \mathrm{d}$ with the same protein content of $60 \mathrm{~g} / \mathrm{d}$ consists for only $10 \mathrm{en} \%$ of protein. To ensure that subjects are not in a 
negative nitrogen and protein balance during a weight loss diet, the absolute amount of protein is of greater importance than the percentage of protein. Ditschuneit et $a l^{69}$ showed that varying the protein content of a formula diet from 0 to $50 \mathrm{~g} / \mathrm{d}$ resulted in a protein loss varying between 1202 to $91 \mathrm{grams}$ measured over 28 days, respectively. The fat loss as percentage of total weight loss varied from $43 \%$ (with protein content of $0 \mathrm{~g} / \mathrm{d}$ ) up to $79 \%$ (with protein content of $50 \mathrm{~g} / \mathrm{d}$ ). These results suggest that a higher protein intake changes body composition in a way that fat mass is lost and fat free mass is spared in the long term. This has also been shown in a weight maintenance study in which an increased protein intake resulted in decreased weight regain. The weight regained consisted of only fat free mass, while fat mass even continued to decrease ${ }^{38 ; 39}$. The favorable effect that high-protein diets seem to have on body composition has been shown to be reflected in the substrate oxidation. Consumption of a high-protein diet over 4 days resulted in increased protein oxidation and decreased $\mathrm{RQ}^{34}$, but also in the long-term additional protein intake has been shown to limit the increase in $R Q$ which is usually seen during weight maintenance after weight lloss ${ }^{39}$.

Recently, several studies claimed that low-carbohydrate diets, such as the Atkins diet, are effective for short-term weight loss. Due to the low carbohydrate content these diets are relatively high in fat and protein. Different mechanisms have been proposed as an explanation of the effectiveness of these diets. The depletion of glycogen stores as a result of the severe carbohydrate restriction produces ketosis similar to that seen during fasting ${ }^{70}$. Circulating ketones have been reported to be appetite-suppressing ${ }^{70}$, but not all studies support these findings ${ }^{71}$. Atkins claims that weight loss during his ad libitum diet is due to increased energy expenditure. However, there is no evidence that high-fat/highprotein diets are highly thermogenic. Although the high-protein content of these diets may increase energy expenditure, the low thermic effect of fat will probably counteract this increase. The success of low-carbohydrate diets has also been attributed to the restriction of the variety of food choices ${ }^{70}$. Although the mechanism responsible for the effectiveness of low-carbohydrate diets requires more research ${ }_{\text {in }}$ the short-term success is probably a combination of the enhanced satiety produced by the high protein content and the monotony of these diets. Since there is debate about the efficacy and safety of lowcarbohydrate diets in the long-term, longer studies are needed. 


\section{WEIGHT LOSS AND WEIGHT MAINTENANCE}

Weight loss is always the first step in obesity treatment. Furthermore, short-term weight loss is easier to achieve than long-term weight maintenance. Therefore it is of interest whether successful weight loss depends on the same behavioral and metabolic targets as weight maintenance. With respect to the behavioral targets, it has been shown that high baseline dietary restraint scores related to less body weight loss ${ }^{6}$. On the other hand, behavioral changes are less important during the first period of weight loss because metabolic effects are large due to an acute negative energy balance. When substantial weight loss has been achieved, the metabolic changes may be reversed due to the weight loss and consequently the less negative energy balance. This reversal effect has been shown for changes in ghrelin and adiponectin during PEG-OB protein induced body weight loss ${ }^{72}$. For weight management a distinction must be made between the acute effects of a negative energy balance in the first period of weight loss and the long-term effects of weight maintenance at a lower energy balance due to a decreased body weight.

\section{CONCLUSIONS}

Based on the results reported in this thesis and from the literature, we conclude that behavioral treatment remains the most important factor in the prevention and treatment of obesity. Successful long-term weight management requires a change in lifestyle. Although several thermogenic supplements are able to affect metabolic targets, an effect on multiple targets is needed to produce beneficial effects for weight management. As such, an increased dietary protein intake, which has been shown to contribute positively to a mixture of metabolic targets seems to be an adequate intervention for successful weight management at this moment.

\section{IMPLICATIONS FOR FUTURE RESEARCH}

The ideal intervention for successful weight management has not yet been discovered. Based on the conclusions of the research described in this thesis, future research should focus on behavioral aspects, and thereby taking the genetic background into account. Furthermore, the use of thermogenic ingredients as a support tool for changes in eating behavior should also be addressed. The topic of increased dietary protein intake, which at the moment seems the most promising intervention, should be further explored. The role of 
different protein sources, and thus different amino acids compositions, remains elusive and requires further investigation. Studying protein metabolism and protein kinetics may provide a better understanding of the thermogenic and satiating properties of protein. It is thought that specific amino acids within dietary proteins are involved in these effects but it is not yet known which the key ones are. When the key amino acids are identified, a high-protein diet can be developed to optimize long-term compliance and thereby stabilize body weight.

\section{REFERENCES}

1. Hensrud DD, Weinsier RL, Darnell BE, Hunter GR (1994) A prospective study of weight maintenance in obese subjects reduced to normal body weight without weight-loss training. Am J Clin Nutr 60, 688-694.

2. Fogelholm M, Kukkonen-Harjula K, Oja $P$ (1999) Eating control and physical activity as determinants of short-term weight maintenance after a very-low-calorie diet among obese women. Int $J$ Obes Relat Metab Disord 23, 203-210.

3. Clark MM, Marcus BH, Pera V, Niaura RS (1994) Changes in eating inventory scores following obesity treatment. Int J Eat Disord 15, 401-405.

4. Pekkarinen T, Takala I, Mustajoki P (1996) Two year maintenance of weight loss after a VLCD and behavioural therapy for obesity: correlation to the scores of questionnaires measuring eating behaviour. Int $J$ Obes Relat Metab Disord 20, 332-337.

5. Westerterp-Plantenga MS, Kempen KP, Saris WH (1998) Determinants of weight maintenance in women after diet-induced weight reduction. Int $J$ Obes Relat Metab Disord 22, 1-6.

6. Lejeune MPGM, Van Aggel-Leijssen DP, Van Baak MA, WesterterpPlantenga MS (2003) Effects of dietary restraint vs exercise during weight maintenance in obese men. Eur J Clin Nutr 57, 1338-1344.

7. Westerterp KR (1999) Obesity and physical activity. Int $J$ Obes Relat Metab Disord 23 Suppl 1, 59-64.

8. Van Dale D, Saris WH, Schoffelen PF, Ten Hoor F (1987) Does exercise give an additional effect in weight reduction regimens? Int $J$ Obes 11, 367375.

9. van Aggel-Leijssen DP, Saris WH, Hul GB, van Baak MA (2001) Shortterm effects of weight loss with or without low-intensity exercise training on fat metabolism in obese men. Am J Clin Nutr 73, 523-531.

10. Ross R, Dagnone D, Jones PJ, Smith H, Paddags A, Hudson R, Janssen I (2000) Reduction in obesity and related comorbid conditions after diet- 
induced weight loss or exercise-induced weight loss in men. A randomized, controlled trial. Ann Intern Med 133, 92-103.

11. Elfhag $K$, Rossner $S$, Barkeling $B$, Rooth $P(2005)$ Sibutramine treatment in obesity: initial eating behaviour in relation to weight loss results and changes in mood. Pharmacol Res 51, 159-163.

12. Lejeune MPGM, Hukshorn CJ, Saris WH, Westerterp-Plantenga MS (2003) Effect of dietary restraint during and following pegylated recombinant leptin (PEG-OB) treatment of overweight men. Int J Obes Relat Metab Disord 27; $1494-1499$.

13. Vogels N, Mariman ECM, Bouwman FG, Westerterp-Plantenga MS Relationship of weight maintenance and dietary restraint with PPARgamma2, GRL and CNTF polymorphisms. Submitted for publication.

14. Yoshioka M, Lim K, Kikuzato $S$, Kiyonaga A, Tanaka $H$, Shindo $M$, Suzuki $M$ (1995) Effects of red-pepper diet on the energy metabolism in men. J Nutr Sci Vitaminol (Tokyo) 41, 647-656.

15. Yoshioka M, St-Pierre S, Suzuki M, Tremblay A (1998) Effects of red pepper added to high-fat and high-carbohydrate meals on energy metabolism and substrate utilization in Japanese women. $\mathrm{Br} J$ Nutr 80 , 503-510.

16. Yoshioka $M$, St-Pierre $S$, Drapeau V, Dionne I, Doucet E, Suzuki $M$, Tremblay A (1999) Effects of red pepper on appetite and energy intake. $\mathrm{Br}$ J Nutr 82, 115-123.

17. Yoshioka M, Doucet E, Drapeau V, Dionne I, Tremblay A (2001) Combined effects of red pepper and caffeine consumption on $24 \mathrm{~h}$ energy balance in subjects given free access to foods. Br J Nutr 85, 203-211.

18. Westerterp-Plantenga MS, Smeets A, Lejeune MP (2004) Sensory and gastrointestinal satiety effects of capsaicin on food intake. Int $J$ Obes Relat Metab Disord, in press.

19. Lejeune MPGM, Kovacs EM, Westerterp-Plantenga MS (2003) Effect of capsaicin on substrate oxidation and weight maintenance after modest body-weight loss in human subjects. Br J Nutr 90, 651-659.

20. Ohnuki K, Niwa S, Maeda S, Inoue N, Yazawa S, Fushiki T (2001) $\mathrm{CH}-19$ sweet, a non-pungent cultivar of red pepper, increased body temperature and oxygen consumption in humans. Biosci Biotechnol Biochem 65, 20332036.

21. Dulloo AG, Duret $C$, Rohrer D, Girardier L, Mensi N, Fathi $M$, Chantre $P$, Vandermander $J$ (1999) Efficacy of a green tea extract rich in catechin polyphenols and caffeine in increasing 24-h energy expenditure and fat oxidation in humans. Am J Clin Nutr 70, 1040-1045. 
22. Dulloo $A G$, Seydoux $J_{i}$ Girardier $L$ (1992) Potentiation of the thermogenic antiobesity effects of ephedrine by dietary methylxanthines: adenosine antagonism or phosphodiesterase inhibition? Metabolism 41, 1233-1241.

23. Borchardt RT, Huber JA (1975) Catechol O-methyltransferase. 5. Structure-activity relationships for inhibition by flavonoids. J Med Chem 18 , 120-122.

24. Diepvens $K$, Kovacs EMR, Nijs IMT, Westerterp-Plantenga MS Effect of green tea on resting energy expenditure and substrate oxidation during weight loss in overweight females. Submitted for publication.

25. Kovacs EM, Lejeune MP, Nijs I, Westerterp-Plantenga MS (2004) Effects of green tea on weight maintenance after body-weight loss. Br J Nutr 91, 431-437.

26. Hase $T$, Komine $Y$, Meguro $S$, Takeda $Y$, Takahashi $H$, Matsui $Y$, Inaoka $S$, Katsuragi $Y$, Tokimitsu I, Shimasaki $\mathrm{H}$, Itakura $\mathrm{H}$ (2001) Anti-obesity effects of tea catechins in humans. J Oleo Sci 50, 559-605.

27. Nagao T, Meguro S, Soga $S$, Otsuka A, Tomonobu K, Fumoto $S$, Chikama A, Mori K, Yuzawa $M$, Watanabe $H$, Hase T, Tanaka $Y$, Tokimitsu I, Shimasaki $H$, Itakura $H$ (2001) Tea catechins suppress accumulation of body fat in humans. J Oleo Sci 50, 717-728.

28. Tsuchida $T$, Itakura $H$, Nakamura $H$ (2002) Reduction of body fat in humans by long-term ingestion of catechins. Prog Med 22, 2189-2203.

29. Nagao $T$, Komine $Y$, Soga $S$, Meguro $S$, Hase $T$, Tanaka $Y$, Tokimitsu I (2005) Ingestion of a tea rich in catechins leads to a reduction in body fat and malondialdehyde-modified LDL in men. Am J Clin Nutr 81, 122-129.

30. Tappy L (1996) Thermic effect of food and sympathetic nervous system activity in humans. Reprod Nutr Dev 36, 391-397.

31. Robinson $S M$, Jaccard $C$, Persaud $C$, Jackson $A A$, Jequier $E$, Schutz $Y$ (1990) Protein turnover and thermogenesis in response to high-protein and high-carbohydrate feeding in men. Am J Clin Nutr 52, 72-80.

32. Mikkelsen PB, Toubro S, Astrup A (2000) Effect of fat-reduced diets on 24$h$ energy expenditure: comparisons between animal protein $n$ vegetable protein, and carbohydrate. Am J Clin Nutr 72, 1135-1141.

33. Westerterp KR, Wilson SA, Roliand V (1999) Diet induced thermogenesis measured over $24 \mathrm{~h}$ in a respiration chamber: effect of diet composition. Int $J$ Obes Relat Metab Disord 23, 287-292.

34. Lejeune MPGM, Westerterp KR, Adam TCM, Luscombe ND, WesterterpPlantenga MS 24h satiety, GLP-1, ghrelin, energy- and substrate metabolism during a high-protein diet measured in a respiration chamber. Submitted for publication. 
35. Johnston CS, Day CS, Swan PD (2002) Postprandial thermogenesis is increased $100 \%$ on a high-protein, low-fat diet versus a high-carbohydrate, low-fat diet in healthy, young women. $J$ Am Coll Nutr 21, 55-61.

36. Luscombe ND, Clifton PM, Noakes M, Farnsworth E, Wittert G (2003) Effect of a high-protein, energy-restricted diet on weight loss and energy expenditure after weight stabilization in hyperinsulinemic subjects. Int $J$ Obes Relat Metab Disord 27, 582-590.

37. Skov AR, Toubro S, Ronn B, Holm L, Astrup A (1999) Randomized trial on protein vs carbohydrate in ad libitum fat reduced diet for the treatment of obesity. Int J Obes Relat Metab Disord 23, 528-536.

38. Westerterp-Plantenga MS, Lejeune MP, Nijs I, van Ooijen M, Kovacs EM (2004) High protein intake sustains weight maintenance after body weight loss in humans. Int J Obes Relat Metab Disord 28, 57-64.

39. Lejeune MPGM, Kovacs EM, Westerterp-Plantenga MS (2005) Additional protein intake limits weight regain after weight loss in humans. $B r J$ Nutr 95, 281-289.

40. Pitkanen O, Takala J, Poyhonen M, Kari A (1994) Branched-chain and mixed amino acid solutions and thermogenesis in postoperative patients. Nutrition 10, 132-137.

41. Tsujinaka T, Sakaue M, lijima S, Ebisui C, Kan K, Kishibuchi M, Morimoto $T$, Kido $Y$ (1996) Modulation of thermogenic response to parenteral amino acid infusion in surgical stress. Nutrition 12, 36-39.

42. Dulloo AG, Jacquet $J$ (1999) Low-protein overfeeding: a tool to unmask susceptibility to obesity in humans. Int $J$ Obes Relat Metab Disord 23, 1118-1121.

43. Dumesnil JG, Turgeon J, Tremblay A, Poirier P, Gilbert M, Gagnon L, St-

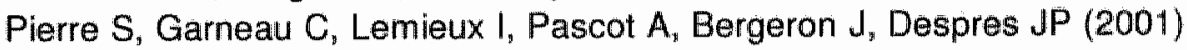
Effect of a low-glycaemic index--low-fat--high protein diet on the atherogenic metabolic risk profile of abdominally obese men. $\mathrm{Br}$ \& Nutr 86 , 557-568.

44. Johnstone AM, Stubbs RJ, Harbron CG (1996) Effect of averfeeding macronutrients on day-to-day food intake in man. Eur J Clin Nutr 50, 418430.

45. Porrini M, Santangelo A, Crovetti R, Riso P, Testolin G, Blundell JE (1997) Weight, protein, fat, and timing of preloads affect food intake. Physiol Behav 62, 563-570.

46. Poppitt SD, McCormack D, Buffenstein R (1998) Short-term effects of macronutrient preloads on appetite and energy intake in lean women. Physiol Behav 64, 279-285.

47. Westerterp-Plantenga MS, Rolland V, Wilson SA, Westerterp KR (1999) Satiety related to $24 \mathrm{~h}$ diet-induced thermogenesis during high 
protein/carbohydrate vs high fat diets measured in a respiration chamber. Eur J Clin Nutr 53, 495-502.

48. Mellinkoff $S M$, Frankland $M$, Boyle $D_{3}$, Greipel $M$ (1956) Relationship between serum amino acid concentration and fluctuations in appetite. $J$ Appl Physiol 8, 535-538.

49. Boirie $\mathrm{Y}$, Dangin M, Gachon P, Vasson MP, Maubois ل الL, Beaufrere B (1997) Slow and fast dietary proteins differently modulate postprandial protein accretion. Proc Natl Acad Sci U S A 94, 14930-14935.

50. Hall WL, Millward DJ, Long SJ, Morgan LM (2003) Casein and whey exert different effects on plasma amino acid profiles, gastrointestinal hormone secretion and appetite. Br J Nutr 89, 239-248.

51. Shilya T, Nakazato $M$, Mizuta $M$, Date $Y$, Mondal MS, Tanaka $M$, Nozoe $S$, Hosoda $\mathrm{H}$, Kangawa $\mathrm{K}_{*}$ Matsukura $\mathrm{S}$ (2002) Plasma ghrelin levels in lean and obese humans and the effect of glucose on ghrelin secretion. $J$ Clin Endocrinol Metab 87, 240-244.

52. Cummings DE, Purnell JQ, Frayo RS, Schmidova K, Wisse BE, Weigle DS (2001) A preprandial rise in plasma ghrelin levels suggests a role in meal initiation in humans. Diabetes 50, 1714-1719.

53. Erdmann J, Lippl F, Schusdziarra V (2003) Differential effect of protein and fat on plasma ghrelin levels in man. Regul Pept 116, 101-107.

54. Greenman Y, Golani N, Gilad S, Yaron M, Limor R, Stern N (2004) Ghrelin secretion is modulated in a nutrient- and gender-specific manner. Clin Endocrinol (Oxf) 60, 382-388.

55. Erdmann J, Topsch R, Lippl F, Gussmann P, Schusdziarra V (2004) Postprandial response of plasma ghrelin levels to various test meals in relation to foad intake, plasma insulin, and glucose. I Clin Endocrinol Metab 89, 3048-3054.

56. Drucker DJ (1998) Glucagon-like peptides. Diabetes 47, 159-169.

57. Flint A, Raben A, Astrup A, Holst JJ (1998) Glucagon-like peptide 1 promotes satiety and suppresses energy intake in humans. $J$ Clin Invest 101, 515-520.

58. Gutzwiller JP, Goke B, Drewe J, Hildebrand P, Ketterer S, Handschin D, Winterhalder R, Conen D, Beglinger C (1999) Glucagon-like peptide-1: a potent regulator of food intake in humans. Gut 44, 81-86.

59. Rocca AS, Brubaker PL (1995) Stereospecific effects of fatty acids on proglucagon-derived peptide secretion in fetal rat intestinal cultures. Endocrinology 136, 5593-5599.

60. Ritzel U, Fromme A, Ottleben M, Leonhardt U, Ramadori G (1997) Release of glucagon-like peptide-1 (GLP-1) by carbohydrates in the perfused rat ileum. Acta Diabetol 34, 18-21. 
61. Adam TCM, Westerterp-Plantenga MS (2005) Nutrient-stimulated GLP-1 release in normal weight men and women. Horm Metab Res 37, 111-117.

62. Elliott RM, Morgan LM, Tredger JA, Deacon S, Wright J, Marks V (1993) Glucagon-like peptide-1 (7-36)amide and glucose-dependent insulinotropic polypeptide secretion in response to nutrient ingestion in man: acute postprandial and 24-h secretion patterns. J Endocrinol 138, 159-166.

63. Cordier-Bussat M, Bernard C, Levenez F, Klages N, Laser-Ritz B, Philippe J, Chayvialle JA, Cuber JC (1998) Peptones stimulate both the secretion of the incretin hormone glucagon-like peptide 1 and the transcription of the proglucagon gene. Diabetes 47, 1038-1045.

64. Raben A, Agerholm-Larsen L, Flint A, Holst JJ, Astrup A (2003) Meals with similar energy densities but rich in protein, fat, carbohydrate, or alcohol have different effects on energy expenditure and substrate metabolism but not on appetite and energy intake. Am J Clin Nutr 77, 91-100.

65. Crovetti R, Porrini M, Santangelo A, Testolin G (1998) The influence of thermic effect of food on satiety. Eur J Clin Nutr 52, 482-488.

66. Netherlands HCot (2001) Dietary reference intakes: energy, proteins, fats and digestible carbohydrates. The Hague: Health Counsil of the Netherlands.

67. Poortmans JR, Dellalieux O (2000) Do regular high protein diets have potential health risks on kidney function in athletes? Int $J$ Sport Nutr Exerc Metab 10, 28-38.

68. Eisenstein J, Roberts SB, Dallal G, Saltzman E (2002) High-protein weightloss diets: are they safe and do they work? A review of the experimental and epidemiologic data. Nutr Rev 60, 189-200.

69. Ditschuneit HH (1984) Ergebnisse ambulanter Adipositastherapie mit verschiedenen proteinreichen Diäten. In Ergebnisse der Adipositasforschung, pp. 171-178 [HH Ditschuneit, JG Wechsler, editors]. Erlangen: perimed Fachbuch-Verlagsgesellschaft mbH.

70. Astrup A, Meinert Larsen T, Harper A (2004) Atkins and other lowcarbohydrate diets: hoax or an effective tool for weight loss? Lancet 364, 897-899.

71. Freedman MR, King J, Kennedy E (2001) Popular diets: a scientific review. Obes Res 9 Suppl 1, 1S-40S.

72. Lejeune MPGM, Hukshorn CJ, Saris WHM, Westerterp-Plantenga MS Reversal of changes in ghrelin and adiponectin during human pegylated recombinant leptin induced body weight loss. Submitted for publication. 


\section{Summary}


A stable body weight is achieved through a balance between energy intake and energy expenditure. If the equilibrium between energy intake and energy expenditure shifts towards a positive balance, the excess of energy will be stored as adipose tissue. Obesity will develop when this imbalance continues in the long-term. Body weight management consists of controlling body weight by tuning energy intake to energy requirement, and thereby avoiding accumulation of excess energy as fat. The research in this thesis was focused on targets that may play a role in the prevention and treatment of overweight and obesity. Both behavioral targets, i.e. eating behavior and physical activity, and metabolic targets, ile. satiety, energy expenditure, substrate oxidation, body composition, and energy efficiency were focused on.

In the first part it was shown that the ability to change eating behavior contributes more to the long-term success of weight management than increased physical activity. The effects of pharmacological treatment, e.g. PEG$\mathrm{OB}$, of obesity in the long-term was investigated in relation to the role of eating behavior during weight loss and the first period of weight maintenance thereafter. Although treatment with PEG-OB protein led to a greater body weight loss relative to placebo, weight maintenance was not supported by this treatment. On the contrary, dietary restraint was more effective in the first period of weight maintenance in the placebo treated group, resulting in a slower regain of body weight. It may be that pharmacological treatment limits the change in lifestyle necessary for weight maintenance after weight loss. So, during pharmacological treatment of obese subjects, they must also be stimulated to change their eating behavior.

With respect to the metabolic targets, the focus was on the thermogenic ingredients capsaicin and green tea. Capsaicin has been shown to have a short-term effect on fat oxidation, and the results showed that this also holds in the long-term during a period of weight maintenance. The short-term effects on appetite did not appear in the long-term. A long-term study investigating the effects of green tea supplementation during weight maintenance failed to reproduce the short-term results on energy expenditure and fat oxidation, and weight maintenance was not improved. Since the caffeine intake in this study population under free-living conditions was without restrictions, it is likely that the magnitude of the habitual caffeine intake may have overruled the effectiveness of green tea. In this regard, the low caffeine consumers showed a better weight maintenance compared to the high caffeine consumers. So, although the effects of these thermogenic ingredients on body weight were limited, the effects may be large enough to have an added beneficial effect when combined with other weight management strategies (e.g. changing eating behavior). 
The composition of the ideal weight loss and weight maintenance diet is subject of debate. Recently, there is a growing interest in high-protein diets. It is hypothesized that high-protein diets enhance weight loss due to an increased thermogenesis and satiety. Here, the beneficial effect of a higher protein intake on body weight was shown in a long-term weight maintenance study. The improved weight maintenance implied several factors, i.e. improved body composition, fat distribution, substrate oxidation and satiety. These results suggest that improved weight maintenance is possible when it is supported multi-factorially. To further unravel the mechanism of protein-induced satiety, the effects of a high-protein diet were assessed in a respiration chamber study, where carbohydrate was exchanged for protein iso-energetically over a period of 4 days, thus keeping energy density constant. The mechanism of proteininduced satiety was hypothesized to be related to energy inefficiency (an elevated thermogenesis) and/or so-called satiety hormones (ghrelin and GLP. 1). Results showed that a high-protein diet compared to a normal-protein diet consumed in energy balance over 4 days increased 24h satiety, which was related to energy expenditure and energy intake, and not to ghrelin or GLP-1 concentrations.

Although behavioral changes are an important target for long-term body weight management, it may be less important during the first period of weight loss because metabolic effects are largely due to an acute negative energy balance. When substantial weight loss has been achieved, the metabolic changes may be reversed due to the weight loss and consequently the less negative energy balance. This reversal effect has been shown for changes in ghrelin and adiponectin during PEG-OB protein induced body weight loss. For weight management a distinction must be made between the acute effects of a negative energy balance in the first period of weight loss and the long-term effects of weight maintenance at a lower energy balance due to a decreased body weight.

Based on the results reported in this thesis and from the literature, it is concluded that behavioral treatment remains the most important factor in the prevention and treatment of obesity. Successful long-term weight management requires a change in lifestyle. Although several thermogenic supplements are able to affect metabolic targets, an effect on multiple targets is needed to produce beneficial effects for weight management. As such, an increased dietary protein intake, which has been shown to contribute positively to a mixture of metabolic targets, currently seems to be an adequate intervention for successful weight management. 


\section{Samenvatting}


Een stabiel lichaamsgewicht is een weerspiegeling van een balans tussen energie inname en energiegebruik. Als het evenwicht tussen energie inname en energiegebruik doorslaat naar een positieve balans wordt het teveel aan energie opgeslagen als lichaamsvet. Wanneer deze disbalans lange tijd aanhoudt, ontstaat overgewicht. Gewichtsbeheersing bestaat uit het afstemmen van de energie inname op het energiegebruik, waardoor de opslag van extra energie als vet wordt voorkomen. De experimenten beschreven in dit proefschrift richten zich op factoren die een rol kunnen spelen bij het voorkómen en de behandeling van overgewicht en obesitas. Zowel gedragsmatige factoren (eetgedrag en lichamelijke activiteit) als ook metabole factoren (verzadiging, energiegebruik, substraat oxidatie, lichaamssamenstelling en energie efficiency) werden onderzocht.

In het eerste deel van dit proefschrift werd aangetoond dat een verandering van eetgedrag meer bijdraagt aan gewichtsbeheersing dan een verhoogde lichamelijke activiteit.

De lange termijn effecten van een farmacologische behandeling met PEG-OB protein werden onderzocht in relatie tot verandering in eetgedrag tijdens gewichtsverlies en de daaropvolgende periode van gewichtsbehoud. Hoewel de behandeling met PEG-OB protein leidde tot een groter gewichtsverlies, werd de periode van gewichtsbehoud hierdoor niet ondersteund. Omgekeerd was de verandering in eetgedrag effectiever in de placebo groep tijdens de periode van gewichtsbehoud, dit leidde tot een langzamere toename van het lichaamsgewicht in deze groep na de behandeling. Als zodanig zou een farmacologische behandeling van overgewicht de verandering in levensstijl die nodig is voor succesvol gewichtsbehoud na gewichtsverlies kunnen beperken. Tijdens een farmacologische behandeling moeten mensen dus ook worden gestimuleerd om hun eetgedrag aan te passen.

Om de metabole factoren te onderzoeken werd gebruik gemaakt van de thermogene ingrediënten capsaicine en groene thee. Van capsaicine is aangetoond dat het op korte termijn een gunstig effect heeft op de vetoxidatie, en dit bleek ook het geval te zijn op de lange termijn tijdens een periode van gewichtsbehoud. Echter, op de lange termijn waren de korte termijn effecten op hongergevoelens niet reproduceerbaar. Eveneens konden de korte termijn effecten van een groene thee supplement op energiegebruik en vetoxidatie niet worden gereproduceerd in een lange termijn studie. Gewichtsbehoud was dan ook niet verbeterd in vergelijking met de placebo groep. Omdat er geen beperkingen zaten aan de cafeĩne inname in deze studiepopulatie, is het waarschijnlijk dat de gebruikelijke cafeïne inname de mogelijke effecten van groene thee te niet heeft gedaan. De mensen met een lage cafeïne inname bleken namelijk ook een beter gewichtsbehoud te vertonen dan mensen met een hoge cafeĩne inname. Hoewel de effecten van deze thermogene 
ingrediënten op lichaamsgewicht beperkt waren, zijn ze mogelijk wel groot genoeg om een additioneel effect te hebben in combinatie met andere strategieën, bijvoorbeeld verandering van eetgedrag.

Het ideale dieet voor gewichtsverlies en gewichtsbehoud is nog steeds onderwerp van discussie. Tegenwoordig is er veel interesse voor diëten met een hoog eiwitgehalte. $\mathrm{Er}$ wordt verondersteld dat hoog eiwit diëten gewichtsverlies stimuleren doordat ze de thermogenese en verzadiging verhogen. In dit proefschrift werd in een lange termijn studie het gunstige effect van een verhoogde eiwit inname op het behoud van lichaamsgewicht aangetoond. Dit verbeterde gewichtsbehoud was afhankelijk van verschillende factoren, namelijk een verbeterde lichaamssamenstelling, vetverdeling, substraat oxidatie en verzadiging. Deze resultaten suggereren dat gewichtsbehoud mogelijk is als het door meerdere factoren wordt ondersteund. Om het mechanisme van eiwit geïnduceerde verzadiging te onderzoeken, werden de effecten van een hoog eiwit dieet onderzocht in een respiratiekamer experiment waar koolhydraat iso-energetisch werd uitgewisseld met eiwit gedurende een periode van 4 dagen. De hypothese was dat het mechanisme van eiwit geïnduceerde verzadiging gerelateerd is aan energie inefficiëntie (een verhoogde thermogenese) en/of aan de verzadigingshormonen (ghreline en GLP-1). De resultaten toonden aan dat een hoog eiwit dieet in vergelijking met een iso-energetisch normaal eiwit dieet gedurende 4 dagen de 24-uurs verzadiging verhoogt. De 24-uurs verzadiging was gerelateerd aan energiegebruik en energie inname, maar niet aan ghreline of GLP-1 concentraties.

Hoewel gedragsverandering een belangrijke factor is voor gewichtmanagement op lange termijn, is het misschien minder belangrijk tijdens de eerste fase van gewichtsverlies. In deze fase zijn de metabole effecten namelijk erg groot als gevolg van een acute negatieve energie balans. Nadat er een substantiële hoeveetheid gewicht is verloren, blijken de aanvankelijke metabole veranderingen tijdens de vervolgens minder negatieve energiebalans reversibel te zijn. Dit reversibele effect werd aangetoond voor veranderingen in ghreline en adiponectine concentraties tijdens PEG-OB protein geïnduceerd gewichtsverlies. Voor gewichtsmanagement dient dus onderscheid te worden gemaakt tussen de acute effecten van een negatieve energie balans tijdens de eerste fase van gewichtsverlies en de lange termijn effecten op gewichtsbehoud bij een verminderde negatieve energie balans als gevolg van een verlaagd lichaamsgewicht.

Uit de resultaten beschreven in dit proefschrift en de literatuur, kan worden geconcludeerd dat gedragsbehandeling de belangrijkste strategie in de preventie en behandeling van obesitas is. Succesvolle gewichtsbeheersing op 
lange termijn vereist een verandering in leefstijl. Hoewel thermogene supplementen de metabole factoren effectief kunnen beïnvloeden, is er een multi-factorieel proces nodig om een gunstig effect op behoud van het lichaamsgewicht te hebben. Een verhoogde eiwit inname, waarvan is aangetoond dat het een multi-factorieel effect heeft, lijkt op dit moment de meest adequate interventie voor succesvolle gewichtsbeheersing. 


\section{Dankwoord}


$\mathrm{Na}$ flink wat pagina's te hebben geschreven (ik) en gelezen (jullie) is het dan eindelijk tijd voor de echte laatste loodjes: het dankwoord. Ik zou het simpel kunnen houden door te zeggen EEDEREIN BEDAANK, maar iets in mij zegt me dat het toch iets uitgebreider moet.

Margriet, bedankt dat je genoeg vertrouwen in me had om me te 'promoveren' van onderzoeksassistent naar promovendus. Door jouw efficiènte manier van werken (o.a. de zeer snelle correctie van manuscripten), is het gelukt om binnen vier jaar mijn proefschrift te verdedigen.

Klaas, bedankt voor de nuttige discussies over energiemetabolisme en het kritisch doorwerken van mijn manuscripten.

De beoordelingscommissie, bestaande uit prof. dr. E. Mariman, prof. dr. ir. P. van den Brandt prof. dr. R-J. Brummer, dr. J. Strubbe en prof. Dr. D. Tomé, wil ik bedanken voor het beoordelen van mijn proefschrift. A special word of thanks I would like to address to prof. dr. D. Tomé for being a member of my reviewing committee, but also for giving me the opportunity to work in your lab.

Uiteraard schrijf je een proefschrift niet alleen, vandaar dat ik dan ook mijn coauteurs Chris, Dorien, Eva, Ilse, Margriet, Marleen, Natalie, Tanja en Wim wil bedanken voor de productieve samenwerking. Eva, onze intensieve samenwerking heeft niet alleen geleid tot een aantal hoofdstukken in dit proefschrift, maar ook tot een aantal sportieve hoogtepunten.

Lydia en Neeltje, het feit dat jullie als paranimfen achter me zullen staan tijdens de verdediging van mijn proefschrift is voor mij eigenlijk een logisch gevolg van de vriendschap die we de afgelopen jaren hebben opgebouwd. Lydia, de vele zweetdruppels die we verloren tijdens onze trainingen (en tijdens kolonisten), werden vaak weer ruimschoots aangevuld bij een etentje of in de kroeg. Neeltje. THNX voor al je pogingen om onze intra-generatie kloof kleiner te maken. Als je ooit nog eens goede raad van een oude wijze vrouw nodig hebt, je weet me te vinden...

Tanja, Ilse, Astrid, Natalie en Stijn $n$ met jullie als kamergenoten heb ik altijd van de gezellige sfeer op onze kamer genoten. Tanja het ziet ernaar uit dat je nog wel een tijdje aan de andere kant van de wereld blijft wonen, maar ik weet zeker dat onze wegen elkaar nog vaak zullen kruisen. Bedankt voor alle typisch-Tanja momenten.

Veel dank ben ik verschuldigd aan 'de Jura". Deze trouwe espressomaker heeft me vaak over dipjes heen geholpen. Maar een goede espresso komt pas echt tot zijn recht in goed gezelschap. Annemarie, Annemiek, Ariënne, Eva, Freddy, Guy, Joost, Kristel, Lydia, Marieke, Marleen, Mirjam, Natalie, Neeltje en Roy bedankt voor alle gezellige koffie-, thee-, soep- en kletspauzes.

Ward en Lina wil ik bedanken voor hun hulp tijdens experimenten. Ward, er zijn weinig stagiaires die een baan als barkeeper kunnen combineren met een 
studie geneeskunde en tegelijkertijd ook nog eens stage lopen! lik weet niet of het kwam door je 'sociale vaardigheden' als barkeeper, maar de vrouwelijke proefpersonen waren verrassend snel gevonden.

Joan, Jos en Wendy, zonder jullie hulp zou de vriezer nu waarschijnlijk nog vol liggen met vele honderden bloedmonsters. Joan, tijdens mijn eerste 'prikervaringen' was jij mijn steun en toeverlaat. Ook tijdens andere experimenten kon ik altijd een beroep op je doen als ik weer eens een infuusexpert nodig had.

Paul en Loek, bedankt voor jullie snelle hulp bij ventilated hood-, respiratie kamer-en computercalamiteiten. Paul, je hebt me meerdere keren geprobeerd wegwijs te maken in de wondere wereld der techniek. Ondanks jouw subtiele voorkeur voor de Mac, kon ik gelukkig ook altijd met Windows vragen bij je terecht. Loek, jij ook bedankt voor de vele deuteriumbepalingen.

Claudia, Larissa en llona, zonder jullie was ik nu waarschijnlijk nog aan stuntelen met de fax, grote enveloppen, sheets etc.

Uiteraard wil ik ook alle collega's en ex-collega's van Humane Biologie bedanken die de afgelopen jaren voor een goede werksfeer hebben gezorgd.

Zonder proefpersonen zou dit proefschrift nooit tot stand zijn gekomen. Bedankt voor alles wat jullie hebben moeten doen en vooral voor alles wat jullie hebben moeten laten tijdens de soms maandenlange experimenten.

Alle 'niet werk gerelateerde' vrienden en vriendinnen, bedankt voor de steun en interesse in de afgelopen jaren. Mam en Pap, jullie staan altijd achter me en zijn geïnteresseerd in wat $i k$ doe. Zelfs Parijs was niet te ver, al had jullie enthousiasme dat weekend weinig met mijn werk te maken...

Jeroen, eigenlijk zeggen deze vijf woorden genoeg: Never change a winning team! 


\section{PUBLICATIONS}

\section{Full papers}

Lejeune MPGM, DPC van Aggel-Leijssen, MA van Baak, MS WesterterpPlantenga (2003) Effects of dietary restraint vs exercise during weight maintenance in obese men. Eur J Clin Nutr 57, 1338-1344.

Lejeune MPGM, EMR Kovacs, MS Westerterp-Plantenga (2003) Effect of capsaicin on substrate oxidation and weight maintenance after modest bodyweight loss in human subjects. Br J Nutr 90, 651-659.

Lejeune MPGM, CJ Hukshorn, WHM Saris, MS Westerterp-Plantenga (2003) Effect of dietary restraint during and following pegylated recombinant leptin treatment (PEG-OB) of overweight men. Int $J$ Obes Relat Metab Disord 27, 1494-1499.

Kovacs EMR, MPGM Lejeune, MS Westerterp-Plantenga (2003) The effects of enterostatin intake on food intake and energy expenditure. Br J Nutr 90, 207214.

Kamphuis MMJW, MPGM Lejeune, WHM Saris, MS Westerterp-Plantenga (2003) Effect of conjugated linoleic acid supplementation after weight loss on appetite and food intake in overweight subjects. Eur $J$ Clin Nutr 57, 12681274.

Kamphuis MMJW, MPGM Lejeune, WHM Saris, MS Westerterp-Plantenga (2003) The effect of conjugated linoleic acid supplementation after weight loss on body weight regain, body composition, and resting metabolic rate in overweight subjects. Int J Obes Relat Metab Disord 27, 840-847.

Kovacs EMR, MPGM Lejeune, I Nijs, MS Westerterp-Plantenga (2004) Effects of green tea on weight maintenance after body weight loss. Br J Nutr 91, $431-437$.

Westerterp-Plantenga MS, MPGM Lejeune, I Nijs, M van Ooijen, EMR Kovacs (2004) High protein intake supports weight maintenance after body weight loss in humans. Int J Obes Relat Metab Disord 28, 57-64.

Lejeune MPGM, EMR Kovacs, MS Westerterp-Plantenga (2005) Additional protein intake limits weight regain after weight loss in humans. $\mathrm{Br} J$ Nutr 93 , $281-289$.

Westerterp-Plantenga MS, A Smeets, MPGM Lejeune. Sensory and gastrointestinal satiety effects of capsaicin on food intake. Int $J$ Obes Relat Metab Disord In press.

Lejeune MPGM, CJ Hukshorn, WHM Saris, MS Westerterp-Plantenga. Reversal of changes in ghrelin and adiponectin during VLCD induced body weight loss with or without human pegylated recombinant leptin treatment. Submitted for publication. 
Lejeune MPGM, KR. Westerterp, TCM Adam, ND Luscombe-Marsh, MS Westerterp-Plantenga. 24h satiety, GLP-1, ghrelin, energy- and substrate metabolism during a high-protein diet measured in a respiration chamber. Submitted for publication.

Westerterp-Plantenga MS, MPGM Lejeune, EMR Kovacs. Effect of green tea on weight-maintenance after body-weight loss as a function of habitual caffeine intake. Submitted for publication.

Westerterp-Plantenga MS, MPGM Lejeune. Protein intake and body weight regulation. Submitted for publication.

Adam TCM, MPGM Lejeune, MS Westerterp-Plantenga. Nutrient stimulated GLP-1 release after body-weight loss and weight maintenance in humans. Submitted for publication.

\section{Abstracts}

Lejeune MPGM, DPC van Aggel-Leijssen, MA van Baak, MS WesterterpPlantenga (2001) Dietary restraint during weight maintenance with or without exercise training in men. . Int J Obes Rel Metab Disord 25 (suppl 2), S51.

Kamphuis MMJW, MPGM Lejeune, MS Westerterp (2001) Relative fat and carbohydrate intake is different for prop tasters and non-tasters. Int $J$ Obes Rel Metab Disord 25 (suppl 2), 57.

Lejeune MPGM, CJ Hukshorn, WHM Saris, MS Westerterp-Plantenga (2002) Effect of dietary restraint during and following pegylated recombinant leptin treatment (PEG-OB) of overweight men. Int $J$ Obes Rel Metab Disord 26 (suppl 1), S159.

Kamphuis MMJW, MPGM Lejeune, MS Westerterp (2002) CLA affects resting metabolic rate, fat free mass and appetite, but not body weight regain, fat mass or energy intake. Int J Obes Rel Metab Disord 26 (suppl 1), S45.

Kovacs EMR, MPGM Lejeune, MS Westerterp-Plantenga (2002) The effects of enterostatin intake on food intake and energy expenditure. Int $J$ Obes Rel Metab Disord 26 (Suppl. 1), S159.

Lejeune MPGM, CJ Hukshorn, WHM Saris, MS Westerterp-Plantenga (2002) Effect of dietary restraint during and following pegylated recombinant leptin treatment (PEG-OB) of overweight men. Appetite 39, 88.

Kamphuis MMJW, MPGM Lejeune, MS Westerterp (2002) CLA affects resting metabolic rate, fat free mass and appetite, but not body weight regain, fat mass or energy intake. Appetite 39, 83.

Kovacs EMR, MPGM Lejeune, MS Westerterp-Plantenga (2002) The effects of enterostatin intake on food intake and energy expenditure. Appetite $39,86$. 
Lejeune MPGM, EMR Kovacs, MS Westerterp-Plantenga (2003) Additional protein intake limits weight regain after weight loss in humans. Int $J$ Obes Rel Metab Disord 27 (Suppl. 1), S25.

Lejeune MPGM, EMR Kovacs, MS Westerterp-Plantenga (2003) Effect of capsaicin on substrate oxidation and weight maintenance after modest body weight loss in humans. Int J Obes Rel Metab Disord 27 (Suppl. 1), S112.

Kovacs EMR, MPGM Lejeune, I Nijs, MS Westerterp-Plantenga (2003) Effects of green tea on weight maintenance after body weight loss. Int J Obes Rel Metab Disord 27 (Suppl. 1), S113.

Westerterp-Plantenga MS, MPGM Lejeune, EMR Kovacs (2003) Habitual caffeine intake affects weight-loss and affects the effect of green tea on weight-maintenance thereafter. Int $J$ Obes Rel Metab Disord 27 (Suppl. 1), S26.

Westerterp-Plantenga MS, MPGM Lejeune, I Nijs, M van Ooijen, EMR Kovacs (2003) High protein intake supports weight maintenance after body weight loss in humans. Int $J$ Obes Rel Metab Disord 27 (Suppl. 1), S126.

Lejeune MPGM, EMR Kovacs, MS Westerterp-Plantenga (2003) Additional protein intake limits weight regain after weight loss in humans. Appetite 40 , 344.

Lejeune MPGM, EMR Kovacs, MS Westerterp-Plantenga (2003) Effect of capsaicin on substrate oxidation and weight maintenance after modest body weight loss in humans. Appetite 40, 344.

Kovacs EMR, MPGM Lejeune, I Nijs, MS Westerterp-Plantenga (2003) Effects of green tea on weight maintenance after body weight loss. Appetite 40, 342 .

Westerterp-Plantenga MS, MPGM Lejeune, EMR Kovacs (2003) Habitual caffeine intake affects weight-loss and affects the effect of green tea on weight-maintenance thereafter. Appetite 40, 368.

Westerterp-Plantenga MS, MPGM Lejeune, I Nijs, M van Ooijen, EMR Kovacs (2003) High protein intake supports weight maintenance after body weight loss in humans. Appetite 40, 369.

Lejeune MPGM, CJ Hukshorn, WHM Saris, MS Westerterp-Plantenga (2004) Reversal of hormone concentrations during phases of body weight loss. Int $J$ Obes Rel Metab Disord 28 (Suppl. 1), S177.

Westerterp-Plantenga MS, A Smeets, MPGM Lejeune (2004) Oral and gastrointestinal satiety effects of capsaicin on food intake. Int $J$ Obes Rel Metab Disord 28 (Suppl. 1), S35.

Lejeune MPGM, CJ Hukshorn, WHM Saris, MS Westerterp-Plantenga (2004) Reversal of hormone concentrations during phases of body weight loss with or without PEG-OB. Appetite 42, 378.

Westerterp-Plantenga MS, A Smeets, MPGM Lejeune (2004) Oral and gastrointestinal satiety effects of capsaicin on food intake. Appetite 42, 408. 


\section{Curriculum Vitae}


Manuela Petrus Gerardus Maria Lejeune was born on 28 January 1974 in Maastricht. She completed secondary school in 1992. In the same year she started her academic education at the Maastricht University, where she studied Health Sciences with a specialization in Movement Sciences and graduated in 1997. From 1998 until 2000 she studied Journalism at the Academy for Journalism and Public relations in Tilburg. In 1999 she started as a research assistant at the department of Human Biology, Maastricht University. She started her Ph.D. research 'Targets for body weight management: behavioral and metabolic factors' at the same department in 2001. The research performed in this period is described in this thesis. During her Ph.D. period she was rewarded with several travel awards (2002: New Investigator Award SSIB, 2004: Travel Award Van Walree Fonds, 2005: Young Investigator Award SSIB) to visit the Annual meetings of the Society for the Study of Ingestive Behavior (SSIB). In 2005 she received a grant of the Netherlands Organization for Scientific Research to work in the lab of Prof. dr. Daniel Tomé (Institut National Agronomique Paris-Grignon, France). Here she investigated the effects of high-protein diets in newborn rats. 
